\title{
Environmental Regulatory Guide for Radiological Effluent Monitoring and Environmental Surveillance
}

January 1991

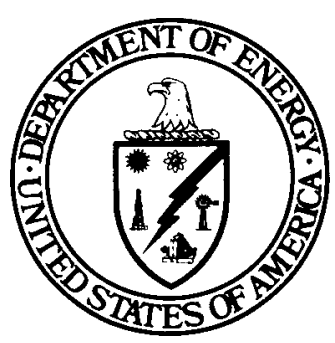

\section{U.S. Department of Energy}

Assistant Secretary for Environment,

Safety and Health

Washington, D.C. 20585

This document is

PUBLICLY RELEASABLE B stelle

Deter $\quad 5-33-17$ 


\section{DISCLAIMER}

This report was prepared as an account of work sponsored by an agency of the United States Government Neither the United States Government nor any agency thereof, nor any of their employees, make any warranty, express or implied, or assumes any legal liabij. ty or responsibility for the acauracy, completeness, or usefund of any information, apparatus, product, or pross disclosed, or reprents that its use would not infringe privately owned rights. Reference herein to any specific commercial product, process, or service by trade name, trademark, manufacturer, or otherwise does not necessarily constitute or imply its endorsent, recommendation, or favoring by the United States Government or any agency thereof. The viem and opinions of authors expressed herein do not necessar. ily state or reflect those of the United States Government or any agency thereof. 


\section{DISCLAIMER}

Portions of this document may be illegible in electronic image products. Images are produced from the best available original document. 



\section{PREFACE}

Effluent monitoring and environmental surveillance of radioactive materials are a continuing major part of the radiological protection programs at U.S. Department of Energy (DOE) sites. The purpose of this regulatory guide is to establish elements of a radiological effluent monitoring and environmental surveillance program considered acceptable to DOE, in support of DOE 5400.5 (Radiation Protection of the Public and the Environment) and DOE 5400.1 (General Environmental Protection Program).

The regulatory guide identifies those monitoring and surveillance elements that are considered high priorities for a radiological effluent monitoring and environmental surveillance program. In the regulatory guide, these high-priority elements are written as procedures and activities that "should*" be performed, and what is intended as guidance is written as procedures and activities that "should" be performed. The regulatory guide both incorporates and expands on requirements embodied in DOE 5400.5 and DOE 5400.1 . 


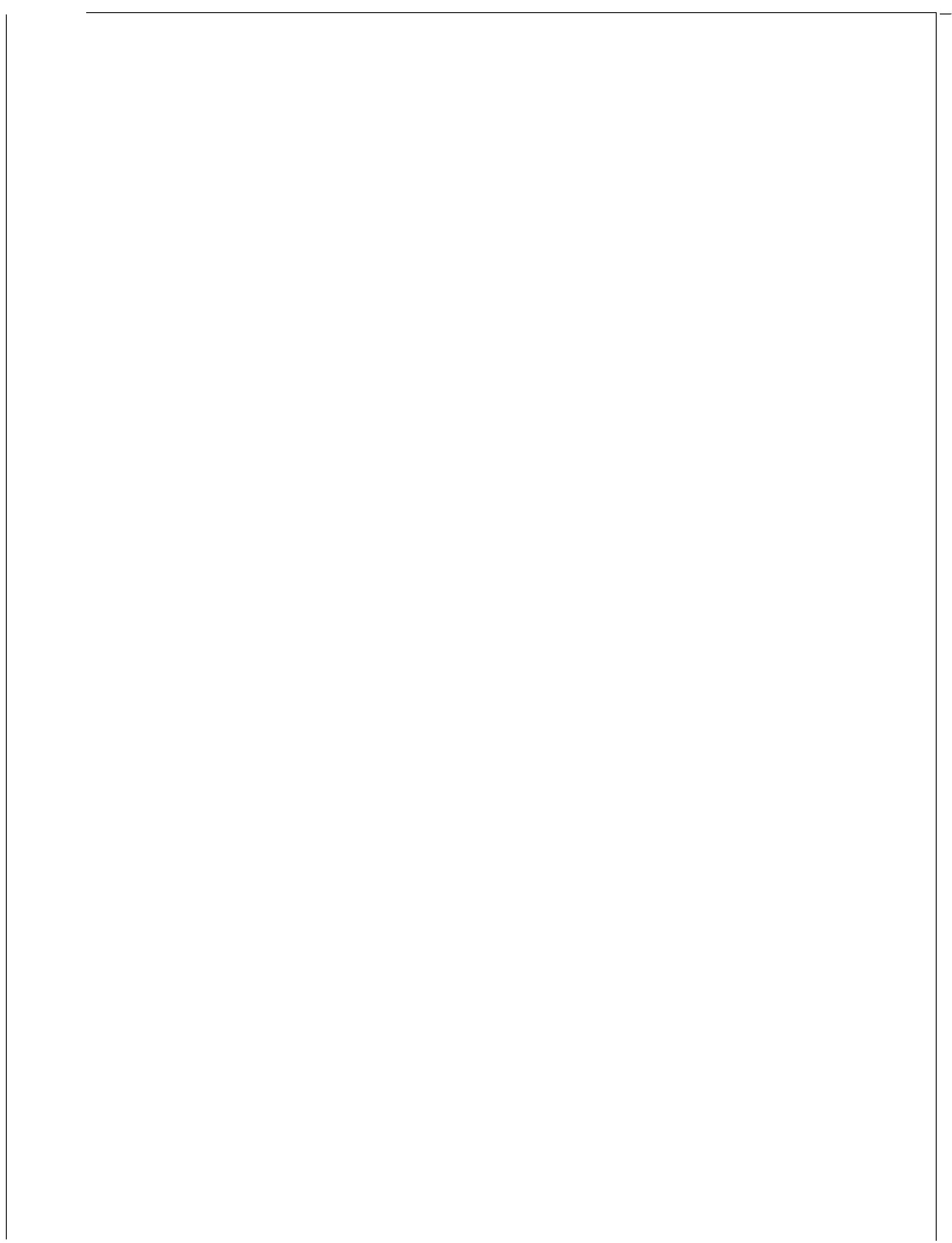




\section{TABLE OF CONTENTS}

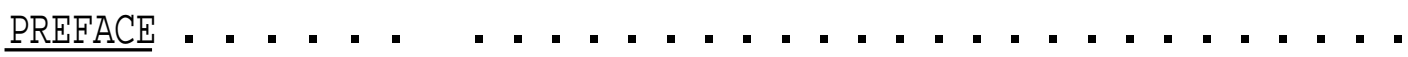

SUMMARY OF EFELUENT MONITORING AND ENVIRONMENTAL SURVEILLANCE

PROGRAMELEMENTS $\ldots \ldots \ldots \ldots \ldots . \ldots . \ldots . \ldots$

$x i$

CHAPTER 1.0 - INTRODUCTION

1.1 Purpose and Scope ................... 1-1

1.1.1 Environmental Monitoring . . . . . . . . . . 1-2

1.2 Manual Organization and Terminology . . . . . . . . . . . 1-2

CHAPTER 2.0 - LIOUID EFFLUENT MONITORING

2.1 Summary of General Criteria and Monitoring Requirements . . . . 2-1

2.2 Performance Standards for Liquid Effluent Monitoring Systems . . 2-2

2.2.1 Continuous Mon itoring/Sampting . . . . . . . . . : 2-2

2.2.2 Sampling Systems ............... 2-3

2.2.3 System Calibration ................. 2-3

2.2.4 Environmental Conditions . . . . . . . . . . . 2-3

2.3 Sampling System Design Criteria . . . . . . . . . . . . 2-3

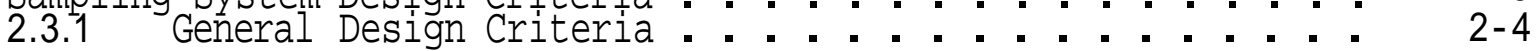

2.3.2 Stream Flow Characteristics.............. . 2-5

2.3.3 Sampling Locations .... . . . . . . . . . . . 2-5

2.3.4 Delivery Lines ................ 2- . .

2.3.5 Liquid Movers ..................... $2-5$

2.3.6 Sample Collectors................ 2-5

2.3.7 Special Considerations . . . . . . . . . . . . 2-6

2.3.8 Environmental Considerations . . . . . . . . . . . . 2-7

2.4 Monitoring System Design Considerations. . . . . . . . . . . . . 2-7

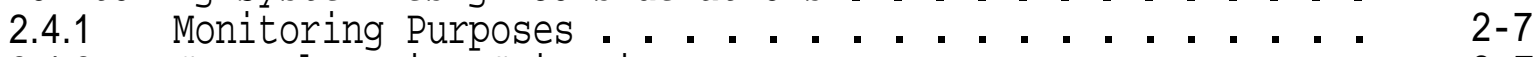

2.4.2 General Design Criteria... . . . . . . . . . . $2-7$

2.4.3 Types of Radiation . . . . . . . . . . . . . . . 2-8

2.4 .4 High Background .............. $2-8$

2.4.5 Release Duration ............... 2-9

2.4.6 Environmental Effects............... 2-9

2.5 Alarm Levels ....................... . . . . . . . . . . . . . .

2.6 Quality Assurance..................... $2-9$

\section{CHAPTER 3.0 - AIRBORNE EFFLUENT MONITORING}

3.1 Summary of General Criteria and Monitoring Requirements . . . . . 3-1

3.2 Requirements for Compliance with EPA Regulations . . : : : : $3-3$

3.3 Performance Standards for Air-Sampling Systems . . . . . . . . . 3-3

3.3.1 Defining Point or Diffuse Sources... . . . . . . . $3-3$

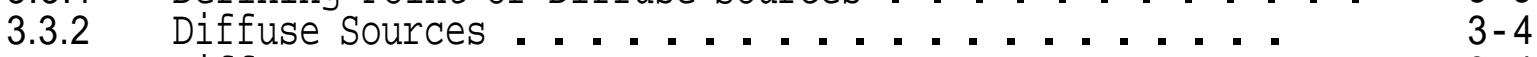

3.3.3 Diffuse Source Assessment............... $3-4$

3.4 Design Criteria for System Components. . . . . . . . . . . . . $3-4$

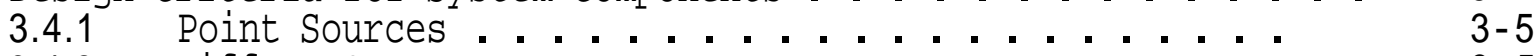

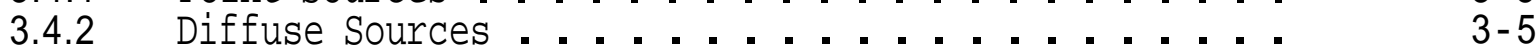


3.4.3 Gases and Vapors Versus Particulates . . . . . . . . 3-6

3.5 Point-Source Design Criteria .................. 3-6

3.5.1 Gas-Stream Characterization Methods . . . . . . . . 3-6

3.5.2 Location of Sample-Extraction Sites .......... 3-6

3.5.3 Sample-Extraction Probes .............. 3-7

3.5.4 Sample-Transport Lines .............. . . 3-8

3.5.5 Air-Moving Systems . . . . . . . . . . . . . . . . 3-8

3.5.6 Air-Flow Measurements................. $3-8$

3.5.7 Sample Collectors .................. 3-9

3.5.8 Continuous Monitoring Systems............. 3-9

3.6 Alarm Levels . . . . . . . . . . . . . . . . . . . . . $3-17$

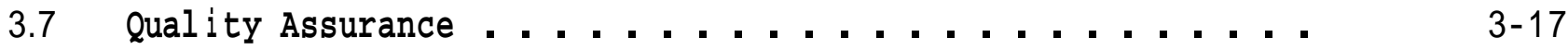

\section{CHAPTER 4.0 - METEOROLOGICAL MONITORING}

4.1 Meteorological Program Basis . . . . . . . . . . . . . . 4-2

4.1.1 Calculations for Dose Assessment . . . . . . . . . . 4-2

4.1.2 Calculated Atmospheric Transport and Diffusion . . . . 4-3

4.1.3 Use of Realistic Models................ . 4-3

4.2 Di ffusion Coefficients . . . . . . . . . . . . . 4-4

4.2.1 Stability Estimation .. . . . . . . . . . . . . 4-4

4.2.2 Methods of Determining Stability Class . . . . . . . . 4-4

4.2.3 EPA-Preferred Methods............... 4-5

4.2.4 Atmospheric Turbulence Measurements . . . . . . . . . . 4-5

4.3 Plume Rise and Building Wakes . . . . . . . . . . . . . . . . . . 4-5

4.4 Meteorological Measurements . . . . . . . . . . . . . . . 4-6

4.4.1 Location of Meteorological Measurements . . . . . . . 4-6

4.4.2 Instrument Mounting ................. . 4-6

4.4.3 Measurement Recording Systems............. . 4-7

4.5 Measurement System Accuracy . . . . . . . . . . . . . . . . . 4-7

4.6 Inspection, Maintenance, and Calibration .......... 4-8

4.7 Supplementary Instrumentation ......... . . . . . . . . . . 4-8

4.8 Large-Site Meteorological Programs . . . . . . . . . . . . . . 4-8

4.9 Data Summarization and Archiving . . . . . . . . . . . . . . . . 4-9

4.10 Meteorological Data Processing . . . . . . . . . . . . . . . 4-9

4.10.1 Routine Releases ............... 4-9

4.10 .2 Accidental Releases............... 4-10

4.10.3 Data Needs .................. 4-10

4.11 Quality Assurance . . . . . . . . . . . . . . . . . . . . .

\section{CHAPTER 5.0 - ENVIRONMENTAL SURVEILLANCE}

5.1 Summary of General Criteria and Surveillance Requirements . . . . 5-1

5.1.1 Evaluation of Need ................. 5-3

5.1.2 Emergency Monitoring Provisions........... . 5-3

5.2 Performance Requirements for Environmental Surveillance
Programs . . . . . . . . . . . . . . . . . .

5.2.1 Specific Performance Requirements........... 5-4

5.2.2 Air Sampling Systems . . . . . . . . . . . . . . . 5-4

5.2.3 Consultation with Game Officials . . . . . . . . . . . 5-4

5.2.4 Consultation with State and Regional EPA Offices . . . $5-4$

5.3 Design Criteria.................... 5- 5 
5.3.1 Environmental Surveillance Program Objectives . . . . . 5-5

5.3.2 Program Planning and Design...... . . 5-6

5.4 Basis for External Exposure Monitoring . . . . . . . . . . . 5-7

5.4.1 External Exposure ............... 5-7

5.4.2 External Exposure in Water . . . . . . . . . . 5-7

5.4.3 Limiting External Exposures. . . . . . . . . . . . . 5-7

5.5 External Radiation Measurement Locations and frequency . . . . 5-7

5.5.1 Factors in Selection : : : : : : : : : : : 5-8

5.5.2 Location of Background Measurement Stations . . . . . . 5-8

5.5.3 Offsite Locations................ 5-9

5.5.4 Shoreline Locations............... . . 5-9

5.5.5 Height and Frequency of Measurements . . . . . . . . 5-9

5.6 Direct Radiati on Measurement . . . . . . . . . . . . . . . . 5-10

5.6.1 Continuous Exposure Monitoring . . . . . . . . . . 5-10

5.6.2 Neutron Monitoring ................. $5-10$

5.6.3 Instruments and Methods................ 5-10

5.7 Air . . . . . . . . . . . . . . . . 5-11

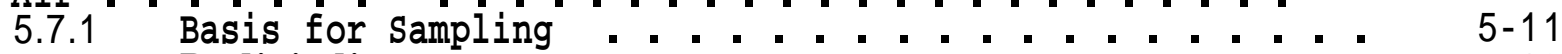

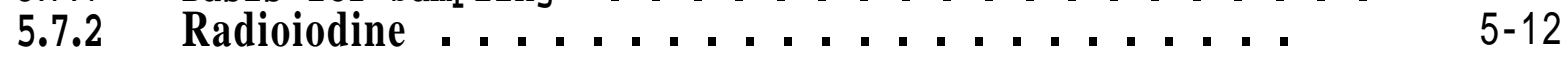

5.7.3 Tritium ..................... . . 5-12

5.7.4 Sampling Locations ................ 5-12

5.7.5 Sampling Frequency . . . . . . . . . . . . . 5-13

5.7.6 Sampling Methods and Criteria............. 5-14

5.8 Basis for Sampling Terrestrial Foodstuffs . . . . . . . . . . . 5-19

5.8.1 Possibility of Long-Term Buildup : : : : : : : : : : 5-19

5.8.2 Agricultural Products.................. 5-20

5.8.3 Game Animals ................. 5-24

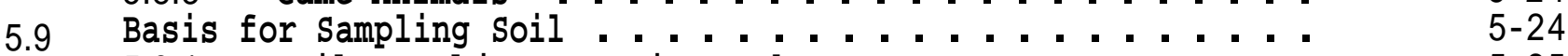

5.9.1 Soil Sampl ing Location and Frequency . . . . . . . . 5-25

5.9.2 Soil Sampling Methods............... . 5-25

5.10 Basis for Sampling Water ................ 5-26

5.10 .1 Water Sampling Locations . . . . . . . . . . . . 5-26

5.10.2 Water Sampling Frequency .............. 5-30

5.10.3 Water Sampling Methods . . . . . . . . . . . . 5-30

5.10.4 Settleable Solids in Effluent Discharge........ 5-32

5.11 Basis for Sampling Aquatic Foodstuffs . . . . . . . . . . . . . 5-33

5.11 .1 Freshwater Foods . . . . . . . . . . . . $5-34$

5.11 .2 Marine Foods . . . . . . . . . . . . . $5-36$

5.12 Basis for Sampling Sediment. . . . . . . . . . . . . . . 5-36

5.12.1 Location and Frequency . . . . . . . . . . . 5-37

5.12.2 Sediment Sampling.............. 5-37

5.13 Quality Assurance ..................... 5-38

\section{CHAPTER 6.0 - LABORATORY PROCEDURES}

6.1 Summary of Laboratory Procedure Requirements . . . . . . . . . . $6-1$

6.1.1 Sample Identification System . . . . . . . . . . . . 6-1

6.1.2 Procedures Preventing Cross-Contamination . . . . . . $6-1$

6.1.3 Documentation of Methods . . . . . . . . . . . . 6-2

6.1.4 Gamma-Emitting Radionuclides . . . . . . . . . . . . $6-2$

6.1.5 Calibration....................... 6-2 
6.2 Handling of Samples . . . . . . . . . . . . . 6-2

6.2.1 Measurement of Activity Levels Using Monitoring

Equipment . . . . . . . . . . . . . 6-2

6.2.2 Shipping, Unpacking, and Repackaging of Samples . . . . 6-3

6.2.3 Prevention of Cross-Contamination . . . . . . . . 6-3

6.2.4 Selection of Sample Sizes According to Gross Beta and

Gross Alpha Activities ............. . 6-3

6.2 .5 Preparation of Samples . . . . . . . . . . 6-4

6.2.6 Sample Archiving . . . . . . . . . . . . . . 6-8

6.3 Analysis Method and Capabilities . . . . . . . . . 6-10

6.4 Gross Alpha, Beta, and Gamma Measurements . . . . . . . . . . 6-10

6.5 Direct Gamma-Ray Spectrometry : : : : : : : : : : : : : : : 6eta Counters 6 6-11

6.7 Alpha-Energy Analysis .................. 6-11

6.8 Radiochemical Separation Procedures . . . . . . . . . 6-12

6.9 Reporting of Results : : : : : : : : : : : : : : : : : $6-12$

6.10 Intercalibration of Equipment and Procedures : : : : : : : : ${ }^{6-12}$

6.12 Counter Background .................... . . 6-13

6.13 Quality Assurance . . . . . . . . . . . . 6-13

CHAPTER 7.0 - DATA ANALYSIS AND STATISTICAL TREATMENT

7.1 Summary of Data Analysis and Statistical Treatment Requirements . 7-1

7.2 Variability of Effluent and Environmental Data . . . . . . . 7-2

7.2.1 Sources of Variability in Effluent/Environmental Data : . 7-2

$7,2,2$ Estimating Accuracy and Precision......... . 7-2

7.3 Summarization of Data and Testing for Outliers . . . . . . 7-2

7.3.1 Distribution Analysis . . . . . . . . . . . . 7-2

7.3.2 Measures of Central Tendency . . . . . . . . . . 7-4

7.3.3 Measures of Dispersion . . . . . . . . . . 7-4

7.3.4 Less-Than-Detectable Values . . . . . . . . . . 7-5

7.3.5 Testing for Outliers ............... . . 7-5

7.3.6 Elements of Good Practice . . . . . . . . . . . $7-6$

7.4 Treatment of Significant Figures . . . . . . . . . . . 7-6

7.5 Parent-Decay Product Relationships . . . . . . . . . . 7-7

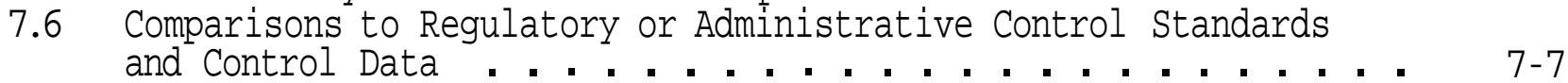

7.6.1 Single Concentration Measurements . . . . . . . . 7-7

7.6 .2 Groups of Measurements . . . . . . . . . . . 7-7

7.7 Quality Assurance . . . . . . . . . . . . . 7-8

\section{CHAPTER 8.0 - DOSE CALCULATIONS}

8.1 Performance Standards for Public Dose Calculations . . . . . . 8-1

8.1.1 Required Standards ............... . 8-1

8.1.2 Documentation and Conformance with other Requirements : . 8-2

8.2 Major Considerations .................. 8-2

8.2.1 Considerations for Selection . . . . . . . 8-3

8.2.2 Misuses of Models ............... 8- . 8-3

8.3 Transport Models . . . . . . . . . . . . . 8-3

8.3.1 Atmospheric Transport and Dispersion Models . . . . . 8-4 
8.3.2 Surface- and Ground-Water Transport Models .... . . 8-5

8.4 Environmental Pathway Models .............. 8-6

8.5 Internal Dosimetry Models . . . . . . . . . . . . .

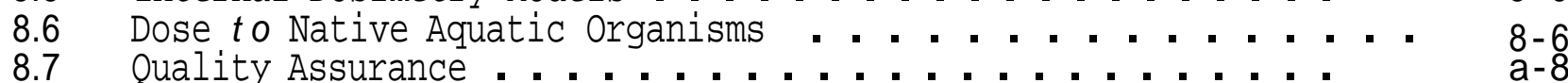

\section{CHAPTER 9.0 - RECORDS AND REPORTS}

9.1 Record-Keeping . . . . . . . . . . . . . . . . . 9 9-2

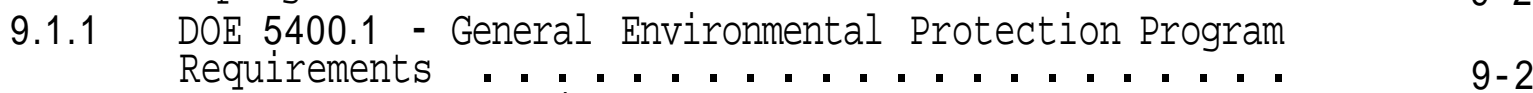

9.1 DOE 5700.68 - Quality Assurance . . . . . . . 9- 9-2

9.1.3 40 CFR Part 61 - National Emission Standards for

9.1.4 40 CFR Parts 260-265 - Resource Conservation and

Recovery Act Regulat ions . . . . . . . . . . . . 9-4

9.2 Reporting.................. 9- 9-4

9.2.1 DOE 5400.1 - General Environmental Protection Program

9.2 Requirements ................. . . 9-5

9.2 .2 DOE 1324.2 - Records Disposition . . . . . . 9-6

9.2.3 DOE 5400.4 - Comprehensive Environmental Response,

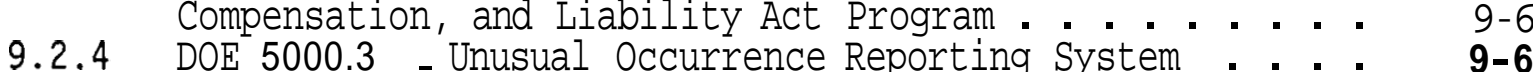

9.2.5 40 CFR Part 61 - National Emission Standards for Hazardous Air Pollutants . . . . . . . . . . . . 9-6

9.2.6 40 CFR Part 191 - Environmental Standards for the Management and Disposal of Spent Nuclear fuel, High-Level and Transuranic Radioactive Wastes . . . . . . . . . .

9.2.7 Office of Management and Budget Circular A-106 -

Reporting Requirements in Connection with the Prevention, Control, and Abatement of Environmental Pollution at

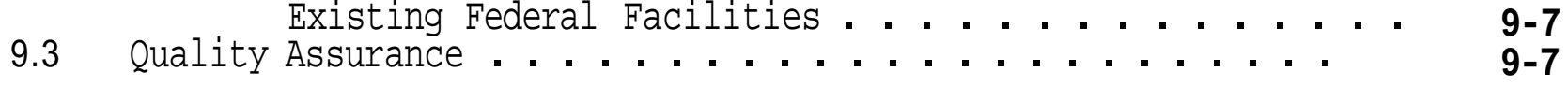

\section{CHAPTER 10.0 - QUALITY ASSURANCE}

10.1 Mandatory $Q A$ Requirements . . . . . . . . . . . . . . 10-2

10.1.1 QA Plan .................... 10.... 10.

10.1 Audits . . . . . . . . . . . . . . . . . 10-2

10.1.3 Elements of the $Q A$ Plan $: \cdots: \cdots: \cdots: 10-2$

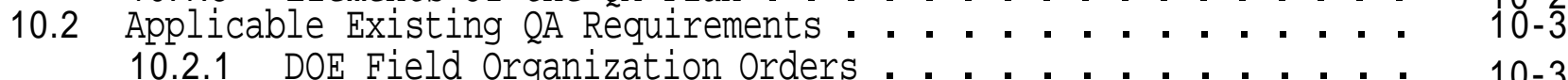

10.2.2 Contractor Corporate 0 A Programs . . . . . . . . . 10-3

10.2.3 Environmental Legislation $Q A$ Requirements . . . . . . . $10-3$

10.3 QC Guidance . . . . . . . . . . . . . . . . . . . . 10 10-3

10.3.1 Written Monitoring Procedures . . . . . . . . 10-4

10.3.2 Analytical QC Program . . . . . . . . . . 10-4

CHAPTER 11.0 - REEERENCES $\ldots \ldots \ldots \ldots \ldots$. . . . . . . . . . 11-1

APPENDIX A . . . . . . . . . . . . . . . . A A-1 


\section{FIGURES}

8-1 - Major Steps in Performing Public Radiation Dose Calculations . . 8-2

8-2 - Potential Steps in Performing Public Radiation Dose Calculations for Various Environmental Pathways . . . . . . . . . . .

\section{$\underline{\text { TABLES }}$}

3-1 - Criteria for Emission Monitoring . . . . . . . . . . . 3-2

5-1 - Minimum Criteria for Determining Need for Environmental Surveillance .................... . . . 5-2

5-2 - Minimum Air Sample Collections and Analyses to Be Performed as a Function of Estimated Effective Dose Equivalent to the Maximally Exposed Individual, as Determined from

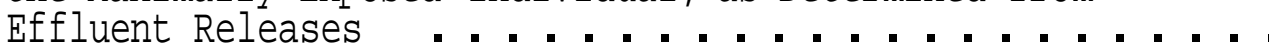

7-1 - Sources of Variability in Effluent Monitoring Data . . . . . . 7-3

8-1 - Potential Pathways to be Considered in Environmental Pathway Analyses . . . . . . . . . . . . . .

9-1 - Applicable Environmental and Effluent Regulations and 


\section{SUMMARY OF EFFLUENT MONITORING AND ENVIRONMENTAL SURVEILLANCE PROGRAM ELEMENTS}

\section{General Elements}

a. Operators of DOE-controlled facilities should* provide the capabilities to detect and quantify planned and unplanned releases of radionuclides, consistent with the potential for offsite impact, and to support consequence assessments as necessary.

b. The recommendations found in this guide should* be incorporated into the design and operation of effluent monitoring and environmental surveillance systems.

c. Documentation of the decisions made concerning incorporation of the specific guidance statements, including a description of any alternative methods selected, should* be included in the site Environmental Monitoring Plan.

d. The potential for airborne or liquid release of radioactive material (including accidental releases) should* be evaluated and documented in the Environmental Monitoring Plan. Based on this documentation, those effluent streams that do not have the potential for releasing radioactive material are not subject to selected provisions of this guide. Heads of Operations Offices, in consultation with the appropriate Program Office and EH-I, may approve specific requests for exceptions.

\section{Liquid Effluent Monitoring}

a. All liquid effluent streams should* be evalSection 2.0 uated and their potential for release of radioactive material assessed. Based on this assessment, decisions should* be made regarding necessary effluent monitoring systems and the rationale should* be documented in the Environmental Monitoring Plan.

b. Liquid effluents from DOE-controlled facilities that have the potential for radioactive contamination should* be monitored in accordance with the requirements of DOE 5400.1 and DOE 5400.5.

c. Facil ity operators should* provide monitoring of liquid waste streams adequate to 1) demonstrate compliance with the requirements of DOE 5400.5, Chapter 11, paragraphs la, Id, 2a, and 3,2) quantify radionuclides released from each discharge 
point, and 3) alert affected process supervisors of accidents in processes and emission controls.

d. When continuous monitoring or continuous sampling is provided, the overall accuracy of the results should* be determined ( $\pm \%$ accuracy and the \% confidence level) and documented in the Environmental Monitoring Plan.

e. Provisions for monitoring of liquid effluents during an emergency should* be considered when determining routine liquid effluent monitoring program needs.

f. The selection or modification of a liquid effluent monitoring system should" be based on a careful characterization of the source(s), pollutant(s) (characteristics and quantities), sample-collection system(s), treatment $\operatorname{system}(s)$, and final release point(s) of the effluents.

g. For all new facilities or facilities that have been modified in a manner that could affect effluent release quantity or quality or that could affect the sensitivity of the monitoring or surveillance systems, a preoperational assessment should* be made and documented in the Environmental Monitoring Plan to determine the types and quantities of liquid effluents to be expected from the facility and to establish the associated effluent monitoring needs of the facility.

h. The performance of the effluent monitoring systems should* be sufficient for determining whether effluent releases of radioactive material are within the Derived Concentration Guides specified in DOE 5400.5 and to comply with the reporting requirements of Chapter 11, paragraph 7, of that order.

i. The required detection levels of the analysis and monitoring systems should* be sufficient to demonstrate compliance with all regulatory requirements consistent with the characteristics of the radionuclides that are present or expected to be present in the effluent. 
j. Sampling systems should* be sufficient to collect representative samples that provide for an adequate record of releases from a facility, to predict trends, and to satisfy needs to quantify releases.

k. Continuous monitoring and sampling systems should* be calibrated before use and recalibrated any time they are subject to maintenance, modification, or system changes that may affect equipment calibration.

1. Sampling and monitoring systems should* be recalibrated at least annually and routinely checked with known sources to determine that they are consistently functioning properly.

m. Environmental conditions (e.g., temperature, humidity, radiation level, dusts, and vapors) should* be considered when locating effluent monitoring systems to avoid conditions that will influence the operation of the system.

n. Off-line liquid transport lines should* be replaced if they become contaminated (to the point where the sensitivity of the system is affected) with radioactive materials or if they become ineffective in meeting the design basis within the established accuracy/confidence levels.

o. If continuous monitoring/sampling and recording of the effluent quantity (stream flow) is not feasible for a specific effluent stream, the extenuating circumstances should* be documented in the Environmental Monitoring Plan.

p. Sampling/monitoring lines and components should* be designed to be compatible with the chemical and biological nature of the 1 iquid effluent.

q. The output signal instrumentation, monitoring system recorders, and alarms should* be in a location that is continuously occupied by operations or security personnel.

r. To signal the need for corrective actions that may be necessary to prevent public or environmental exposures from exceeding the

Section 2.2.4

Section 2.2.4

Section 2.3.2

Section 2.3.7

Section 2.4

Section 2.5 
limits or recommendations given in DOE 5400.5, when continuous monitoring systems are required, they should" have alarms set to provide timely warnings.

s. As they apply to the monitoring/sampling of

Section 2.6 liquid effluents, the general quality assurance program provisions described in Chapter 10 of this guide should" be followed.

3. Airborne Effluent Monitoring

a. All airborne emissions from each facility (DOE site) should" be evaluated and their potential for release of radionuclides assessed. Based on this assessment, decisions should" be made regarding necessary effluent monitoring systems and the rationale should* be documented in the site Environmental Monitoring Plan. The potential for emissions should" include consideration of the loss of emission controls while otherwise operating normally.

b. Airborne emissions from DOE-controlled facilities that have the potential for causing doses exceeding 0.1 mrem (effective dose equivalent) to a member of the public under realistic exposure conditions from emissions in a year should" be monitored in accordance with the requirements of DOE 5400.1 and DOE 5400.5 .

c. The criteria for monitoring listed in Chapter 3 of this guide should" be used to establish the airborne emission monitoring programs for DOE-controlled sites.

d. For all new facilities or facilities that have been modified in a manner that could affect effluent release quantity or quality or that could affect the sensitivity of monitoring or surveillance systems, a preoperational assessment should" be made and documented in the site Environmental Monitoring Plan to determine the types and quantities of airborne emissions to be expected from the facility, and to establish the associated airborne emission monitoring needs of the facility.

Section 3.0

Section 3.0

Section 3.1

Section $\mathbf{3 . 3}$

xi V 
e. The performance of the airborne emissions

Section $\mathbf{3 . 3}$ monitoring systems should* be sufficient for determining whether the releases of radioactive materials are within the limits or requirements specified in DOE 5400.5.

f. Sampling and monitoring systems should* be calibrated before use and recalibrated any time they are subject to maintenance or modification that may affect equipment calibration.

g. Sampling and monitoring systems should* be recalibrated at least annually and routinely checked with known sources to determine that they are consistently functioning properly.

h. Provisions for monitoring of airborne emissions during accident situations should* be considered when determining routine airborne emission monitoring program needs.

Diffuse sources (i.e., area sources or multiple point sources in a limited area) should" be identified and assessed for their potential to contribute to public dose and should* be considered in designing the site emissions monitoring arid environmental surveillance program. Diffuse sources that may contribute a significant fraction (e.g., $10 \%$ ) of the dose to members of the public resulting from site operations should* be identified, assessed, documented, and verified annually.

j. Airborne emission sampling and monitoring systems should* demonstrate that quantification of airborne emissions is timely, representative, and adequately sensitive.

k. To the extent practicable, samples should* be extracted from the effluents from a location and in a manner that provides a representative sample, using multiport probes if necessary.

1. Where a significant potential (greater than once per year) exists for approaching or exceeding a large fraction of the emission standard (e.g., 20\%), continuous monitoring should* be required.

Section $\mathbf{3 . 3}$

Section $\mathbf{3 . 3}$

Section 3.3

Section 3.3.2

Section 3.4

Section 3.5.2

Section 3.5.8 
m. The design of radioiodine monitors will be

Section 3.5.8.3 such that replacement of sorbent and filter should" not disturb the geometry between the collector and detectors.

n. To signal the need for corrective actions that may be necessary to prevent public or environmental exposures exceeding the 1 imits or recommendations given in DOE 5400.5, when continuous monitoring systems (as required by the criteria in Chapter 3) are required, they should" have alarms set to provide timely warnings.

o. As they apply to the monitoring of airborne emissions, the general quality assurance program provisions of Chapter 10 of this guide should* be followed.

\section{Meteorological Monitoring}

a. Each DOE site should* establ ish a meteorological monitoring program that is appropriate to the activities at the site, the topographical characteristics of the site, and the distance to critical receptors.

b. The scope of the program should* be based on an evaluation of the regulatory requirements, the meteorological data needed for impact assessments, environmental surveillance activities, and emergency response, considering the mathematical procedures, models, and input data requirements necessary for computing atmospheric transport and diffusion computations and performing dose assessments.

c. The program should* be documented in a meteorological monitoring section of the Environmental Monitoring Plan in compliance with DOE 5400.1 .

d. For data from an offsite source to be acceptable, the data should* be representative of conditions at the DOE facility and provide statistically valid data consistent with onsite monitoring requirements.

e. Specific meteorological information requirements for each facility should* be based on the magnitude of potential source terms, the

Section 4.0

Section 4.0

Section 4.0

Section 4.0

xVi 
nature of potential releases from the facility, possible pathways to the atmosphere, distances from release points to critical receptors, and the proximity of the site to other DOE facilities.

f. Meteorological information requirements for facilities should" be sufficient to support environmental monitoring and surveillance programs.

g. The meteorological monitoring program for each DOE site should" provide the data for use in atmospheric transport and diffusion computations that are appropriate for the site and application.

h. Before any model is deemed appropriate for a specific application, the assumptions upon which the model is based should* be evaluated and the evaluation results documented.

i. Meteorological programs for sites where onsite meteorological measurements are not required should* include a description of climatology in the vicinity of the site and should" provide ready access to representative meteorological data.

j. Potential release modes, distances from release points to receptors, and meteorological conditions should* be considered in assessments for DOE facilities required to take onsite measurements.

k. Meteorological measurements should* be made in locations that, to the extent practicable, provide data representative of the atmospheric conditions into which material will be released and transported.

1. The instruments used in the monitoring program should" be capable of continuous operation in the normal range of atmospheric conditions at the facility.

m. Wind measurements should" be made at a sufficient number of altitudes to adequately characterize the wind at potential release heights. 
n. If instruments are mounted on booms extend-

Section 4.4 .2 ing to the side of a tower, the booms should" be oriented in directions that minimize the potential effects of the tower on the measurements. The instruments

should* be at least two tower diameters from the tower, but should be three to four tower diameters from the tower.

o. The meteorological monitoring program should" provide for routine inspection of the data and scheduled maintenance and calibration of the meteorological instrumentation and data-acquisition system at a minimum, based on the calibration frequency recommendations of the manufacturers.

p. Inspections, maintenance, and calibrations should* be conducted in accordance with written procedures, and logs of the inspections, maintenance, and calibrations should* be kept and maintained as permanent records.

q. The instrument system should* provide data recovery of at least $90 \%$ on an annual basis for wind direction, wind speed, those parameters necessary to classify atmospheric stability, and other meteorological elements required for dose assessment.

r. The topographic setting of a facility and the distances from the facility to points of public access should* be considered when evaluating the need for supplementary instrumentation.

s. If meteorological measurements at a single location cannot adequately represent atmospheric conditions for transport and diffusion computations, supplementary measurements should* be made.

t. A site-wide meteorological monitoring program should" be established at each multifacility site to provide a comprehensive data base that can be used for all facilities located within the site.

u. As they apply to meteorological monitoring, the general quality assurance program provisions of Chapter 10 of this guide should* be followed. 
5. Environmental Surveillance

a. An evaluation should* be conducted and used as the basis for establishing an environmental surveillance program for all DoEcontrolled sites. The purpose of the surveillance program is to characterize the radiological conditions of the offsite environs and, if appropriate, estimate public doses related to these conditions, confirm predictions of public doses based on effluent monitoring data, and, where appropriate, to provide compliance data for all applicable regulations. The results of this evaluation should" be documented in the site Environmental Monitoring Plan.

b. The environmental surveillance program for DOE-controlled sites should" be conducted in accordance with the requirements of DOE 5400.1 and DOE 5400.5.

c. The criteria for environmental surveillance programs listed in Chapter 5 should* be used for establishing the environmental surveillance program for DOE-controlled sites. Additional site-specific criteria should* be documented in the site Environmental Monitoring Plan.

d. The need for environmental sampling and analysis should* be evaluated, by exposure pathway analysis, for each site radionuclide effluent or emission (liquid or airborne). This analysis with appropriate data, references, and site-specific assumptions, along with site-specific criteria for selection of samples, measurements, instrumentation, equipment, and sampling or measurement locations should" be documented in the site Environmental Monitoring Plan.

e. A critical pathway analysis (radionuclide/ media) should* be performed, documented, and referenced in the Annual Site Envircnmental Report.

Section $\mathbf{5 . 0}$

Section 5.1

Section 5.1 .1

Section 5.1 .1 
f. If the projected dose equivalent from inhalation of particulates exceeds the criteria

Section 5.1.1 of Chapter 5, particle-size analysis of the emission should* be conducted at least annually .

9. Further provisions shouldt be made, as appropriate, for the detection and quantification of unplanned releases to the environment of radioactive materials, including radionuclides that may be transported by stormwater runoff, flooding, or resuspension of ground-deposited material.

h. For all new or modified facilities coming on-line, a preoperational assessment should* be made and documented in the site Environmental Monitoring Plan to determine the types and quantities of effluents to be expected from the facility and to establish the associated environmental surveillance program.

i. Calibration of dosimeters and exposure-rate instruments should* be based on traceability to NIST standards.

j. Gross radioactivity analyses should* be used only as trend indicators, unless documented supporting analyses provide a rel iable relationship to specific radionuclide concentrations or doses.

k. The overall accuracy ( $\pm \%$ accuracy) should* be estimated, and the approximate Environmental Detection Limit at a specified \% confidence level for environmental measurements of beta-gammas, alphas, and neutrons, as appropriate, should* be determined and documented.

1. Sample preservation methods should* be consistent with the analytical procedures used.

Section 5.2

m. All environmental surveillance techniques should" be designed to take a representative sample or measurement of the important radiation exposure pathway media.

n. Sampl ing or measurement frequencies for each significant radionuclide or environmental

Section 5.2

Section 5.1 .2

Section 5.2

Section 5.2

Section 5.2

$\mathrm{XX}$

Section 5.2.1 
medium combination (e.g., those contributing $10 \%$ or more to offsite dose greater than 0.1 mrem EDE from emissions in a year) should* take into account the half-life of the radionuclides to be measured and should* be documented in the site Environmental Monitoring Plan.

o. "Background" or "control" location measurements should* be made for every significant radionuclide and pathway combination (e.g., those contributing $10 \%$ or more to offsite dose greater than 0.1 mrem EDE from emissions in a year) for which environmental measurements are used in the dose calculations.

p. An annual review of the radionuclide composition of effluents or emissions should* be made and compared with those used to establish the site Environmental Monitoring Plan. Any deviations from routine environmental surveillance requirements, including sampling or measurement station placement, should* be documented in an approved revised site Environmental Monitoring Plan.

q. The air sampling rate should* not vary by more than $\pm 20 \%$, and total air flow or total running time should* be indicated; air sampling systems should* be leak-tested, flow-calibrated, tested, and inspected on a routine basis at a minimum, using the calibration frequency recommendations of the equipment manufacturers.

r. State and local game officials should* be consulted when selecting appropriate protected species to sample.

s. DOE Operations Office and contractor staff should $^{*}$ ensure that ground-water monitoring plans are consistent with State and regional EPA ground-water monitoring requirements under RCRA and CERCLA to avoid unnecessary duplication. DOE Operations Offices and contractor staff should* consult with State and regional EPA offices, as needed, to ensure that the requirements are incorporated into the Radiological Monitoring Plan.

Section 5.2.1

Section 5.2.1

Section 5.2 .2

Section 5.2 .3

Section 5.2 .4

$\mathbf{x x}$ i 
t. Any changes in the site-specific or generic

Section 5.3.2 factors should* be noted in the Environmental Monitoring Plan and the retired or replaced values preserved for historical purposes.

U. When neutron monitoring is required, the method of measurement should* be based on the anticipated flux and energy spectrum.

Section 5.6 .2

V. The sample exchange frequency for nonparticulate sampling should be determined on a site-specific basis and should* be documented in the environmental surveillance files.

w. The analytica procedure to be used shouldt be considered when choosing a method for preserving mi $\mathbf{k}$ samples.

x. As they apply to environmental surveillance activities, the general quality assurance program provisions of Chapter 10 of this guide shouldt be followed.

6. Laboratory Procedures

a. Laboratory procedures and practices should* be documented in the site Environmental Monitoring Plan.

b. Each monitoring and surveillance organization should* have a sample identification system that provides positive identification of samples and aliquots of samples throughout the analytical process. The system should* incorporate a method for tracking all pertinent information obtained in the sampling process.

c. Each laboratory should* establish and adhere to written procedures to minimize the possibility of cross-contamination between samples. High-activity samples should* be kept separate from low-activity samples.

d. The integrity of samples should* be maintained (j,e,, minimize degradation of samples by using proper preservation and handling practices that are compatible with analytical methods).

Section 6.0

Section 6.1.1

Section 6.1 .2

Section 5.8.2.1

Section 5.13 
e. Specific'analytical methods should* be idenSection 6.1 .3 tified, documented, and used to identify and quantify all radionuclides in the facility inventory or effluent that contribute $10 \%$ or more to the public dose or environmental contamination associated with the site.

f. Standard analytical methods should" be used for radionuclide analyses (when available). Any modification of standard methods should* be documented.

g. Methods, requirements, and necessary documentation should* be specified in analytical contracts.

h. All sites that release or could release gamma-emitting radionuclides should* have the capability (either in-house or outside) of having samples (routine, special, or emergency) analyzed by gamma-ray spectroscopy systems .

i. Counting equipment should* be calibrated using, at a minimum, the calibration frequency recommendations of the manufacturers to obtain accurate results.

j. Check sources should* be counted periodically on all counters to verify that the counters are giving correct results.

k. Samples that are sent offsite for analysis or for laboratory intercomparison should* be monitored for contamination and radiation levels and should" be packaged in a manner that meets applicable transportation regulations and requirements.

1. As they apply to laboratory procedures, the general quality assurance program provisions of Chapter 10 of this guide should* be followed.

7. Data Analvsis and Statistical Treatment

a. The statistical techniques used to support the concentration estimates, to determine their corresponding measures of reliability, and to compare radionuclide data between sampling and/or measurement points and times

Sect on 6.1.3

Sect on 6.1.3

Section 6.1.4

Section 6.1 .5

Section 6.1 .5

Section 6.2.2

Section 6.13

Section 7.0

xxi i i 
should* be designed with consideration of the characteristics of effluent and environmental data.

b. Documented and approved sampling, sample-

Section 7.0 handling, analysis, and data-management techniques should* be used to reduce the variability of results.

c. The level of confidence in the data due to the radiological analyses should* be estimated by analyzing blanks and spiked pseudosamples and by comparing the resulting concentration estimates to the known concentrations in those samples.

d. The precision of radionuclide analytical results should* be reported as a range, a variance, a standard deviation, a standard error, and/or a confidence interval.

e. Data should* be examined and entered into the data base promptly after analysis.

f. Outliers should* be excluded from the data only after investigation confirms that an error has been made in the sample collection, preparation, measurement, or data analysis process. As each data point is collected, it should* be compared to previous data, because such comparison can help identify unusual measurements that require investigation or further statistical eval uation.

g. As they apply to data analysis and statistical treatment activities, the general quality assurance program provisions of Chapter 10 of this guide should* be followed.

\section{Dose Calculations}

a. Except where mandated otherwise (e.g., compliance with 40 CFR Part 61), the assessment models selected for all environmental dose assessments should* appropriately characterize the physical and environmental situation encountered. The information used in dose assessments should* be as accurate and realistic as possible. 
b. Complete documentation of models, input

Section 8.1 .1

data, and computer programs should* be pro-

vided in a manner that supports the annual

site environmental report or other

application.

c. Default values used in model applications

should* be documented and evaluated to determine appropriateness to the specific modeling situation.

d. When performing human foodchain assessments, a complete set of human exposure pathways should* be considered, consistent with current methods, and should* be documented supporting the site Environmental Monitoring Plan.

e. Surface- and ground-water modeling should* be conducted as necessary to conform with the applicable requirements of the State government and the regional office of the EPA.

f. The general quality assurance program provisions of Chapter 10 of this guide should* be followed as they apply to performing calculations that assess dose impacts.

\section{Records and Reports}

a. DOE officials and DOE Management and Operating Contractors should* identify and comply with the relevant reporting requirements.

b. Timely notification of occurrences and information involving DOE and its contractors should* be made to the appropriate DOE officials and to other responsible authorities.

c. Auditable records relating to environmental surveillance and effluent monitoring should* be maintained. Calculations, computer programs, or other data handling should* be recorded or referenced.

d. As they apply to records and reporting activities, the general quality assurance program provisions of Chapter 10 of this guide should" be followed.

Section 9.0

Section 9.0 
10. Qualitv Assurance

a. A QA Plan should" be prepared and included

Section 10.0

as a section of the Environmental Monitoring

Plan and should* cover the monitoring activ-

ities at each site, consistent with appli-

cable elements of the 18-element format in

ANSI/ASME NQA-1.

b. Periodic audits should" be performed to verify compliance with operational procedures, $\mathrm{QC}$ procedures, and all aspects of the $\mathrm{QA}$ program.

c. Audits should* be performed independently in accordance with written procedures or checklists by personnel who do not have direct responsibi 1 ity for performing the activities being audited (i .e., supervisors cannot audit their own facilities).

d. Audit results should* be documented and reported to and reviewed by responsible management. Follow-up action should* be taken where indicated.

e. The elements of a $Q A$ program should" be derived from the 18 criteria in ANSI/ASME NQA-1 and those stipulated in 10 CFR Part 50.

f. Radiation measuring equipment, including portable instruments, environmental dosimeters, in situ monitoring equipment, and 1 aboratory instruments, should" be calibrated with standards traceable to NIST calibration standards.

Section 10.1 .2

Section 10.1 .2

Section 10.1 .2

Section 10.1.3

Section 10.3.2 


\subsection{IMTRODUCT ION}

Under the Atomic Energy Act of 1954, as amended, the U.S. Department of Energy (DOE) is obligated "to regulate its own activities so as to provide radiation protection for both workers and the public." Presidential Executive Order 12088, "Federal Compliance with Pollution Control Standards; " further requires the heads of executive agenc es to ensure that all Federal facilities and activities comply with applicable pollution control standards and to take all actions necessary for the prevent on, control, and abatement of environmental pollution.

It is the policy of DOE to conduct effluent monitoring and environmental surveillance programs that are adequate to determine whether the public and the environment are adequately protected during DOE operations and whether operations are in compliance with DOE and other applicable Federal, State, and local radiation standards and requirements. It is also DOE policy that Departmental monitoring and surveillance programs be capable of detecting and quantifying unplanned releases and meet high standards of quality and credibility. It is DOE's objective that all DOE operations properly and accurately measure radionuclides in their effluents and in ambient environmental media.

This regulatory guide describes the elements of an acceptable effluent monitoring and environmental surveillance program for DOE sites involving radioactive materials. These elements are applicable to all DOE and contractor activities for which the DOE exercises environmental, safety, and health responsibilities, and are intended to be applicable over the broad range of DOE facilities and sites. In situations where the high-priority elements may not provide sufficient coverage of a specific monitoring or surveillance topic, the document provides additional guidance. The high-priority elements are written as procedures and activities that "should*" be performed, and the guidance is written as procedures and activities that "should" be performed. The regulatory guide both incorporates and expands on requirements embodied in DOE 5400.5 and DOE 5400.1.

\subsection{PURPOSE AND SCOPE}

The primary purpose of the regulatory guide is to specify the necessary elements for effluent monitoring and environmental surveillance of radioactive materials at DOE sites to comply with both applicable Federal regulations and DOE policy. The high-priority radiological effluent monitoring and environmental surveillance program elements contained in this document are given in the form of generic performance criteria - that is, the numeric limits and actions required for maintaining and operating an adequate radiation protection program for the public and the environment. In addition to the highpriority elements, this document also contains guidance to help define how the performance criteria can be met. The guide includes specific actions, equipment selections, and operational methods that would be expected to meet the performance requirements. 
For new facilities and/or new effluent monitoring and environmental surveillance systems, the guidance, as defined by the "should" statements, should be considered high-priority elements and be adopted to the extent applicable. The adoption of the guidance for new facilities and/or systems is a necessary step in fulfilling the commitment that environmental obligations be carried out consistently across all operations and among all field organizations and programs.

The regulatory guide addresses the effluent monitoring and environmental surveillance practices associated with normal operations at a DOE facility. These practices may not be adequate for quantitative assessment of releases or environmental impacts associated with more serious unusual occurrences and emergency situations; these more serious situations may require a significantly different program. Precautions in this regard have been incorporated into the document as appropriate. All facilities are expected, in accordance with applicable DOE orders, to take appropriate actions to ensure a capability to detect and quanti fy releases of radioactive material during unusual occurrences and emergency situations.

\subsubsection{Environmental Monitoring}

As required in the Environmental Monitoring Requirements section of DOE 5400.1, all DOE sites should* develop and maintain documentation concerning their environmental protection programs in the form of environmental monitoring plans. These required plans should* clearly describe how the minimum requirements defined in this document are to be met and how compliance will be ensured. In meeting the minimum requirements, each site should* also consider the guidance provided in this document as "should" statements and document the specific procedural criteria that are adopted.

The responsibility for ensuring development, documentation, and implementation of the site-specific effluent measurement and environmental surveillance programs for each DOE site remains with the individual field office responsible for the facility. Copies of each site-specific environmental protection program plan that has been approved by the Program Office should be submitted to $\mathrm{EH}$ for information purposes.

\subsection{MANUAL ORGANIZATION AND TERMINOLOGY}

This regulatory guide is organized by sections as follows:

1) Introduction

2) Liquid Effluent Monitoring

3) Airborne Effluent Monitoring

4) Meteorological Monitoring

5) Environmental Surveillance 
6) Laboratory Procedures

7) Data Analysis and Statistical Treatment

8) Dose Calculations

9) Records and Reports

10) Quality Assurance

11) References

The user of this regulatory guide is assumed to have a working knowledge of DOE standards and requirements and of basic radiation protection concepts and terminology. Special terms are defined in Appendix A. 


\subsection{LIQUID EFFLUENT MONITORING}

All liquid effluent streams from DOE facilities should* be evaluated and their potential for release of radionuclides assessed. This evaluation is required to adequately control such releases. The results of this assessment provide the basis for the facility's Effluent Monitoring Program (DOE 5400.5), which should* be documented in the.site Environmental Monitoring Plan (as described in DOE 5400.1 ), to show'

- Effluent monitoring (sampling or in situ measurement) extraction locations used for providing quantitative effluent release data for each outfall

- Procedures and equipment used to perform the extraction and measurement

- Frequency and analyses required for each extraction (continuous monitoring and/or sampling) location

- Minimum detection level and accuracy

- Qual ity assurance components

- Effluent outfall alarm settings and bases.

Liauid effluents from DOE-controlled facilities that have the potential for radioactive contamination should* be monitored in accordance with the requirements of DOE 5400.1 and DOE 5400.5. As appropriate, component systems may be grouped and standard procedures referenced.

\subsection{SUMMARY OF GENERAL CRITERIA AND MONITORING REOUIREMENTS}

Facility operators should* provide monitoring of liquid waste streams adequate to 1) demonstrate compliance with the applicable requirements of DOE 5400.5 , Chapter II, paragraphs $1 \mathrm{a}, 1 \mathrm{~d}, 2 \mathrm{a}$, and 3,2 ) quantify radionuclides released from each discharge point, and 3) alert affected process supervisors of upsets in processes and emission controls. Continuous radionuclide monitoring should be provided on those release points that could 1) exceed 1 DCG equivalent at the point of release averaged over 1 year and that are detectable with state-of-the-art continuous monitoring devices, or 2) result in unanticipated releases to the environment that could exceed 1 DCG averaged over 1 year. Continuous sampling with frequent analysis may be used in lieu of continuous monitoring if the emissions from the radioactive materials are not detectable by state-of-the-art continuous monitoring devices. The monitoring effort for effluents should be commensurate with the importance of the sources during routine operations and from potential accidents with respect to their potential contribution to public dose or to contamination of the environment. When continuous monitoring or continuous sampling is provided, the overall accuracy of the results should* be determined $( \pm \%$ accuracy and the $\%$ confidence level) and documented in the Environmental Monitoring Plan. The 
lower limit of detection for continuous monitoring systems should be stated in the Environmental Monitoring Plan. The lower limit of detection should be sufficiently low to ensure that analyses necessary to comply with the reporting requirements of DOE 5400.5, Chapter II, paragraph 7, can be completed. In addition, provisions for monitoring of liquid effluents during an emergency should* be considered when determining routine liquid effluent monitoring program needs. Emergency 1 iquid effluent monitoring systems and procedures should be specified in the site/facility Emergency Response Plan. Liquid effluent monitoring requirements for DOE-controlled facilities are shown in the summary.

\subsection{PERFORMANCE STANDARDS FOR LIOUID EFELUENT MONITORING SYSTEMS}

In addition, the selection or modification of a liquid effluent monitoring system should* be based on a careful characterization of the source(s), pol lutant (s) (characteristics and quantities), sample-collection system(s), treatment system(s), and final release point(s) of the effluents. For all new facilities or facilities that have been modified in a manner that could affect effluent release quantity or quality or that could affect the sensitivity of monitoring or surveillance systems, a preoperational assessment should* be made and documented in the Environmental Monitoring Plan to determine the types and quantities of liquid effluents to be expected from the facility and to establish the associated effluent monitoring needs of the facility. Characterization should include the identification of the actual or potential presence of radionuclides and their chemical and physical properties that might affect required performance of the sampling or monitoring equipment

used. The performance of the effluent monitoring systems should* be sufficient for determining whether effluent releases of radioactive material are within the Derived Concentration Guides (DCGs) specified in DOE 5400.5 and to comply with the reporting requirements of Chapter 11, paragraph 7, of that Order. The required detection levels of the analysis and monitoring systems should* be sufficient to demonstrate compliance with all regulatory requirements consistent with the characteristics of the radionuclides that are present or expected to be present in the effluent.

\subsubsection{Continuous Monitoring/Sampling}

For those effluent streams requiring continuous monitoring/sampling, all data received from the continuous monitoring system should be used when performing statistical analyses. In the case of discharge points releasing radionuclides emitting alpha or weak beta radiation, with no documentable ratios to beta and/or gamma emitters that could be used as indicator radionuclides (i .e., where it is not technologically feasible to monitor continuously), continuous proportional sampling and analysis can be used as an alternative to continuous monitoring. However, the consideration of new technologies to continuously monitor such effluent streams is encouraged. 


\subsubsection{Sampling Svstems}

Sampling systems should* be sufficient to collect representative samples that provide for an adequate record of releases from a facility, to predict trends, and to satisfy needs to quantify releases.

\subsubsection{Svstem Calibration}

Continuous monitoring and sampling systems should* be calibrated before use and recalibrated any time they are subject to maintenance, modification, or system changes that may affect equipment calibration. In addition, they should* be recalibrated at least annually and routinely checked with known sources to determine that they are consistently functioning properly. Calibration(s) should be performed in a manner consistent with manufacturers' instructions and specifications. Each system should be checked on a routine basis, at least weekly. Sampling systems should be functioning properly before a facility is placed in operation. The use of redundant sampling systems may be necessary to provide adequate sampling capabilities and prevent delays in process operation.

\subsubsection{Environmental Conditions}

Environmental conditions (e.g., temperature, humidity, radiation level, dusts, and vapors) should* be considered when locating sampling and monitoring systems to avoid conditions that will influence the operation of the system. Off-line liquid transporting lines should* be replaced if they become contaminated (to the point where the sensitivity of the system is affected) with radioactive materials or if they become ineffective in meeting the design basis within the established accuracy/confidence levels.

\subsection{SAMPLING SYSTEM DESIGN CRITERIA}

Reliable quantification of radionuclides in liquid effluent streams requires representative sampling, which in turn requires consideration of stream flow rate and variability, sample port and collector design, delivery system reliability, effluent-stream chemical and biological characteristics, and the need for sample preservation. Useful advice on representative 1 iquid sampling is available from the American Public Health Association (APHA 1985) and the American Society for Testing and Materials (ASTM 1986b). There are four basic 1 iquid-effluent sampling alternatives:

1) Off-line periodic - grab samples of waste streams are taken periodically, concentrated if desired, and delivered to the laboratory for analysis; 
2) Off-line sequential - can be used when a stream flow-rate is relatively constant so that waste streams are sampled by taking time aliquots of the effluent, and the accumulated aliquots are analyzed in the laboratory;

3) Off-line proportional - a known fraction of the effluent is continuously collected before laboratory analysis; and

4) Off-line continuous - samples are collected continuously at a known, uniform rate.

The first alternative (commonly called grab sampling) is suitable for ensuring that previously determined release rates have not changed significantly or that radionuclides are not being introduced into the previously nonradioactive liquid effluent being sampled. Off-line sequential sampling is suitable for quantifying uniformly low concentrations of radionuclides being released via effluent lines to the environs. Off-line proportional sampling is appropriate for obtaining representative samples from streams with fluctuating flow rates and radionuclide concentrations. Off-1 ine continuous sampling is appropriate for taking samples at a constant rate from effluents that have nearconstant flow (i .e., flow that does not vary by more than 50\%).

\subsubsection{General Design Criteria}

The following criteria should be considered when operating a liquid effluent sampling system:

- Location of sampling and monitoring systems

- Use of a pump in areas where necessary to provide a uniform continuous flow in the main sample line

- A redundant sample-collection system or one of the following alternatives to permit continued sampling during replacement or servicing of the system: 1) a substitute sample-transport system, 2) the capability to shut down the system for fast repair, or 3) an alternate method for estimating releases when the system is not capable of operating

- Location of sample ports in liquid effluent lines suff ciently far downstream from the last feeder line to allow complete mixing (as complete as possible) of liquid and design of the samp e port to allow intake of a proportional part of the liquid effluent stream

- Capability to determine the effluent stream and sample-line flows within an accuracy of at least $\pm 10 \%$

- Design of the system to minimize deformation and sedimentation and to prevent freezing of effluent sample lines. 


\subsubsection{Stream Flow Characteristics}

Variability in the flow rate of liquid effluents may be the most significant variable in the sample calculations. Thus, continuous monitoring and recording of effluent quantity should be performed. If continuous monitoring/ sampling and recording of the effluent quantity (stream flow) is not feasible for a specific effluent stream, the extenuating circumstances should" be documented in the Environmental Monitoring Plan. The sampling point should be located in an accessible section of the effluent line at the position providing the most complete mixing. Liquid effluent flow rates should be measured within an accuracy of at least $\pm 10 \%$ and recorded. A variety of measuring devices are available for measuring flow rates, such as V-notch weirs or ultrasonic or turbine flow meters. The recorded flows and the concentrations of radionuclides measured in the sample provide the information needed to compute the total amount of radioactive material released to the environment via the sampled stream. Very little accuracy is gained from proportional sampling of effluent streams having near-constant continuous flow. Continuous constant-rate sampling is more reliable and simpler. Thus, continuous sampling is recommended for near-constant, continuous-flow effluent streams (i,e., flow that does not vary by more than $50 \%$ ).

\subsubsection{Sampling Locations}

The sampling ports should be 1) positioned downstream from the last component stream entering, in a location that will provide complete mixing; and 2) designed to accommodate a proportional amount of the full range of effluent flow for transport to the collection system. If proportionality cannot be automated, both the effluent and sample flow rates should be measured.

\subsubsection{Delivery Lines}

The integrity of the junction of the liquid-sample line with the sampling port is important. Liquid effluent lines can expand and contract considerably, depending on the thermal loading variation in the line(s). Consequently, design for such a junction should consider either line snubbers or special fabrications to handle the added mechanical stress.

\subsubsection{Liquid Movers}

Unless sufficiently high and constant hydraulic pressure exists within an effluent system, a sampling pump of high reliability should be installed. Removal of the sample from the liquid effluent line where a sampling pump is required should be accomplished using a constant-volume pump that will maintain a constant flow, regardless of line pressure changes.

\subsubsection{Samole Collectors}

The design of the collector portion of the sampling system should allow for the collection of a sample that is consistent with the method of analysis. For example, if the effluent stream has a small flow, a small container might be used to obtain a grab sample that is counted directly in the laboratory. If concentration of the sample is necessary, a large-volume sample will 
be necessary. If the collection system requires measured aliquots taken sequentially every few minutes, then both the frequency and required sensitivity of analysis have an impact on the size of the container to be used. The sample line should be routed back to either the effluent line or a waste treatment system. Thus, location of the sample collection system can be based in part on the return flow of the sample line.

\subsubsection{Special Considerations}

The following special conditions should be considered when designing and operating a liquid effluent sampling/monitoring system:

- Effluent lines are frequently buried in soil, which creates accessibility problems for sampling unless special provisions are considered in the discharge system design.

- Biological growths can cause sample-1ine flow restrictions.

- Effluent lines often move or are stressed mechanically.

- Large fluctuations in effluent flow rates are common.

- Small-volume wastes are easier to collect in batch tanks, lending themselves to grab sampling and analysis before release.

- Sample collection may require extra precautions (e.g., precoating sample containers) .

- Effluent velocity and corrosion can significantly affect in-line sampling or monitoring probes.

- Effluent monitoring systems and procedures should be designed to identify and quantify the full range of potential accidental releases as well as those from routine operations.

It is especially important to consider these factors during the design stages of a sampling/monitoring system so proper allowance can be made to accommodate them. Sampling/monitoring lines and components should" be designed to be compatible with the chemical and biological nature of the liquid effluent. Biological growth around or within a sampling/monitoring systs can plug or distort sampling orifices and equipment. If biocides are used, they should be selected and applied so as not to interfere with the sampling and analytical processes. When batch tanks are used for collecting liquid effluents before release to the environment, three factors should be considered:

- Adequate mixing of the sampled volume to provide that liquids in the tank are homogeneous for sample withdrawal

- Recirculation of tank liquid through the sample lines to provide that the sample is representative 
- Frequent checks for residual liquid or sludge accumulation as needed.

\subsubsection{Environmental Considerations}

The external environment surrounding the sampling system and effluent lines must be considered. The sampling system should be protected from adverse environmental factors including unusual operational impacts. At sample collection points, the ambient dose rate originating in the effluent line(s) and the sampling apparatus should be evaluated for compliance with shielding and contamination control requirements necessary for reducing worker exposure. Components of the sampling system should be readily accessible for maintenance.

\subsection{MONITORING SYSTEM DESIGN CONSIDERATIONS}

Design considerations for 1 iquid effluent monitoring systems should include the purpose of the monitoring, the types and levels of expected radionuclides, potential background dose rates, expected duration of releases, and environmental effects. One of the primary purposes of using a monitoring system is to utilize its ability to provide a prompt signal if a significant release occurs. Thus, the output signal from monitoring systems should be continuously monitored by responsible personnel. . In addition, written response procedures should be provided describing the action that responsible personnel must take if an abnormal signal is detected. The output signal instrumentation, monitoring system recorders, and alarms should* be in a location that is continuously occupied by operations or security personnel.

\subsubsection{Monitoring Purposes}

An unshielded in-line monitoring system should be sufficient to quantify the gamma-emitting radionuclides in the liquid effluent line, if low ambient dose-rate conditions exist. For moderate ambient dose rates, in-1 ine monitoring may be sufficient, but shielding should be employed. For high ambient dose conditions ( $i . e$. , those above which shielding is no longer a practical solution to controlling the background influence), off-1 ine monitoring should be used. If the primary purpose of the monitoring system is to alert operating staff to significant unplanned increases in gamma-emitting radionuclides within the liquid effluent line, in-line monitoring may be preferred. A combination of in-line and off-1 ine monitoring may be required to accommodate both routine and emergency monitoring.

\subsubsection{General Design Criteria}

The following general design criteria should be considered $n$ the design and operation of routine 1 iquid effluent monitoring systems:

1) If off-line monitoring is employed,

- Use criteria in Section 2.3 for sample transport. 
- Use criteria in Section 2.3.8 for environmental protection, maintenance, and modification.

- Use characterization study data for radionuclide measurements, including ratios of radionuclides not directly measurable, if present.

- Use adequate shielding for detector operation and to maintain personnel exposure as low as reasonably achievable.

- Use a predefined alarm level that is just above normal variations in release levels.

- Locate alarm annunciators in normally occupied locations.

- Use stable electric power sources to provide uniform voltage to the monitor and alarm systems.

2) If in-line monitoring is employed,

- Use the criteria for off-line monitoring.

- Use interpretive curves (primarily for ion chamber and GeigerMuller tube monitors) that allow quick conversion of dose rates or count rates to radionuclide release rates $\left(e, g_{1}, \mu \mathrm{Ci} / \mathrm{min}\right)$, such that both concentrations of and curies released by the various radionuclides can be estimated.

\subsubsection{Iyoes of Radiation}

In liquid effluent streams, direct measurement is only possible with gamma-emitters or by making gross beta-gamma measurements. In situ alpha measurement is not feasible (at this time) with existing technology. Exceptions may exist when coincident gamma radiation is involved with alpha emissions. Gross beta measurement is possible using thin, plastic scintillators. However, it should be demonstrated that the chosen detector is capable of measuring with the required sensitivity. Sampling and analysis should be used to quantify release of alpha-emitters and some beta-emitters (i .e., those that cannot be adequately measured using detectors) .

\subsubsection{High Background}

Even though some shielding is provided by the liquid contents themselves, direct or indirect measurement in areas with high ambient radiation levels requires shielding or off-line analysis. Even with shielding, the low-energy gamma spectrum may be biased when using in situ monitoring in locations of relatively high background dose rates [depending on the radionuclide(s) being measured and the composition of the background]. Consequently, when designing 
installations for locations that are expected to have relatively high radiation dose rates, off-line monitoring should be used.

\subsubsection{Release Duration}

Radioactive material in effluents occasionally originates from a fluctuating source(s). If the content and radioactivity concentration are constant but the release is of short duration, the effluent is considered a "batch" release. Before a batch is released, a representative grab sample should be drawn and analyzed to determine releasability. If the effluent originates from a continuing source(s), it is considered a "continuous" stream and should be continuously monitored and/or sampled.

\subsubsection{Environmental Effects}

Environmental conditions can play a key role in the efficient design of a monitoring or sampling system. Air conditioning for hot locations and heating for cold locations should be considered to provide reliable system operation, particularly for systems using electronic components. The system should be designed and located so that the ambient dose rates will permit access for system calibration and servicing, and minimize worker exposure. Shielding may be required to control worker exposure during calibration and servicing.

\subsection{ALARM LEVELS}

To signal the need for corrective actions that may be necessary to prevent public or environmental exposures from exceeding the limits or recommendations given in DOE 5400.5, when continuous monitoring systems are required, they should* have alarms set to provide timely warnings. To prevent the cumulative impacts of small releases from producing a significant impact, routine grab, continuous, or proportional samples should be collected often enough to detect radionuclides of interest including those with relatively short halflives.

\subsection{QUALITY ASSURANCE}

As they apply to the monitoring/sampling of liquid effluents, the general quality assurance program provisions of Chapter 10 should* be followed. Specific quality assurance requirements for the facility's liquid effluent monitoring program are to be contained in the Quality Assurance Plan associated with the facility. 


\subsection{AIRBORNE EFELUENT MONITORING}

All airborne emissions from DOE-controlled facilities(a) should* be evaluated and their potential for release of radionuclides assessed. This assessment is required to demonstrate that all such releases are adequately controlled and their environmental impacts properly evaluated. The potential for emissions should* include consideration of the loss of emission controls while otherwise operating normally. The results of this evaluation also provide the basis for the site's effluent monitoring program (as discussed in DOE 5400.5), which should" be documented in the site Environmental Monitoring Plan (as discussed in DOE 5400.1) to show

- Effluent monitoring (sampling or in situ measurement) extraction locations used for providing quantitative emission data for each emission point

- Procedures and equipment needed to perform the extraction and measurement

- Frequency and analyses required for each extraction (continuous monitoring and/or sampling) location

- Minimum detection level and accuracy

- Qual ity assurance components

- Investigation and al arm levels.

Airborne emissions from DOE-controlled facilities that have the potential for causing doses exceeding 0.1 mrem (effective dose equivalent) to a member of the public under realistic exposure conditions-from emissions in a year should $^{*}$ be monitored in accordance with the requirements of DOE 5400.1 and DOE 5400.5. As appropriate, component systems may be grouped and standard procedures referenced.

\subsection{SUMMARY OF GENERAL CRITERIA AND MONITORING REQUIREMENTS}

The criteria listed in Table 3-1 should* be used to establish the airborne emission monitoring program for DOE-controlled sites. The criteria listed in Table 3-1 are based on the projected effective dose equivalent in one year to a member of the public (in mrem). Additional airborne emission requirements for DOE-controlled facilities that are required under DOE 5400.1 and DOE $\mathbf{5 4 0 0 . 5}$ are given in the summary and discussed in this chapter. The monitoring effort should be commensurate with the importance of the sources during routine operation and from potential accidents with respect to their potential contribution to public dose or to contamination of the environment.

(a) DOE usage of the terms "site" and "facility" is considered equivalent to $40 \mathrm{CFR}$ Part 61 usage of the terms "facility" and "source." 
TABLE 3-1. Criteria for Emission Monitoring

Calculated Maximum Dose from Emissions in a Year to Members of the Public: $\mathrm{H}_{\mathrm{E}}$ mrem [effective dose equivalent (EDE)]
$H_{E} \geq 1$
1) Continuously monitor emission points that could contribute $\geq 0.1 \mathrm{mrem}$ in a year
2) Identify radionuclides that contribute $\geq 10 \%$ of the dose
3) Determine accuracy of results ( $\pm \%$ accuracy and $\%$ confidence level)
4) Conduct a confirmatory environmental survey annually
or Monitor at the receptor:
1) Continuously sample air at receptor
2) Collect and measure radionucl ides contributing $\geq 1$ mrem (EDE) above background
3) Establish sampler density sufficient to esti- mate dose to critical receptor given typical variability of meteorol ogical conditions
4) Obtain prior approval from EPA
$0.1<H_{E}<1$
1) Continuously monitor emission points that could contribute $\geq 0.1 \mathrm{mrem}$ in a year
2) Identify radionucl ides that contribute $10 \%$ or more of the dose
3) Conduct confirmatory effluent monitoring at emission points where possible
4) Conduct a confirmatory environmental survey every few years
$H_{E}<0.1$
1) Take periodic confirmatory measurements
2) Test to determine need to monitor by calcu- lating dose $\left(H_{E}\right)$ for normal operation, assuming that the emissions controls are inoperative
3) Conduct a confirmatory environmental survey at least every five years

(a) Permission for the use of alternative criteria may be obtained through EH, who will coordinate the request with EPA Headquarters to obtain EPA concurrence, where applicable. Coordination with EPA Regional Offices should be accomplished through DOE Program Office authority. 


\subsection{REOUIREMENTS FOR COMPLIANCE WITH EPA REGULATIONS}

Airborne emissions of radioactive materials from DOE-controlled facilities are subject to the regulations of the U.S. Environmental Protection Agency (EPA). The primary regulation is $40 \mathrm{CFR}$ Part 61, "National Emission Standards for Hazardous Air Pollutants" (NESHAP). The specific emission standard is contained in Subpart $\mathrm{H}$ of $40 \mathrm{CFR}$ Part 61. Additional requirements that cover specific DOE-controlled operations are found in 40 CFR Part 192, regulating emissions from uranium and thorium mill tailings operations. For the purpose of compliance with the dose equivalent limits contained in $40 \mathrm{CFR}$ Part 61, Subpart H, a "facility" is considered to be the entire site (e.g., Hanford Site, Savannah River Site, Idaho National Engineering Laboratory), including all of its potential "sources," or DOE-controlled facilities. Procedural requirements of 40 CFR Part 61 , such as applications for approval to construct, also apply to individual DOE-controlled facilities within each site. Subpart H of $40 \mathrm{CFR}$ Part 61 contains EPA-approved principles and methods by which airborne emissions are measured to demonstrate compliance with the emission standard.

\subsection{PERFORMANCE STANDARDS FOR AIR-SAMPLING SYSTEMS}

The frequency requirements for airborne emission monitoring (continuous monitoring and/or sampling) programs are summarized in Table 3-1. Application of these criteria to an individual facility (DOE-controlled site) or source (DOE-controlled facility) requires that an adequate study of the expected releases, potential exposure pathways, and resulting dose be conducted. For all new facilities or facilities that have been modified in a manner that could affect effluent release quantity or quality or that could affect the sensitivity of monitoring or surveillance systems, a preoperational assessment should* be made and documented in the site Environmental Monitoring Plan to determine the types and quantities of airborne emissions to be expected from the facility, and to establish the associated airborne emission monitoring needs of the facility. The performance of the airborne emissions monitoring systems should" be sufficient for determining whether the releases of radioactive materials are within the limits or requirements specified in DOE 5400.5. Sampling and monitoring systems should be calibrated before use and recalibrated any time they are subject to maintenance or modification that may affect equipment calibration. Sampling and monitoring systems should* be recalibrated at least annually and routinely checked with known sources to determine that they are consistently functioning properly. Provisions for monitoring of airborne emissions during accident situations should" be considered when determining routine airborne emission monitoring program needs.

\subsubsection{Defining Point or Diffuse Sources}

The sources (DOE-controlled facilities) contributing to the total emissions from a facility (DOE-controlled site) can be considered as either "point" sources or "diffuse" sources. A point source is a single defined point (origin) of an airborne release such as a vent or stack.. A diffuse source is an area source or several sources of radioactive contaminants released into the atmosphere (generally, all sources other than point sources). 


\subsubsection{Diffuse Sources}

The category of diffuse sources covers many situations, most of which are difficult to characterize (e.g., ponds, contaminated areas, structures without ventilation or with ventilation that does not result in a welldefined release point). Attempts to define the emissions under such an array of conditions and other complex and ill-defined factors affecting the transport of the emissions (generally meteorological and topographical factors) would require complex sampling techniques, and repositioning of equipment may be necessary. Diffuse sources should ${ }^{*}$ be identified and assessed for their potential to contribute to public dose and should* be considered in designing the site effluent monitoring and environmental surveillance program. Diffuse sources that may contribute a significant fraction $(\mathrm{e}, \mathrm{g} ., 10 \%)$ of the dose to members of the public resulting from site operations should* be identified, assessed, documented, and verified annually.

\subsubsection{Diffuse Source Assessment}

If a diffuse source assessment is warranted because of potential contribution to the offsite dose, the following procedures should be applied:

1) The assessment should be accomplished by using appropriate computational model $\mathbf{s}$ and/or a downwind array of samplers arranged and operated over a sufficient period to characterize the concentrations of radionuclides in any resulting plume.

2) Empirical data and sound assumptions should be used with the computational models to define the source term for a diffuse source.

The validity of the resulting release estimates relies on the professional judgment and knowledge of the individuals involved and is usually difficult to verify. As a general rule, reliance will be placed on the site environmental surveillance program to confirm predictions.

\subsection{DESIGN CRITERIA FOR SYSTEM COMPONENTS}

Airborne emission sampling and monitoring systems should* demonstrate that quantification of airborne emissions is timely, representative, and adequately sensitive. The design of such systems begins with a characterization and documentation of the emission sources. The level of detail required should be sufficient to provide that the system is qualified for the task. A number of factors are critical to this characterization, but their importance can vary in a specific situation. The following factors are among those that should be considered:

- Identification of the actual or potential radionuclides present (e.g., type, concentration)

- Identification of fallout and naturally occurring (background) radionuclides 
- Presence of materials (chemical, biological) that could adversely affect the sampling and monitoring system or detection of radionuclides

- Internal and external conditions that could have a deleterious effect upon the quantification of emissions (e.g., environmental factors such as temperature, humidity, and ambient ionizing radiation; events that could result in a complete loss of the systems, such as fires, floods, or earthquakes; and gas-stream characteristics, such as temperature, pressure, humidity, and velocity)

- Process descriptions and variability

- Particle-size distribution of particulate materia $\mathbf{s}$

- Cross-sectional homogeneity of radionuclide distr bution at the sampling point.

Additional information on factors that influence sampl ng systems and aerosol behavior can be found in Hinds (1982) and Hidy (1984). For most DOE operations, effluents are assumed to 'be emitted to" the ambient atmosphere under two physical configurations - point and diffuse sources.

\subsubsection{Point Sources}

For point sources, documentation of the important characteristics of the exhaust handling system and other pertinent structural information, the pertinent characteristics of the process and process-emission control systems, and the sampling and measurement systems should be included in the site Environmental Monitoring Plan. Any reports or data from studies conducted to evaluate the operational performance or real or suspected deficiencies of the systems should also be provided at a single, readily accessible location (e.g., the site airborne emission monitoring files).

\subsubsection{Diffuse Sources}

The types of information to be documented in the site Environmental Monitoring Plan for diffuse sources are less readily identifiable. Diffuse sources can range from large areas of contaminated soil to ponds or uncontrolled releases from openings in a structure. The factors that have a significant influence on the air suspension of radionuclides from these situations depend on the force applied (which results in suspension of the radionuclide in air) and the factors that resist suspension (g,g, , subdivision of 1 iquid surface by shear stress (sprays) from ambient winds, over-pressure phenomena within a structure that result in the atmospheric release of radionuclides, the exchange of indoor and outdoor atmospheres at portals, and aerodynamic entrainment of contaminated soil]. A potential source should be adequately described to show the radionuclides present, the form of the materials, and the factors contributing to suspension. The rationale to substantiate the approach used to assess and characterize the source should be documented. Information on considerations in diffuse-source sampling can be found in Hesketh and Cross (1983). The most reliable source of data is likely 
to be local experience with similar installations. In addition to the discussions of input parameters in documentation supporting the EPA/CAP-88 and

AIRDOS computer codes, additional insight into the parameters necessary for estimating dose from fugitive emissions is provided by Whelan et al. (1987), Gilbert et al. 1989, and E9A-600/12-87-068.

\subsubsection{Gases and Vapors Versus Particulates}

Radionuclides in gaseous effluents can be in the form of noncondensable gases, vapors, and particulate materials. The design criteria for gases and vapors (considered to have the same flow behavior) can be less rigorous than those required for sampling particulate materials, since the inertial forces that affect the distribution of particles in a gas stream are much less important. Where criteria or requirements have not been specified in this section, guidance is provided to aid users in designing and operating air-sampling systems .

\subsection{POINT-SOURCE DESIGN CRITERIA}

\subsubsection{Gas-Stream Characterization Methods}

Accepted methods [C 3154-72, 3195-73, D 3464-75, 0.3796-79 (ASTM 1985); EPA Method 1 (Smith 1984)] should be used to measure gas-stream characteristics (e.g., velocity, static pressure, temperature, and moisture content) consistent with sampling conditions. The characteristics and conditions of gas flow can vary widely, and the frequency of the measurements needed to meet the required accuracy for flow-rate determination will be based on the stability of flow from that source (DOE facility), the impact of the gas characteristic on the sample taken, and the significance of the contribution from that source (DOE facility) to the radiological impact of the emissions from the facility (DOE site). EPA Methods 1, 2, and 4 should be used to measure and determine stack velocity, static pressure, temperature, and moisture content. EPA Method 1 determines where and how many velocity measurements must be taken. EPA Method 2 is the actual procedure used to measure and determine stack gas velocity, static pressure, and volumetric flow rate. EPA Method 4 is used to determine moisture content in stack gases.

\subsubsection{Location of Sample-Extraction Sites}

Samples of gaseous effluents should be extracted from an accessible location in the stack downstream from any obstruction, preferably near the outlet, so that concentrations of the material of concern are uniform. To the extent practicable, samples should* be extracted from the effluents from a location and in a manner that provides a representative sample, using multiport probes if necessary. If feasible, gaseous effluents should be extracted at least eight stack or duct diameters downstream and two stack or duct diameters upstream from any major flow disturbances (e.g., bends, transitions, open flames, last stream entry, sampling probes, etc.) (EPA Method 1, Smith 1984). The extraction point should be as close as practicable to the point where the emissions from that source (DOE facility) are released to the atmosphere while still complying with the criteria defined above. If possible 
while meeting the mixing length requirement, extraction sites should be located in vertical sections of the stack or duct. The absence of cyclonic flow at the extraction site should be demonstrated (EPA Method 1, Smith 1984). EPA Method 1 states that in no case will sample extraction sites be located less than two (2) stack diameters downstream and one-half (0.5) stack diameter upstream from any flow disturbance, unless approved by EPA. If uniform flow and concentration can be demonstrated at a stack or duct location during all anticipated operating conditions, a single probe with the average velocity of the effluent flow integrated over the cross section of the probe opening can be used (ANSI N13.1-1969). If uniform flow and concentration cannot be demonstrated or if incomplete mixing is suspected in large-diameter stacks or ducts (diameters greater than $30 \mathrm{~cm}$ ), the need for multiple inlet probes under continuous sampling conditions should be considered. If multiple inlet probes are used, the volume flow through each inlet should be proportional to the volume fraction of the effluent flow in the annular area sampled.

\subsubsection{Sample-Extraction Probes}

Requirements for the sampling of gases and vapor depend on the presence of particulate material. If the material of concern exists as a gas or vapor that does not interact with particulate material in the gaseous effluent, simply extracting a known fraction of the effluent flow is adequate provided the criteria for uniform flow and concentration are met. Such conditions are not the norm; many vapors (e.g., radioiodine) interact with existing particles, and all materials should be collected so that quantification of emissions is accurate.

Extraction probes and nozzles for the sampling of particulate materials should be consistent with ANSI N13.1-1969 and EPA Method 5 (Smith 1984) for particulate materials. These referenced standards/methods are also recommended as general guidance for the sampling of gases and vapors. Probes for aerosol sampling should be positioned isoaxially in the stack or duct and sized to extract at the same velocity as the effluent stream sampled (isokinetic sampling) when particle mass median diameter exceeds $0.5 \mu \mathrm{m}$. Although it is believed that isokinetic sampling conditions are not required to extract aerosols that have passed through a properly operating high-efficiency particulate filter system (because of the removal of large-diameter airborne particulate material), it is good practice to provide isokinetic sampling conditions to the extent practicable and to consider transport under moderate turbulence conditions to minimize the loss of any particulate materials present.

Probe nozzles for the sampling of aerosols should be constructed of seamless stainless-steel tubing (or, for corrosive atmospheres, other rigid, seamless tubing that will not degrade under sampling conditions) with sharp, tapered edges. The angle of taper should be $30^{\circ}$, and the taper should be on the outside edge to preserve a constant internal diameter (EPA Method 5, Smith 1984). Probes should be designed so that they can be easily removed for cleaning, repair/replacement, or deposition evaluation. Changes in flow direction should be made with bends having a curvature radius of at least five tube diameters (ANSI N13.1-1969) to accommodate the diameter of the largest particle in the sample. Probe nozzles for the sampling of only gases and vapors should be constructed of corrosion-resistant materials that do not 
react to any significant degree with the materials collected. The nozzles should be rigid to the point of collection, accumulation, or measurement. If aerosol samples are extracted from more than one location in the stack/duct, all individual nozzles should provide isokinetic sampling conditions

(ANSI N13.1-1969). Each individual nozzle should be designed to extract a proportionate volume of the sample.

\subsubsection{Samole-Transoort Lines}

Where the material(s) of concern is in particulate form, gaseous effluent samples should be transported in lines that comply with ANSI N13.1-1969. If the material(s) of concern is in the form of gas(es) or vapor(s), the samples of gaseous effluents should be transported in lines with no significant leakage or loss of material (by chemical reaction, condensation, etc.). For consistency with EPA Method 5, significant leakage is any leakage rate in excess of either $4 \%$ of the average sampling rate or $0.02 \mathrm{cfm}$, whichever is less. Lines should be kept as short as possible. Sample lines should be constructed of conducting material only. Systems that directly expose the collector or monitor to the effluent stream are preferred. Line diameter and materials of construction should be selected to minimize wall losses under anticipated sampling conditions. Aerosol transport lines should be rigid and should be electrically grounded to the point where the particles are collected/accumulated. Aerosol transport lines should not have sharp bends. Changes in direction should be made with radii of curvatures greater than five tube diameters. The transport 1 ines should be adequately supported to prevent sagging and undue stress. Transport lines should be made of materials resistant to corrosion under anticipated sampling conditions and should, as required by ambient temperature, be insulated and/or trace-heated to prevent condensation of materials under anticipated sampling conditions.

\subsubsection{Air-Moving Svstems}

Air-moving systems for gaseous effluent sampling should be constant displacement systems (e.g., rotary vane, gear) or other systems that will maintain constant air flow in anticipated sampling conditions. A central vacuum system with a vacuum pump and receiver large enough to provide simultaneous flow for all samplers may be used in situations where sampling from many locations is anticipated. Pumps and other mechanical components should be designed to operate continuously under anticipated operating conditions, with scheduled preventive maintenance and repair. Equipment used for intermittent or grab sampling should be designed to operate continuously for the duration of the sampling period(s).

\subsubsection{Air-Flow Measurements}

Sampler gas flows should be continuously measured and measurements recorded over the duration of the sampling period. The period over which measurements are integrated and the frequency of the recording should be determined by the significance of the emission being measured and the anticipated flow fluctuations. All sampling systems should, at a minimum, have a gas-flow gage that is read and recorded daily, unless it can be demonstrated that the flow rate is constant, and at the start and end of each sampling 
period. Unless extenuating circumstances dictate otherwise, the flow measurements should be accurate to $\pm 10 \%$ by calibration with standards traceable to the National Institute of Standards and Technology (NIST) (D0E/EP-0096). The most frequently used devices for these measurements are rotameters. Venturi meters, fixed orifices, vane anemometers, and Pitot tubes may be used within their limitations (ANSI N13.1-1969). Other devices, such as hot-wire anemometers, can also be applied within their limitations, but all devices should be calibrated under conditions of anticipated use with NIST-traceable or equally acceptable (in the case where an NIST standard does not exist) standards. Flow-measuring devices used for compliance determinations should be located downstream from the collector since deposition, condensation, and corrosion can result in erroneous measurements. The main objective of accurate effluent flow measurement is to allow accurate estimates of radionuclides in the effluent. Knowledge of the fraction is important for the maintenance of isokinetics. Performance standards and design criteria for the measurement and control of the bulk effluent flows (i.e., flow in the process effluent stream) should be consistent with the requirements for sampling flow measurement and control. Because the intent is to extract a known fraction of the gaseous effluent being sampled, accurate and rel iable measurement of the effluent flow is also important. Normally, automatic air-flow feedback systems that adjust sampler flow, which is induced by the monitoring-system sampling pump, by continuously measuring effluent flow to maintain isokinetic sampling conditions will not be required. The need for feedback systems should be considered for each emission stream having large fluctuations in flow (greater than a factor of two) and contributing a major fraction (e.g., greater than $10 \%$ ) of the offsite emission limit for radionuclides from the facility.

\subsubsection{Sample Collectors}

The design and capabilities of the collector will depend on the form of the radionuclides to be collected, the sampling conditions, and the analytical techniques to be used. The radionuclides in gaseous effluents can be found in all three physical forms - gases, vapors, and particulate materials. Different techniques are needed to collect and separate the physical forms or individual chemical compounds within the forms. ANSI N13.1-1969 should be followed to the extent practicable. Because the intent of sampling and measurement is to provide accurate, reliable quantification of radionuclide emissions, collectors with the most reproducible collection efficiency under anticipated sampling conditions should be used. Collector housing and hardware should be designed to minimize sample loss.

\subsubsection{Continuous Monitoring Systems}

Timeliness should be considered when quantifying radionuclides in gaseous effluents. Where the potential offsite radiological impacts are well below the standard, radionuclide sampling and collection with periodic measurement (e.g., laboratory analysis) are sufficient to quantify the radionuclides. However, where a significant potential (greater than once per year) exists for approaching or exceeding a large fraction of the emission standard (e.g., 20\%), continuous monitoring should* be required. System specifications require a careful balancing of sensitivity, energy response, response 
time, and accuracy for the radionuclide of interest [ANSI N42.18-1974

(R 1980)]. The electrical and electronic factors to be considered are covered in IEC N. 761-1. Continuous monitoring systems range from a simple ionization chamber to a system that monitors and records a spectrum of radionuclides (e.g., flow-through ionization chambers preceded by absolute filters and iodine removal systems). Compensation or adjustment should be provided for pressure, temperature, humidity, and external background. To interpret the measurements correctly, the composition of any noble gases present must be known. If significant amounts of tritium are present, tritium removal is necessary before other measurements are taken. Monitors using a stainless-steel vessel with a known volume of gas and a lithium-drifted germanium detector [Ge(Li)] or an intrinsic germanium detector or equivalent should be used (DOE/ EP-0096). Monitoring can be performed by either in-line or off-line systems. In-line systems are those in which the detector assembly is immersed in the effluent stream, usually in a well or other protection, while off-line systems pull an aliquot from the effluent stream for collection or conveyance to a detector assembly. In-line systems are less complex than off-line systems but may not provide specific radionuclide measurements directly (DOE/EP-0096). In certain types of facilities (e.g., chemical separations plants), a representative sample may require dehumidification and reheating before distribution to separate monitors for specific measurements (e.g, alpha, beta, gamma spectroscopy, radioiodines, krypton). Specifications that should be considered for airborne emission monitoring systems are as follows (other guidance may be found in DOE/EP-0096).

\subsubsection{In-line and Off-line System Specifications}

- Meet all design criteria for air sampling except those for air sample transport.

- Have calibrated curves for the detector assembly that allow conversion of instrument signals to release rates from which both the current concentrations and the total specific radionuclide emissions can be estimated.

- Have only the detectors and small electronic assemblies located in or adjacent to the effluent stream (IEC N. 761-3). A detector should not be particularly sensitive to environmental conditions or require frequent attention or adjustment.

- Use appropriate calibrations for radionuclides to be measured, including ratios to other nonmeasurable radionuclides, if present.

- Meet performance requirements within the anticipated environmental conditions (e.g., temperature, humidity, radiation levels). Systems to control the environment for the proper functioning of the monitors should be provided.

- Have adequate access for maintenance, repair, and calibration.

- Have a stable source of electrical power. 


\subsubsection{Special Housing}

Special housing may be necessary to meet these specifications. In either case, the available signal range should include the full range of operating conditions. The signal range of routine effluent monitoring systems that are also identified for use during accidents should be sufficient to monitor releases from design basis accidents. If a measuring cell or gas chamber is used to provide a known volume of gas for measurement with an immersed or adjacent detector, the following design features should be considered:

- A flow-through type vessel or chamber with or without absorbing medium or pressuri zat ion

- Specifications for cell volume and pressure

- Separation of the detector from the sample by a protective screen if practicable

- A readily removable detector mounted so that it will be returned to and maintained in its original position, and provision for an alternate position or other means of varying response by a factor of at least 10.

\subsubsection{Soecific Radionuclide Monitors}

The following criteria are guidelines to be considered for monitors that measure specific radionuclides.

Tritium Monitors. ANSI N42.18-1974 (R 1980) specifies a minimum level of detectability (MLD) for tritium of $5 \times 10^{-6} \mu \mathrm{Ci} / \mathrm{mL}$ for continuous monitors used in gaseous effluent streams. IEC N.761-5 specifies a minimum level of detectability of $2 \times 10^{-6} \mu \mathrm{Ci} / \mathrm{mL}$. The ANSI MLD is a 1974 minimum standard, and it specifies measurable concentrations at a 95\% confidence level after 4 hours of sample collection. However, the detectability level may not be obtainable with mixtures of radionuclides, and instrument response is limited by natural airborne radioactive materials (radon and thoron in equilibrium with their decay products). Additional concerns that should be considered in instrument design for tritium monitors based on the IEC standard (IEC N.7615) are as follows:

- Temperature control during sample transport to prevent condensation (much of the tritium may be in the form of airborne water vapor); and

- Trapping or retention of water by a filter or sorbent (since much tritium is commonly in the form of HTO).

Ionization Chambers. These chambers are widely used for measuring gaseous tritium (00E/EP-0096). They are simple and economical. A useful ruleof-thumb for measuring tritium in air with ionization chambers is that ionization current collected at saturation is approximately $1 \mu \mathrm{A} / \mathrm{C} \hat{i}$. Tritium measurements of about $10^{-} \mu \mathrm{Ci} / \mathrm{mL}$ are possible in low-background environments, 
which produce ions at a rate equivalent to $1 \mathrm{mrem} / \mathrm{hour}$. Shielding may be required for specific applications. If shielding is not practical, a second chamber exposed to the same gamma field without tritium is recommended. Changes in pressure and temperature in the chamber can affect the calibration, and appropriate adjustment controls for these factors should be provided. Ionization chambers are more sensitive to radioactive (noble) gases that produce larger energies per disintegration and may cause major interferences. Proportional counters are also used to measure airborne tritium (DOE/EP-0096). They are relatively insens'itiveto background radiation and have energy discrimination capabilities. Systems using proportional counters are more complicated than those required for ionization chambers. Proportional counters require a counting gas, and many gases are flammable or combustible. Radioactive material present in natural products (e.g., commercial natural gas) may provide interference for tritium measurements and should be accounted for if used. Air can be added to methane up to $30 \%$ by volume at a dewpoint of $14^{\circ} \mathrm{C}$ without truncating the counting plateau to unacceptable levels. Dry air may be required where tritium exists as water vapor. The high voltage should be stabilized by feedback from a known source for unattended operations.

Radioiodine Monitors. Iodine cartridges used to collect radioiodine may be monitored at the collection point with a shielded detector, usually a single-channel thall ium-activated sodium iodide [NaI(TI)] detector. Typical systems have one or more charcoal cartridges in a series, preceded by an absolute particulate filter. In-line measurements of low concentrations of radioiodine in air will usually not be feasible because of the presence of other radionuclides or radiation fields. Iodine cartridges must be replaced at least weekly and the measurements verified by laboratory counting (DOE/ EP-0096). Minimum levels of detectability for various iodine isotopes for continuous monitors of gaseous effluents must be established for a site, considering current state-of-the-art monitoring capabilities. The same general specifications given in the preceding discussion of tritium monitors, based on the IEC standard, should be considered for iodine monitors. Specifications for iodine monitors are as follows:

- Protection of the detector head from contamination (by the gaseous medium) by an interchangeable thin screen; easy removal of supplemental devices such as temperature sensors, heaters, etc., in the inlet for decontamination; and use of construction materials that are easily decontaminated or are contamination resistant.

- Design of collection assembly and detector to minimize the holdup of gases.

- Determination of the characteristics (e.g., collection efficiency, retention capacity, delay-time constants) for all media in the collection train (solid sorbent, absolute particulate filter) for varous radioactive gases of significance in the gaseous effluents, ncluding radon and thoron. 
- Design of systems such that replacement of sorbent and filter should* not disturb the geometry between the collector and detectors.

Noble Gas Monitors. The lower level of detectability specified for noble gas monitors for gaseous effluents listed in ANSI N42.18-1974 $\mathbf{R}$ 1980) ranges from $5 \times 10^{-6} \mu \mathrm{Ci} / \mathrm{mL}$ to $2 \times 10^{-7} \mu \mathrm{Ci} / \mathrm{mL}$. MOLs must be establ shed for a site, considering current state-of-the-art field-monitoring capabi ities. Flow-through ionization chambers or proportional counters may be used. Usable signals from noble gas monitors depend on adequate removal of other radionuclides from the sample stream.

\subsubsection{Particulate Monitors (General)}

The lower level of detectability specified in ANSI N42.18-1974 (R 1980) for radjonuclides that could exist in particulate form ranges from $4 \times 10^{-7} \mu \mathrm{Ci} / \mathrm{mL}$ for $54 \mathrm{Mn}$ to $2 \times 10^{-12} \mu \mathrm{Ci} / \mathrm{mL}$ for many of the heavy metals. Minimum detection levels must be established for a site, considering current state-of-the-art monitoring capabilities. IEC N. 761-4 addresses aerosol effluent monitors. Aerosols are defined as suspensions of fine solid or liquid particles generally in the range of $0.01 \mu \mathrm{m}$ to a few tenths of a micrometer in diameter. The standard considers gross alpha and gross beta monitors.

The following instrument characteristics described in the standard should be considered:

- The total equivalent window thickness $\left(\mathrm{mg} / \mathrm{cm}^{2}\right)$ that an ionizing particle normally emitted from the surface of the collected aerosol will cross to reach the sensitive area of the detector (includes distance covered in air plus the window thickness and that of any thin, protective screen)

- The best estimate of the surface emission rate determined from a primary or secondary standard or by reference to an instrument that has been calibrated against a primary or secondary standard

- A check source, supplied with the monitor, designed to be used in place of the filter i.n the retention device

- A protective cover over the detector that can be easily exchanged from the front of the detector or designed to facilitate decontamination of the detector head

- The general monitor concerns for sampling and exhaust piping for tritium monitors

- For alpha monitors, filters that retain the particles on the surface

- A filter holder that facilitates decontamination, considers the mechanical strength of the filter medium use and pump characteristics, and minimizes wall deposition 
- Avoidance of gross nonuniform part cle deposition

- A detector assembly that minimizes the volume of a samp e which may affect the response of the detector

- A filter holder design that minimizes in-leakage and internal leakage around the filter

- A filter holder design that permits fast and easy removal

- A useful detector area approximately equal to that of the part cle collecting surface

- A total equivalent window thickness that is less than $2 \mathrm{mg} / \mathrm{cm}^{2}$ for alpha monitors and is appropriate for the beta spectrum anticipated for beta monitors.

The following methods of discrimination against natural background radiation (radon, thoron, and their decay products) are spec fied by the standard:

- Delayed measurements after suitable decay of natural rad onuclides

- Energy spectrum analysis (primarily with alpha monitors)

- Use of other physical properties of natural radionuclides (e.g., pseudo-coincidence, particle-size selection)

- Electronic compensation.

00E/EP-0096 provides additional guidance for specific types of aerosol monitors - alpha-emitting transuranics (plutonium), uranium, and other particulates. For plutonium, the usual counting methods determine a gross alpha activity with application of an independent determination of isotopic content.

\subsubsection{Transuranic (TRU) Radionuclide Monitors}

ANSI N317-1980 covers "performance criteria for instruments used for inplant plutonium monitors." Much of the standard addresses contamination survey instrumentation and specifically does not include "personnel dosimeters, effluent monitoring systems, or instruments needed in bioassay programs." ANSI N317-1980 also does not "define those requirements which may be needed to monitor emergency conditions."

Fixed Monitoring Instruments. Section 5.2 of ANSI N317-1980 addresses fixed monitoring instruments [i.e., continuous air monitors (CAMS)], which are also used as gaseous effluent monitors. These instruments can be used for monitoring TRU emissions. The following specifications must be considered:

- The establishment of a minimum detection level, based on current state-of-the-art field-monitoring capabilities 
- An operating range of at least 100 times the minimum detectable levels

- A maximum error of $\pm 20 \%$ over the upper $80 \%$ of its operating range

- The measurement repeatability within $\pm 10 \%$ at the 95\% confidence level for the midscale or mid-decade reading

- A response time less than that required to maintain background readings within required accuracy

- Continuous operation within the specified accuracy in relative humidities of $40 \%$ to $95 \%$

- Less than 5\% change in calibration with continuous operation at ambient pressure and temperature

- Voltage and frequency variations of $\pm 15 \%$ of design values resulting in reading variations of less than $5 \%$

- Insensitivity to radio-frequency microwaves associated with powerline noise suppression

- Batteries capable of supplying power for 18 hours of normal operations, or 2 hours under alarm conditions

- A sample transport line designed to meet the requirements of ANSI N13.1-1969 through primary calibration at least once with NIST-traceable standards.

Transuranic Aerosol Effluent Monitor Design. The IEC(a) draft standard specifically addresses transuranic aerosol effluent monitors. Window thickness is defined in the same manner as for the aerosol effluent monitors. Collection efficiency is defined as the ratio of concentration represented by the collection media to the concentration in air sampled. Two types of monitors are covered - alpha spectrometers and gross-alpha monitors. The specifications in the IEC draft standard that should be considered are

- Provide check sources; design to allow the check source to be held in the retention device in place of the filter or collection medium.

- Protect the detector assembly or design for easy exchange or decontamination.

(a) International Electrochemical Commission. 1985 (Draft). "Specific Requirements for Transuranic Aerosol Effluent Monitors." In Equipment for Continuously Monitoring Radioactivity in Gaseous Effluents, Part C. 45B (Central Office) 67, International Electrotechnical Commission, Geneva, Switzerland. 
- Extract under isokinetic conditions; design sample transport 1 ines and collection device to prevent particle loss.

- Hold the sample flow rate to $-110 \%$ specified air flow with an error no greater than $\pm 10 \%$ of total air volume sampled..

- Collect by filtration or impaction; select collection medium that minimizes absorption of alpha radiation by the collection medium.

- Design the filter holder on the mechanical strength of the filter and the collection rate needed to achieve the required detection levels; filters may be circular, square, or rectangular.

- Design the monitor to minimize leaks, particularly internal leaks, allowing flow to bypass the collection medium.

- Design the monitor to allow rapid, easy removal of the collection medium without significant risk of damage to the detector.

- Design the monitor to allow complementary laboratory analysis of the collection media.

- Assess the collection efficiency of the retention device over the range of 0.01 to $10.0 \mu m$ aerodynamic equivalent diameter under normal conditions of proposed use.

- Assess detector characteristics (e.g., effective area, maximum total equivalent window thickness, protective coating, variation in detector efficiency as a function of energy).

- For alpha spectrometers, determine the full width at one-half maximum energy resolution of the detector to the alpha energy spectrum of interest under specific background radiation levels.

- Design monitors to prevent effects of noxious chemicals and water vapor.

The standard also specifies three acceptable methods of discrimination against natural background radiation:

- Alpha spectroscopy

- Reduction of interfering radon-thoron decay products by use of impaction

- Delayed measurement. 


\subsubsection{Uranium Monitors}

The continuous strip filter counters with combined alpha and beta counting ratios can be considered if uranium is the only particulate radionuclide present. Gamma spectroscopy is suggested for consideration at high concentrations. DOE/EP-0096 can provide further guidance.

\subsubsection{Particulate Fission and Activation Product Monitors}

Other radionuclides in the form of particulate materials are commonly monitored by collection on filters and counted for gross beta activity if the identities.and ratios of radionuclides are known (00E/EP-D096). Shielded beta detectors are considerably more practical than gamma detectors, and most gamma emitters also emit beta radiation. If measurements of specific, gammaemitting radionuclides are required, $N_{a} I(T)$, lithium-drifted germanium $[\mathrm{Ge}(\mathrm{L} i)]$, or intrinsic germanium detectors should be used.

\subsection{ALARM LEVELS}

To signal the need for corrective actions that may be necessary to prevent public or environmental exposures from exceeding the limits or recommendations given in DOE 5400.5, when continuous monitoring systems (as required by the criteria in Table 3-1) are required, they should* have alarms set to provide timely warnings. Gaseous effluents from DOE facilities are predominantly from point sources. Often the effluent is treated to control the emissions of radionuclides to near-background levels of naturally occurring airborne radionuclides. However, the cumulative effect of many low-level releases may result in impact near the criteria for continuous emission monitoring. Emission sampling is only part of the overall protection system at DOE facilities. Environmental sampling and monitoring provide an additional level of measurement so that any such releases are detected.

\subsection{QUALITY ASSURANCE}

As they apply to the monitoring of airborne emissions, the general quality assurance program provisions discussed in Chapter 10 should* be followed. Specific quality assurance requirements for the facility's airborne emission monitoring program are to be contained in the Quality Assurance Plan associated with the facility. 


\subsection{METEOROLOGICAL MONITORING}

Environmental protection activities, including the assessment of impacts of planned and unplanned airborne releases on public health and safety and the demonstration of compliance with applicable Federal, State, and local laws, regulations, and Orders, require meteorglpgical information representative of conditions at DOE facilities (sources). (a) This information is needed to assess the transport, diffusion, and deposition of materials released to the atmosphere by a DOE facility. It is also important in the design of environmental monitoring networks.

Each DOE site (facility) (a) should* establish a meteorological monitoring program that is appropriate to the activities at the site, the topographical characteristics of the site, and the distance to critical receptors. The scope of the program should* be based on an evaluation of the regulatory requirements, meteorological data needed for impact assessments, environmental surveillance activities, and emergency response. For each site, the factors considered should include the following: the magnitude of potential source terms, possible pathways to the atmosphere, distances from release points to critical receptors, and proximity of the site to other DOE facilities. The site's meteorological program should* be documented in a meteorological monitoring section of the Environmental Monitoring Plan (DOE 5400.1).

The type of meteorological information required by DOE facilities is not explicitly stated in laws, regulations, or DOE Orders. However, there is implicit recognition in regulations and directives of the type of information required. Meteorological considerations, which characterize atmospheric dispersion conditions, are an integral part of the dose assessment capabilities for both planned and unplanned releases. For example, 40 CFR Part 61.93, "National Emission Standards for Hazardous Air Pollutants; Standards for Radionuclides," states in part:

Compliance with this standard will be determined by calculating the dose to members of the public at the point of maximum annual air concentration in an unrestricted area where any member of the public resides or abides.

In general, DOE sites will be required to have onsite measurements of wind direction, wind speed, and atmospheric stability available to evaluate atmospheric dispersion in the vicinity of facilities and to perform the required dose calculations specified in $40 \mathrm{CFR}$ Part 61. Large, multifacility sites and those sites where one monitoring site location is inadequate to represent atmospheric conditions for transport and diffusion computations are required to establish monitoring programs that include additional meteorological measurements and measurements at more than one location to adequately evaluate transoort and diffusion of effluents. This section Drovides guidance in selection and operation of meteorological instrumentation to obtain the required information.

(a) DOE usage of the terms "site" and "facility" is considered equivalent to $40 \mathrm{CFR}$ Part 61 usage of the terms "facility" and "source." 
Some sites may choose to establish a meteorological program that makes use of meteorological measurements obtained from offsite sources such as the National Weather Service. For data from an offsite source to be acceptable, the data should* be representative of conditions at the DOE facility and provide statistically valid data consistent with onsite monitoring requirements. A determination of the acceptability of offsite data should be made by a qual ifi ed meteorol ogist.

Specific meteorological information requirements for each facility should* be based on the magnitude of potential source terms, the nature of potential releases from the facility, possible pathways to the atmosphere, distances from release points to critical receptors, and the proximity of other DOE facilities. Dose assessment includes estimation of the transport, diffusion, and deposition of material released to the atmosphere. Methods that are appropriate for estimating transport and diffusion at a facility depend on the type, size, and location of the facility.

Meteorological information requirements for facilities should* be sufficient to support environmental monitoring and surveillance programs. For example, meteorological information is required in the selection of locations for monitoring stations if monitoring is to take place at the projected points of maximum impact of a facility. The EPA (EPA-450/278-027R) provides useful guidance for the selection or prediction of the point or points of maximum impact.

The meteorological monitoring program requirements that need to be incorporated into the radiological effluent monitoring and environmental surveillance programs at a DOE site are presented in the summary.

\subsection{METEOROLOGICAL PROGRAM BASIS}

The principal use of meteorological data at DOE sites is to characterize atmospheric dispersion conditions. Such characterization is necessary to assess

- potential consequences of radiological releases from projected new or modified facilities

- consequences of actual routine radiological releases from existing facilities to demonstrate compliance with applicable regulations and standards

- consequences of actual accidental radiological releases.

\subsubsection{Calculations for Dose Assessment.}

Atmospheric dispersion calculations used for dose assessment vary in sophistication and complexity from relatively simple computations to extensive computations that require the use of computers. Similarly, the meteorological data required for the calculations range from essentially none, for 
some of the simple techniques, to extensive data sets for some of the computer-intensive techniques. Use of the AIRDOS-EPA model currently referred to as CAP-88 or an EPA-approved alternative (40 CFR Part 61.93) is required to demonstrate compliance with 40 CFR Part 61. The meteorological input to the AIRDOS-EPA model includes the joint-frequency distribution of wind direction and atmospheric stability, and an average wind speed for each combination of wind direction and stability. The model also requires an average mixing1 ayer depth and an average temperature.

\subsubsection{Calculated Atmospheric Transport and Diffusion}

The meteorological monitoring program for each DOE site should* provide the data for use in atmospheric transport and diffusion computations that are appropriate for the site and application. Before any model is deemed appropriate for a specific application, the assumptions upon which the model is based should* be evaluated and the evaluation results documented. For example, assumptions that are reasonable in models used to demonstrate compliance with annual average concentration standards might not be reasonable in models used for emergency-response appl ications.

Use of simple compliance assessment techniques (NCRP Commentary 3), which are based'on conservative assumptions and use 1 ittle or no meteorological data, could be sufficient for some DOE sites. Meteorological programs for sites where onsite meteorological measurements are not required should* include a description of climatology in the vicinity of the site and should* provide ready access to representative meteorological data. Data from offsite sources, such as the National Weather Service, the Federal Aviation Administration, or military installations, can be used in these situations if the meteorological instruments are well-maintained and the data are readily available and representative of conditions at the site.

\subsubsection{Use of Realistic Models}

As the maximum magnitude of potential releases from a facility increases, the use of more realistic models is necessary to assess the consequences of the releases or demonstrate compliance with laws, regulations, and Orders. Potential release modes, distances from release points to receptors, and meteorological conditions should* be considered in assessments for DOE facilities required to take onsite measurements. Computational techniques based on straight-1 ine Gaussian models [e.g., AIRDOS-EPA (EPA 520/1-79-009)] are appropriate for facilities that are located in simple topographic settings. Straight-line Gaussian models are described in detail in many reports, including two in Meteorologv and Atomic Eneruv - 1968 (Gifford 1968; Slade 1968), three in Atmospheric Science and Power Production (Barr and Clements 1984; Randerson 1984a,b), and one in GENII (Napier et al. 1988) As a minimum, these models require specification of wind direction, wind speed, and atmospheric stability. They may require the specification of mixing-layer thickness. If the models estimate deposition, they could require information on precipitation, and if the models compute plume rise for stack releases, the ambient air temperature could be required. Where appropriate, onsite measurements (e.g., tracer gas studies) could be used to help model atmospheric transport and diffusion and could also aid in model selection. 
Straight-line Gaussian models are not appropriate for facilities that are located in valleys, near coasts or mountains, and on large sites. In these settings, strictly applied straight-line Gaussian models could underestimate the consequences of a release, as well as incorrectly identify locations where significant consequences occur. Trajectory models provide more realistic assessments in these settings. If AIRDOS-EPA or another EPA-approved straight-line model is used to demonstrate compliance with 40 CFR Part 61.93 for a facility located in complex terrain, an additional dose assessment should be made using a procedure that realistically accounts for temporal and spatial variations in atmospheric conditions and release rates.

Trajectory model S (NUREG/CR-0523; EPA-600/8-84-207; EPA-600/8-86-024; NUREG/CR-3344; NUREG/CR-4000) treat atmospheric transport and diffusion as separate processes. This additional complexity is necessary to consider spatial and temporal variations of the atmosphere. These model s generally require the same types of meteorological data as the straight-line models. However, to make full use of their capabilities to characterize spatial variations, use of meteorological data from more than one location is necessary. In addition, input to trajectory models is generally a series of hourly meteorological observations that include wind direction and speed, stability, temperature, and mixing-1ayer depth, rather than sets of frequency distributions.

\subsection{DIFFUSION COEFFICIENTS}

Gaussian straight-1ine and trajectory models make use of diffusion coefficients (commonly referred to as $\sigma y$ and $\sigma_{z}$ ) to describe the spread of plumes. These coefficients are generally estimated on the basis of an atmospheric stability class and the distance the material has traveled since its release. The turbulence that causes diffusion is related to atmospheric stability; stability classes are used to permit climatological summarization of data. Gifford (1976) discusses various methods for determining diffusion coefficients .

\subsubsection{Stabilitv Estimation}

Routine meteorological measurements by the National Weather Service and other organizations typically do not include the direct measurement of atmospheric stability or the determination of stability classes. Instead, a method of estimating stability classes based on wind speed and cloud cover (Gifford 1961; Pasquill 1961; Turner 1964; PHS Publication 999-AP-26) can be used to estimate stability classes from routine National Weather Service meteorologi-!l observations. The meteorological data required include cloud cover, s ling height, and wind speed.

\subsubsection{Methods of Determining Stabilitv Class}

Common methods of determining stability class from onsite meteorological measurements include the use of vertical temperature gradient, standard deviation of the wind direction $(\sigma \theta)$, and the standard deviation of the elevation angle of the wind $(\sigma \phi)$. The methods using the temperature gradient and $\sigma \Theta$ are described in the American National Standards Institute's ANSI/ANS-2.5-1984 and 
NRC Regulatory Guide 1.23. Irwin (1980) discusses the $\sigma \theta$ and $\sigma \phi$ methods and presents a method that uses both $\sigma \ominus$ and wind speed. This method is described in the EPA air quality modeling guidelines (EPA-450/2-78-027R).

\subsubsection{EPA-Preferred Methods}

The method of estimating stability classes described by PHS Publication 999-AP-26, used with onsite data, is preferred by the EPA (EPA-450/2-78-027R) for air quality modeling. If the data required by this method are not available, the EPA order of preference is 1) the $\sigma \phi$ method using onsite data; 2) the $\sigma \theta$ wind-speed method using onsite data; and 3) the Turner method using onsite wind speed, and cloud cover and ceiling height from a nearby, representative National Weather Service site. The temperature gradient method of determining stability class has been held by ANSI and the NRC to be acceptable for estimating both the horizontal and vertical diffusion coefficients, while the $\sigma \Theta$ method has been held to be acceptable only for estimating the horizontal diffusion coefficient.

\subsubsection{Atmospheric Turbulence Measurements}

Numerous studies (NUREG/CR-0798; Lague et al. 1980; Lalas et al. 1979; Luna and Church 1972; Mitchell 1982; Sedefian and Bennett 1980; Skaggs and Robinson 1976; Weil 1979) have compared methods of determining stability classes. When hourly data are examined, the results of the various methods are not highly correlated. Consequently, the use of stability classes should be avoided when assessing the effects of short duration releases that take place at a known time. Diffusion coefficients for this application can be estimated directly from atmospheric turbulence measurements (Hanna et al. 1977; Irwin 1983; Pasquill 1979; Ramsdell et al. 1982). Turbulence data for estimating the horizontal diffusion coefficient can be obtained from the same sensors used for wind direction and speed measurements with additional signal processing. Obtaining turbulence data for estimating vertical diffusion coefficients generally requires special but readily available sensors.

\subsection{PLUME RISE AND BUILDING WAKES}

Evaluation of the consequences of releases through free-standing stacks may include consideration of the effective plume rise due to momentum and buoyancy. Generally accepted methods for estimating plume rise are described by Briggs (1984), although EPA models estimate plume rise using earlier methods developed by Briggs and others (EPA-450/2-78-027R). Estimation of plume rise requires air temperature and wind speed at release height, vertical temperature gradient, and an estimate of the mixing-layer thickness. It also requires information on the stack dimensions, stack flow, and effluent temperature. Basic straight-line and trajectory plume models assume (except in computation of plume rise) that material is released from a point source. When it is necessary to evaluate the consequences of a release on receptors near the release point, the basic models should be modified to account for deviations from this assumption. Diffusion in the vicinity of buildings and other obstacles may result in the need for model modification to account for wake effects. Wake effects are discussed by Hosker (1984) and EPA-450/4-86/005a. 
For ground-level releases, the standard modifications increase the diffusion coefficients on the basis of dimensions of the structure. For elevated releases, the modifications adjust the height of release based on the ratio between the initial vertical velocity of the effluent and the wind speed at release height.

\subsection{METEOROLOGICAL MEASUREMENTS}

Meteorological measurements should* be made in locations that, to the extent practicable, provide data representative of the atmospheric conditions into which material will be released and transported. A meteorologist or other atmospheric scientist with experience in atmospheric dispersion and meteorological instrumentation should be consulted in determining whether onsite data are required and, if so, in selecting measurement locations and in the design and installation of the meteorological measurement system. Factors to be considered in selecting measurement locations and installation of the instruments include the prevailing wind direction, topography, and obstructions. Also, any special meteorological monitoring requirements imposed by other agencies (outside the DOE) should be taken into consideration when designing meteorological measurement systems and establishing measurement locations. The instruments used in the monitoring program should* be capable of continuous operation in the expected range of atmospheric conditions at the facility. The frequency of thunderstorms, icing, or other chemical or physical agents that may cause damage or deteriorate performance should be considered in selecting specific sensors and designing the sensor installation. An uninterruptable power supply should be included in the system, and an alternate source of power should be available.

\subsubsection{Location of Meteorological Measurements}

Wind measurements should* be made at a sufficient number of heights to adequately characterize the wind at potential release heights. In general, wind measurements should be made at a height of $10 \mathrm{~m}$. If a vertical temperature difference is used to characterize atmospheric stability, the temperature difference should be determined over an interval of sufficient thickness to allow adequate determination of accepted stability classes. A 50-m thickness has been held acceptable (ANSI/ANS-2.5-1984; NRC Regulatory Guide 1.23) for this purpose. For surface releases, ANSI (ANSI/ANS-2.5-1984) and the NRC

(Regulatory Guide 1.23) recommend a measurement of the temperature difference between 10 and $60 \mathrm{~m}$. If releases are to be made through stacks that are taller than $60 \mathrm{~m}$, ANSI and the NRC suggest that the temperature difference between the release height and the 10-m height be determined. Other necessary meteorological measurements should be made using standard instrumentation in accordance with accepted procedures. Standard meteorological measurement techniques are described by Mason and Moses (1984), and accepted procedures are outlined in ANSI/ANS-2,5-1984.

\subsubsection{Instrument Mounting}

Wind and temperature instruments mounted on towers may be placed on top of the towers or on booms extending to the side of the towers. Instruments 
mounted above a tower should be mounted on a mast extending at least one tower diameter above the tower. If instruments are mounted on booms extending to the side of a tower, the booms should* be oriented in directions that minimize the potential effects of the tower on the measurements. Instruments mounted on booms should* be at least two tower diameters from the tower, but should be positioned three to four tower diameters from the tower. The orientation of booms for wind instruments should be determined after considering the frequencies of all wind directions. Orientation of the booms on the basis of only the prevailing direction might not minimize tower effects. In some locations, placement of wind instruments on opposite sides of the tower could be necessary to obtain reliable wind data for all wind directions. Temperature sensors should be placed in aspirated radiation shields, and the shields should be oriented to minimize effects of direct and reflected solar radiation.

\subsubsection{Measurement Recording Systems}

The onsite meteorological measurement system should include two separate data-recording systems, and at least one of the systems should be digitally controlled. The other recording system may be digital or analog. In addition, the output of the instruments should be displayed in a location where instrument performance can be monitored on a regular basis. Digitally recorded data, except for $\sigma \Theta$ and precipitation, should be averaged over at least 30 samples taken at intervals not to exceed 60 secpnds. The time period represented by the averages should not be less than 15 mi'nutes. A minimum of

180 instantaneous wind direction samples are required for estimation of $\sigma \theta$ and $\boldsymbol{\sigma} \phi$. If strip charts are used as one of the recording systems, continuoustrace strip charts should be used for wind data; multipoint strip-chart recorders may be used for the remaining data. If properly located, the strip charts may be used for the data displays.

\subsection{MEASUREMENT SYSTEM ACCURACY}

The accuracies of the monitoring measurements should be consistent with the specifications set forth in either ANSI/ANS-2.5-1984, the version of ANSI/ ANS-2.5 that is current when the monitoring system is designed, or guidance provided by the EPA if EPA guidance recommends more stringent specifications. System accuracy standards for digitally recorded data and instrument specifications contained in ANSI/ANS-2.5-1984 include the following:

Wind direction $\pm 5^{\circ}$ in azimuth with a starting threshold of $0.45 \mathrm{~m} / \mathrm{sec}$ (1 mph). If the sensor is to be used to determine $\sigma \theta$, the damping ratio must be between 0.4 and 0.6 , and the delay distance must not exceed $2 \mathrm{~m}$.

Wind speed $\pm 0.22 \mathrm{~m} / \mathrm{sec}(0.5 \mathrm{mph})$ for speeds less than $2.2 \mathrm{~m} / \mathrm{sec}$ (5 mph); within $10 \%$ for speeds of $2.2 \mathrm{~m} / \mathrm{sec}$ or greater, starting speed of less than $0.45 \mathrm{~m} / \mathrm{sec}$.

Temperature $\pm 0.5^{\circ} \mathrm{C}$.

Temperature difference $\pm 0.15^{\circ} \mathrm{C} / 50 \mathrm{~m}$. 
Precipitation

Time $\pm 0.25 \mathrm{~mm}$ (0.01 in.) resolution, and within $10 \%$ for totals greater than $5 \mathrm{~mm}$ (0.2 in.).

$\pm 5 \min$.

For analog data-recording systems, the allowable error imits for wind direction and speed are increased by 50\%, and the acceptable error in time is increased to 10 minutes.

\subsection{INSPECTION, MAINTENANCE, AND CALIBRATION}

The meteorological monitoring program should* provide for routine inspection of the data and scheduled maintenance and calibration of the meteorological instrumentation and data-acquisition system at a minimum, based on the calibration frequency recommendations of the manufacturers. Inspections, maintenance, and calibrations should* be conducted in accordance with written procedures, and logs of the inspections, maintenance, and calibrations should* be kept and maintained as permanent records. All systems should be calibrated semiannually, unless system performance indicates that more frequent calibra. tions are necessary. The instrument system should* provide data recovery of at least $90 \%$ on an annual basis for wind direction, wind speed, those parameters necessary to classify atmospheric stability, and other meteorological elements required for dose assessment. Data recovery rates for other meteorological elements should be $90 \%$ on an annual basis.

\subsection{SUPPLEMENTARY INSTRUMENTATION}

The topographic setting of a facility and the distances from the facility to points of public access should* be considered when evaluating the need for supplementary instrumentation. If meteorological measurements at a single location cannot adequately represent atmospheric conditions for transport and diffusion computations, supplementary measurements should* be made. Full meteorological instrumentation is not required at a supplementary location. Supplementary instruments need measure only those elements that have significant spatial variation.

\subsection{LARGE-S ITE (MULT IFACILITY INSTALLATION) METEOROLOGICAL PROGRAMS}

Many DOE facilities are located on large multifacility sites (e.g., Savannah River Laboratory, Oak Ridge National Laboratory, Idaho National Engineering Laboratory, and Hanford Site). These sites cover many square miles. As a result, spatial variations in meteorological conditions must be considered in evaluating transport and diffusion between the facilities and points of public access. A site-wide meteorological monitoring program should* be established at each multifacility site to provide a comprehensive data base that can be used for all facilities located within the site. It is not necessary to establish a meteorological program for each individual facility. 
Consequence assessments can be made for individual facilities using facilityspecific source term and release characteristics and a common data base for the transport and diffusion analysis.

\subsection{DATA SUMMARIZATION AND ARCHIVING}

Data used in dose assessments should be collected as 15-minute averages for use in emergency response applications. The 15-minute averages can be combined into hourly averages for use in consequence assessments. The 15-minute data should remain readily available in a temporary archive for at least 24 hours. Then either the 15-minute or hourly averages should be stored for entry into a permanent archive and climatological summarization. These data should be examined and entered into the permanent archive at least monthly. Storage of the 15-minute or hourly data is necessary to develop an adequate data base for use with new assessment tools as they are developed. More frequent examination of the hourly data to detect problems in meteorological instrumentation or in the data acquisition system is recommended. Further guidance in meteorological data collection, processing, and archiving is presented by Crutcher (1984) and in various EPA documents (e.g., EPA-450/ 2-78-027R; Finkelstein et al. 1983).

\subsection{METEOROLOGICAL DATA PROCESSING}

Designing environmental surveillance programs, establishing compliance with regulations, and analyzing the consequences of potential or actual releases require information on a common set of meteorological el ements. Typically these elements are wind direction, wind speed, air temperature and temperature gradient, and mixing-layer thickness. Although the individual applications could require data for a common set of meteorological elements, the format in which the data are required will vary by application and assessment procedure.

\subsubsection{Routine Releases}

Assessment of potential consequences of routine radiological releases from projected new or modified facilities should be based on climatological data because the meteorological conditions at the time of release are unknown. If the postulated release is continuous, the analyses should be made using a joint frequency distribution of wind direction, wind speed, and atmospheric stability based on data from at least one annual cycle. When possible, the frequency distributions should be based on 5 or more years of data. This approach could also be used for intermittent releases if the releases occur randomly and with sufficient frequency to make the use of an annual-frequency distribution appropriate.

Assessments of the consequences of routine releases from existing facilities and demonstrations of compliance can also be made using climatological summaries, provided that a straight-line model is appropriate. Climatological summaries used in the evaluation of consequences of an actual release should be based on hourly data for the specific period of the release. For example, 
if a continuous release occurs from May 15 through June 26, the jointfrequency distribution should be based on the meteorological observations during that period. Where straight-line models are inappropriate, consequence assessments for routine releases and demonstrations of compliance should be made using a time series of hourly averaged data. These time series should include all supplementary data required to account for spatial as well as temporal variations in atmospheric conditions.

\subsubsection{Accidental Releases (Off-Normal, Unusual Occurrence, or Emergency)}

Consequence analyses for postulated accidental releases should be made for each downwind direction using conservative meteorological assumptions for each release scenario. For a ground-level release, these assumptions should include a low wind speed and stable atmospheric conditions; for elevated releases, a range of conditions should be evaluated because a moderate wind speed and neutral atmospheric conditions may be more conservative than a low wind speed and stable conditions. Straight-1ine Gaussian models could be appropriate for assessment of some postulated releases. Trajectory model s could also be used if adequate data are available. The joint-frequency distribution and choices of meteorological conditions for the accident analyses should be based on a minimum of 2 years of hourly averaged data. However, if offsite data are used, the analyses may be based on 2 or more years of hourly observations made with well-maintained instrumentation.

Consequence assessments during the course of an emergency should be based on time series of actual and forecast atmospheric conditions. When necessary, data should be included in the time series to represent spatial variations in the atmospheric conditions. An averaging interval of 15 minutes has been accepted by the NRC as appropriate for data used in emergency response applications. This interval is consistent with the averaging interval specification in ANSI/ANS-2,5-1984. Instantaneous observations are too variable to be used with confidence, and hourly averaged values do not reflect changes in conditions in a timely manner for emergency response applications.

\subsubsection{Data Needs}

Assessment procedures have varying meteorological data needs and a precise format in which the meteorological data must be entered. The data needs and format for AIRDOS-EPA are set forth in EPA 520/1-79-009. Data needs for other EPA models are set forth in the individual documentation of the specific models and are summarized in EPA-450/2-78-027R. In addition to EPA models, there are DOE, NRC, and proprietary models that might be appropriate for consequence assessments. Data requirements for these models must be determined from model documentation.

\subsection{QUALITY ASSURANCE}

As they apply to meteorological monitoring, the general quality assurance program provisions described in Chapter 10 should* be followed. Specific quality assurance activity requirements for the facility's meteorological monitoring program, sufficient to provide acceptable data recovery and accuracy, 
are to be contained in the Quality Assurance Plan associated with the facility. Guidance in quality assurance related to meteorological measurements and meteorological data processing may be found in Finkelstein et al. (1983). 


\subsection{ENVIRONMENTAL SURVEILLANCE}

An evaluation should* be conducted and used as the basis for establishing $n$ environmental surveillance program for all DOE-controlled sites. The purpose of the surveillance program is to characterize radiological conditions of the offsite environs and, if appropriate, estimate public doses related to these conditions, confirm predictions of public dose based on effluent monitoring data, and, where appropriate, to provide compliance data for all applicable environmental regulations. The extent of each environmental surveillance program is to be determined by the responsible DOE field organization, based on the applicable regulations, the hazard potential of the effluents, the quantities and concentrations of effluents, the specific public interest, and the nature of potential or actual impacts on air, land, biota, and water. The results of this evaluation should* be documented in the site Environmental Monitoring Plan (as required by DOE 5400.1) to show

- Environmental measurement and sampling locations used for determining ambient environmental levels resulting from facility operations

- Procedures and equipment needed to perform the measurement and sampling

- Frequency and analyses required for each measurement and sampling location

- Minimum detection level and accuracy

- Quality assurance components

- Investigation and alarm levels.

The environmental surveillance program for DOE-controlled sites should* be conducted in accordance with the requirements of DOE 5400.1 and DOE 5400.5. As appropriate, component systems may be grouped and standard procedures referenced.

\subsection{SUMMARY OF GENERAL CRITERIA AND SURVEILLANCE REOUIREMENTS}

The criteria for environmental surveillance programs (listed in Table 5-1) should* be used for establishing the environmental surveillance program for DOE-controlled sites. Any additional site-specific criteria should* be documented in the site Environmental Monitoring Plan. The criteria in Table 5-1 are based in part on the projected effective dose equivalent (by exposure mode) in a year to members of the public (in mrem) or to the population (in person-rem). In addition to meeting the minimal requirements, environmental monitoring and surveillance may be necessary for other reasons, including legal, public relations, and State/local commitments. 
TABLE.5-1. Minimum Criteria for Determining Need for

Environmental Surveillance

Topic

Routine Surveillance

of All Pathways

(Ingestion, Inhala-

tion, and Immersion

and Submersion Doses)

Periodic Confirmation

Pathway Measurements

Use of Control Data

Unpl anned Releases
Criteria

When feasible, all environmental media that, as determined by site-specific radiation exposure pathway analysis, might lead to a measurable annual dose of site origin at the site boundary should* be routinely sampled and analyzed (for the critical radionuclides to dose) and routine measurements of penetrating radiation should" be performed at those sites that, as determined by site-specific exposure pathway analysis, might result in an annual dose of site origin at the site boundary, if the total exceeds

a) 5 mrem effective dose equivalent; or

b) 100 person-rem collective effective dose equivalent within a radius of $80 \mathrm{~km}$ of a central point in the site.

Environmental surveillance measurements may be performed periodically, but should* be performed at least every five years, to confirm the low dose levels, if the projected annual effective dose equivalent of site origin is $\leq 0.1 \mathrm{mrem}$. The frequency and magnitude of environmental surveillance should be proportional to the potential annual dose. Where potential annual dose represents a significant fraction of the reference dose for routine surveillance, environmental sampling should be more frequent. At $20 \%$ of the reference dose [e.g., 1 mrem (EDE) from emissions during a year], annual surveillance for confirmation should be considered.

Actual measurements on two media for each critical radionuclide/pathway combination, one of which might be the effluent stream, should* be performed as part of the site routine effluent monitoring and environmental surveillance program.

Use of data should* be based on statistically significant differences between the point of measurement and background (or control) data.

Provisions should* be made, as appropriate, for the detection and quantification of unplanned releases of radionuclides to the environment. 


\subsubsection{Evaluation of Need}

The need for environmental sampling and analysis should* be evaluated, by exposure pathway analysis, for each site radionuclide effluent or emission (liquid or airborne). This analysis with appropriate data, references, and site-specific assumptions, along with site-specific criteria for selection of samples, measurements, instrumentation, equipment, and sampling or measurement locations should* be documented in the site Environmental Monitoring Plan. Planning for environmental surveillance programs should be based on expected releases, considering all operating controls on liquid effluents and airborne emissions. If actual releases are significantly greater than expected, or if unplanned or accidental releases occur, environmental surveillance needs should be re-evaluated based on the actual releases. A critical pathway analysis (radionuclide/media) should* be performed, documented, and referenced in the Annual Site Environmental Report. If the projected dose equivalent from inhalation of particulates exceeds the criteria of Table 5-1, particle-size analysis of the emission should* be conducted at least annually. In addition, the lung solubility class that is assumed for the particulates in question should be justified and it should be resubstantiated on an annual basis if it is likely to vary with changing facility operations. If environmental surveillance data are to be used with (or in place of) effluent monitoring and modeling to support the assessment and demonstration of compliance with such regulations as $40 \mathrm{CFR}$ Part 61 , the special requirements of those regulations must be considered in the planning and implementation of the surveillance system (see Table 3-1).

\subsubsection{Emergency Monitoring Provisions}

Although emergency monitoring is beyond the scope of this guide, provisions for environmental monitoring during an emergency situation should be considered when determining routine program needs. Emergency environmental monitoring systems and procedures are specified in the emergency response $\mathrm{pl}$ an in effect for the facility/site. Further provisions should* be made, as appropriate, for the detection and quantification of unplanned releases of radionuclides to the environment, including radionuclides that may be transported by stormwater runoff, flooding, or resuspension of ground-deposited material.

\subsection{PERFORMANCE REOUIREMENTS FOR ENVIRONMENTAL SURVEILIANCE PROGRAMS}

For all new or modified facilities coming on-line, a preoperational assessment should* be made and documented in the site Environmental Monitoring Plan to determine the types and quantities of effluents to be expected from the facility and to establish the associated environmental surveillance program. Calibration of dosimeters and exposure-rate instruments should* be gfsed on tryceability to NIST standards. The most commonly used sources are 60 Co and ${ }^{3} \mathrm{Cs}$. Where significant variations in effluent releases are observed or expected, environmental sampling or measurements should be either continuous or at an interval less than one-half the expected peak-to-peak interval. Gross radioactivity analyses should* be used only as trend indicators, unless documented supporting analyses provide a reliable relationship 
to specific radionuclide concentrations or doses. The overall accuracy ( $\pm \%$ accuracy) should* be estimated, and the approximate Environmental Detection Limit at a specified \% confidence level for environmental measurements for beta-gammas, alphas, and neutrons should* be determined and the two levels documented in the site Environmental Monitoring Plan. Sample preservation methods should* be consistent with the analytical procedures used. All environmental surveillance techniques should* be designed to take a representative sample or measurement of the important radiation exposure pathway media.

\subsubsection{Specific Performance Reauirements}

Sampling or measurement frequencies for each significant radionuclide or environmental medium combination (e.g., those that contribute $10 \%$ or more to offsite dose greater than 0.1 mrem EDE from emissions in a year) should* take into account the half-life of the radionuclides to be measured and should* be documented in the site Environmental Monitoring Plan. A good rule to follow when considering short-half-life radionuclides is that the sampling and measurement intervals should not exceed twice the half-life of the radionuclide. "Background" or "control" location measurements should* be made for every significant radionuclide and pathway combination (e.g., those that contribute 10\% or more to offsite dose greater than 0.1 mrem EDE from emissions in a year) for which environmental measurements are used in the dose calculations. An annual review of the radionuclide composition of effluents or emissions should* be made and compared with those used to establish the site Environmental Monitoring Plan. Any deviations from routine environmental surveillance requirements, including sampling or measurement station placement, should* be documented in an approved revised site Environmental Monitoring Plan.

\subsubsection{Air Sampling Systems}

The air sampling rate should* not vary by more than $\pm 20 \%$ and total air flow or total running time should* be indicated; air sampling systems should* be leak-tested, flow-calibrated, and tested and inspected on a routine basis at a minimum, using the calibration frequency recommendations of the equipment manufacturers.

\subsubsection{Consultation with Game Officials}

State and local game officials should* be consulted when selecting appropriate protected species to sample.

\subsubsection{Consultation with State and Reqional EPA Offices}

DOE Operations offices and contractor staff should* ensure that groundwater monitoring plans are consistent with State and regional EPA groundwater monitoring requirements under RCRA and CERCLA, to avoid unnecessary duplication. DOE Operations Offices and contractor staff should* consult with State and regional EPA personnel as needed to ensure that the requirements are incorporated into the Radiological Monitoring Plan. 


\subsection{DESIGN CRITERIA}

It is important that overall objectives for environmental monitoring programs be established and documented. It is also important that the environmental surveillance program be reviewed periodically and modified as program needs change. The general design criteria for establishing an environmental surveillance program for radioactive materials released in the effluents or emissions from DOE-controlled facilities are discussed in the following subparagraphs.

\subsubsection{Environmental Surveillance Program Objectives}

As required by DOE 5400.1 and DOE 5400.5, the environmental programs conducted at all DOE sites must determine

1) Compliance with al1 applicable environmental qual ity standards and public exposure limits; the requirements of DOE 5400.1 and DOE 5400.5; and environmental commitments made in Environmental Impact Statements, Environmental Assessments, or other official DOE documents

2) The background levels and site contributions of radioactive materials in the environment

3) The effectiveness of effluent treatment and controls in reducing effluents and emissions

4) The validity and effectiveness of models to predict the concentration of pollutants in the environment

5) The long-term buildup and prediction of environmental trends from site-released radioactive material

6) The detection and quantification of unplanned releases.

In addition to determining the need for an environmental surveillance program based on the objectives noted above, certain subsidiary objectives should also be considered, For example, site history and current public interests might indicate the need for an environmental surveillance program that examines specific aspects of a site's environmental impact, even when no other need is indicated. The following is a partial list of subsidiary objectives, as provided in ICRP Publication 43, that should be considered when establishing environmental surveillance program objectives:

- The environmental surveillance program should provide information to the public.

- The program should be capable of distinguishing site radiation contributions from other local sources (natural or manufactured).

- The program should be capable of obtaining data that may be required to assess the consequences of an accident. 
- The program should be capable of identifying changes in relative importance of transfer parameters.

\subsubsection{Proqram Planning and Design}

Factors that affect the relative level of environmental surveillance, and to some extent the points at which measurements are to be made, include 1) the potential hazard of the materials released, considering both expected quantities (including unplanned releases) and relative radiotoxicities; 2) the extent to which facility operations are routine and unchanging; 3 ) the need for supplementing and complementing effluent monitoring; 4) the size and distribution of the exposed population; 5) the cost effectiveness of modifications to the environmental surveillance program; and 6 ) the availability of measurement techniques that provide sufficiently sensitive comparisons with the applicable standard and "background" measurements.

The environmental surveillance media sampled or radiation measurements made should represent, as much as possible, the actual exposure vectors to people. Selection of locations, frequency, media and radionuclides to be measured, and measurement techniques are the basis of an environmental surveillance program. This program must also include any special monitoring requirements, such as trend indicators and additional samples/measurements required for quality assurance. The effort devoted to the environmental surveillance program should reflect the significance of the radiation doses projected.

Once the critical pathways and nuclides are identified (i.e., a critical pathway analysis procedure is carried out), an annual review comparing reported effluent releases with those considered in the original analysis should be conducted and changes in the environmental surveillance program noted in a revised Environmental Monitoring Plan and discussed in the Annual Site Environmental Report.

The effluents and the environment into which they are dispersed are dynamic, exhibiting both spatial and temporal variations of nearly all constituents. The importance of each individual radionuclide depends on its physical and chemical form, which determines its movement in the environment and eventual uptake, deposition, and retention by humans, and on the differential metabolism of the radionuclide by humans.

Table 4 of Section 7 of the Health Physics Society Committee Report, Uparading Environmental Radiation Data (Watson 1980), provides guidance on the minimum number of sampling/measurement locations for environmental surveillance programs. Providing site-specific tables of the minimum number of environmental sampling/measurement locations per site as a function of calculated annual effective dose equivalent to the maximally exposed offsite individual or critical population group is recommended. The values chosen following a site-specific environmental assessment should be documented in the Environmental Monitoring Plan. Any changes in the site-specific or generic factors should* be noted in the Plan and the retired or replaced values preserved for historical purposes. 


\subsection{BASIS FOR EXTERNAL EXPOSURE MONITORING}

DOE 5400.1 and DOE $\mathbf{5 4 0 0 . 5}$ require that each DOE-controlled site perform an environmental surveillance program to provide compliance with all applicable environmental regulations. The extent of each environmental surveillance program is to be determined by the DOE field organization, based on applicable regulations, hazard potential, and quantities and concentrations of materials released (or expected to be released for those facilities not yet in operation). A primary objective is to assess the actual or potential radiation dose to persons in the site environs.

\subsubsection{External Exoosure}

One of the "critical pathways" of exposure for population groups 1 iving within the vicinity of DOE nuclear facilities is exposure to external radiation from those sites (Denham 1979). Exposure of population groups to external radiation from nuclear facility operations includes cloud passage of airborne effluents; previously released and deposited radionuclides on soil, vegetation, or sediments; radiation-generating facilities, especially highenergy accelerators or industrial x-ray equipment, and large isotopic radiation sources; and the storage or movement of large sources of radioactive waste.

\subsubsection{External Exposure in Water}

External exposures from radionuclides in water are generally insignificant. However, unique situations could arise where recreational, commercial, or industrial use of a receiving body of water might cause exposure to certain individuals. Appropriate environmental measurements should be included in the routine program to better define an unusual "source" if the sitespecific pathway analysis shows this to be a significant (greater than 10\% of the total offsite dose) source of exposure.

\subsubsection{Limitinq External Exposures}

For most facilities, the whole-body (or gonads) exposure is limited, and penetrating radiation measurements are satisfactory. Exceptions could include the atmospheric release of beta emitters such as uranium decay products or $85_{\mathrm{Kr}}$ from fuel manufacturing or reprocessing facilities, respectively. For DOE sites, the gamma (and, where applicable, neutron) exposure (or exposure rate) should be measured or calculated; any significant skin dose from airborne beta emitters should be calculated from effluent data (see Chapter 8) . If external beta doses from deposition are considered to be significant, they should be estimated from effluent data, from beta-sensitive dosimeters, or by soil sampling and laboratory analysis.

\subsection{EXTERNAL RADIATION MEASUREMENT LOCATIONS AND FREOUENCY}

Considerable judgment must be used in locating environmental radiation measurement stations. Before final placement of any environmental radiation measurement station (background or control and indicator locations), an 
initial on-the-spot survey should be performed and documented to determine the absence of possible naturally occurring anomalies that could affect interpretation of later measurements. The recommended technique for making these presurveys is to use a low-level radiation survey instrument (e.g., micro-R meter) followed up with a pressurized ion chamber (PIC) measurement at those geographic locations selected on the basis of the preliminary screening by portable instrument survey. If desired, an in situ gamma-ray spectrometer [NaI, IGe, or $\mathrm{Ge}(\mathrm{Li})$ ] can be used to determine which terrestrial nuclides are contributing to the observed exposure rate. Examples of dosimeter placement locations to be avoided, if at all possible, include the following:

- Locations of unique or different geology (i.e., reflecting changes in the terrestrial background)

- Locations where the altitude differs significantly [e.g., altitudinal differences between "background" or control locations and those indicator locations to be used around a given DOE site should not exceed $150 \mathrm{~m}$ (reflecting changes in the cosmic-ray background)]

- Locations where the proximity of structures could alter the measurement results (reflecting changes from shielding or radiation enhancement effects from building materials)

- Valleys or hollows (where puddling of precipitation or runoff could accumulate, or where local topography could shield the dosimeters from the possible passage of airborne effluents).

\subsubsection{Factors in Selection}

Selection of the indicator locations should be based on expected sources of external radiation -- noble gas plumes, soil-deposited atmospheric particulates released from the site, onsite radiation-generating facilities or large radiation sources, or potential routes of waste transport from the site -- and the local population distribution and prevailing wind directions. The technique described by Waite $(1973 a, b)$ for placement of air samplers, based on average meteorological conditions and existing population distributions, should be considered for determining external radiation measurement locations.

\subsubsection{Location of Backqround Measurement Stations}

Background or control measurement stations should be located a minimum distance of 15 to $20 \mathrm{~km}$ from the larger sites and 10 to $15 \mathrm{~km}$ from the smaller sites in the least prevalent wind direction. Control stations should also be placed in areas typical of local geology, away from buildings (which can shield the detectors), and at similar elevations to those for indicator stations. The emphasis here is on the placement of dosimeter stations such that the difference between background/control or preoperational data and the data from those stations expected to be affected by site effluents/activities can be assessed accurately. 


\subsubsection{Offsite Locations}

Offsite radiation measurement locations should be used for each DOE site with predicted external. radiation doses exceeding the criteria in Table 5-1. These offsite measurement locations include a background or control location, site perimeter or boundary locations, and locations in nearby communities (within a $15-\mathrm{km}$ radius of the site). The site perimeter or boundary locations should include locations directly upwind from the maximum predicted ground-level concentration from atmospheric releases averaged over a period of 1 year. Offsite measurement locations should coincide with locations where maximum predicted levels occur and where any member of the public resides or abides. For those sites larger than a few kilometers in radius, the maximum predicted concentrations may actually be onsite. In this case, onsite radiation measurements should also be made to include the location of predicted maximum air concentration(s), as well as other locations needed to help interpret the offsite results.

\subsubsection{Shoreline Locations}

If exposure measurements are to be made at shoreline locations, dosimeters should also be placed to correspond to key water sampling locations (including the site boundary), as well as locations important for recreational, commercial, or industrial use. However, changes in water elevation caused by tides or fluctuating releases from dams may make this impractical, in which case intermittent exposure-rate measurements must be used during the seasons in which recreational use of the shoreline (for hunting, fishing, sunbathing) actually occurs.

\subsubsection{Heiaht and Freauencv of Measurements}

The recommended height for external radiation measurement is $1 \mathrm{~m}$ (a) above the surface. If another height is used, the relationship to the $1-\mathrm{m}$ height should be established and documented for the site. The frequency should be based on predicted exposure rates from site operations at the measurement locations. Integrating devices (e.g., dosimeters) should be exposed long enough (typically 1 calendar quarter) to produce a readily detectable dose (e.g., $10 \mathrm{x}$ the minimum sensitivity of the dosimeter; for TLDs this would represent an exposure on the order of 5 to $10 \mathrm{mR}$ ). If intermittent external radiation measurements are made, their frequency should be timed to coincide with batch atmospheric releases or the intermittent use of large sources or the operation of radiation-generating facilities.

(a) Approximately the height of the gonads in adults standing or walking. 


\subsection{DIRECT RADIATION MEASUREMENT}

\subsubsection{Continuous Exposure Monitoring}

Continuous environmental gamma-ray monitoring is available (Jackson et al. 1985; Urabe and Katsurayama 1984) and highly desirable, yet it cannot always be justified on the basis of initial system cost or long-term maintenance. However, in situ gamma spectrometry should be used as a method of documenting environmental mixtures of radionuclides resulting from natural and manufactured sources (e.g., for dosimeter placement). Historical monitoring information should be considered as well. The deployment of at least one continuously recording exposure-rate instrument is recommended, preferably near the site boundary in the expected direction of a potential plume. Effluent monitors should provide detection and approximate magnitude of sudden changes in ambient radiation levels. An array of continuously recording exposurerate instruments should be considered if there is'a potential for release of large inventories of gamma emitters.

\subsubsection{Neutron Monitoring}

For some sites, especially in the vicinity of high-energy facilities, neutron monitoring may also be required. When neutron monitoring is required, the method of measurement should* be based on the anticipated flux and energy spectrum. A fixed monitor (moderated $8 F_{3}$ counter or rem counter) is recommended, yet site-specific conditions may warrant the use of intermittent portable instrument surveys only during the infrequent periods of machine operation. As with all external radiation measurements, neutron monitoring (or surveys) should be performed at the site boundary or location of nearest occupancy in the direction of maximum expected exposure rates, especially from beam dumps or accelerator targets.

\subsubsection{Instruments and Methods}

Instruments that have application to DOE environmental surveillance programs include Geiger-Muller (GM) and gamma scintillation systems, PICs, TLDs, and moderated $\mathrm{BF}_{3}$ counters or rem counters. The method of measurement should depend on the anticipated type of radiation (beta, gamma, or neutron).

Several materials have been identified as suitable for use in environmental TLDs, including LiF, $\mathrm{CaF}_{2}$, and $\mathrm{CaSO}_{4}$ (Gesell 1982). Several reports are available describing the various TLDs commonly used for environmental surveillance (Fix and Miller 1978; HASL-252; dePlanque and Gesell 1982; Gesell 1982; Hall and LaRocca 1966; Hendee 1967; Hoy 1971; Mejdahl 1970). ANSI-N545-1975 and NRC Regulatory Guide 4.13 should be used for performance testing, procedural specifications, and correction techniques for TLDs. Annealing, calibration, readout, storage, and exposure periods used should be consistent with the ANSI standard recommendations.

Where integrating dosimeters are used, three or more dosimeters should be provided at each location (in the same package, if possible). Integrating dosimeters should be read without undue delay. It is critical that readings are made at a consistent time following collection. 
DOE sites are encouraged to participate in international intercomparison studies, such as the ones reported by dePlanque et al. (1976) and Gesell et al. (1982).

Only if adequate precautions are taken to avoid recording a significant exposure in transit can integrating dosimeters be sent to a distant location for processing.

\subsection{AIR}

The categories of airborne radionuclides that should be considered for measurement in air sampling systems include particulates, gases (principally the noble gases), halogens (principally radioiodines), and tritium. These categories are important to consider for environmental sampling and measurement because they account for virtually all of the radioactive materials released from DOE nuclear sites. For example, in 1983 tritium, noble gases, and fission/activation products accounted for $33 \%, 42 \%$, and $25 \%$, respectively, of the total radionuclides released to the atmosphere from DOE sites (Hawley and Washburn 1985). The basis for performing environmental air sampling and the requirements associated with air sampling methods, criteria, locations, and frequencies are presented below.

\subsubsection{Basis for Sampling}

Because air is a primary exposure pathway 'to humans from radionucl ides released to the atmosphere, environmental air sampling should be conducted to evaluate potential doses to environmental populations from inhaled or ingested radionuclides or from external radiation. The inhalation of airborne radionuclides, coming either directly from the source (facility) or from resuspension following deposition, may result in their absorption from the lung or GI tract. Absorption through the skin may contribute to human exposure.

Radioactive materials in particulate form can result in radiation exposures to individuals both by direct inhalation and by deposition on soil and vegetation. Although particle sizes range across a broad spectrum, with diameters ranging from about 0.01 to $10 \mu \mathrm{m}$, the optimum size for deposition in the upper respiratory tract (and subsequently the deep lung) tends to be in the range of 0.01 to $3 \mu \mathrm{m}$, with $1 \mu \mathrm{m}$ often used for dose assessment. However, particle filters used for sampling will function over the entire size spectrum, collecting particulates in the "respirable" range, as well as those that are not. The collection efficiency of filters used to collect particulate materials should be considered when calculating the concentration of radionuclides in the air that was sampled. If releases of particulate materials could contribute significantly to environmental doses, measurements of particle size should be made. When inhalation of particulates may be significant, lung solubility class assumptions should be substantiated.

\footnotetext{
It ${ }_{13}$ s offen more feasible to determine the impact of short-lived gases (e.g. ${ }^{13} \mathrm{~N}, 4 \mathrm{I}_{\mathrm{Ar}}$ ) by measuring the direct exposure (i.e., external radiation) resulting from them rather than by sampling and analysis. Gamma spectroscopy
} 
of grab samples (e.g., filling a previously evacuated Marinelli sampler) can be used to quantify the concentrations of short-lived gases, which can then be correlated with the observed increase in exposure rates. For longer-1ived noble gases (e.g., ${ }^{85} \mathrm{Kr}$ and $\left.1{ }^{13} \mathrm{X}\right)^{\prime}$,' the suggested technique is the collection of an air sample by compression or cryogenic techniques, separation and purification of krypton and xenon by adsorption on chromatographic columns, and analysis by liquid scintillation counting (Grossman and Holloway 1985; Trevathan and Price 1985).

\subsubsection{Radioiodine}

Atmospheric releases of radioiodine can expose the thyroid and whole body via several pathways, including ingestion of milk and other foodstuffs, as well as inhalation and air submersion. The inhalation pathway is normally assessed by air sampling, while the external radiation component is assessed along with other external radiation sources by dosimeters. In certain instances, a special sampler might be necessary to identify iodine species (elemental, organic, and HOI). Species identification allows differentiation of those forms of iodine that are prone to deposition on vegetation and soil (elemental) from those that are not (organic forms and HOI). All chemical forms can be readily inhaled and contribute to thyroid exposure; however, it is primarily the elemental form that enters the foodchain. The manner in which radiolodine concentrations are distributed among the various chemical forms is key input information for accurate environmental dose estimates.

\subsection{3 $\underline{\text { Tritium }}$}

Environmental tritium can be found in two forms: tritiated molecular hydrogen gas and tritiated water vapor (or tritiated oxide vapor). In terms of exposure potential, tritiated water vapor yields a dose equivalent approximately 25,000 times that of tritium gas for the same concentration (ISO 1975). Thus, air sampling techniques should employ methods that collect moisture from the air. When tritiated water vapor is released to the environment, several inhalation, ingestion, and skin absorption pathways are possible. According to a model developed by Anspaugh et al. (1973), approximately $35 \%$ of the dose to individuals results from inhalation; the remaining $65 \%$ is due to vegetable (36\%), milk (13\%), and meat (16\%) consumption. These perce tages will vary from one site to another because of such factors as climate and land use. For facilities that release tritium to the atmosphere, air samp ing is an important medium, but clearly not the only one.

\subsubsection{Samoling Locations}

Air sampling locations should be selected to represent radionuclide concentrations breathed by the population surrounding the nuclear facility. Selection of background sampling and measurement locations for air must be made with special care. For measurements to be compared with the effects of airborne releases, a minimum distance of 15 to $20 \mathrm{~km}$ from the larger sites and 10 to $15 \mathrm{~km}$ from the smaller sites in the least prevalent wind direction is suggested for background sampling. 
Offsite air samplers should be employed at each DOE site having potential airborne releases that could result in an annual effective dose equivalent greater than 1 mem to the maximally exposed individual. Sample locations should include the following: a background or control location; locations of maximum predicted ground-level concentration from stack (or vent) releases, averaged over a period of 1 year where members of the public reside or abide; and locations in the nearest community within a $15-\mathrm{km}$ radius of the site. For those sites larger than a few kilometers in radius, the maximum predicted concentrations may actually be onsite. In this case, onsite sampling may include the locations of predicted maximum concentration(s) and any other locations needed to help interpret the offsite sample results.

The exact number of samplers will be determined by meteorology, demography, and the magnitude of projected doses to the surrounding population. If the maximally exposed individual could receive an effective dose equivalent of more than 5 mrem, additional air samples should be collected in those communities within a $15-\mathrm{km}$ radius of the site boundary for which the projected dose equivalents exceed the criteria in Table 5-1, and at a control (background) location (10 to $20 \mathrm{~km}$ from the site in the least prevalent wind direction).

Unless documented site-specific evidence exists to justify otherwise, the sample(s) at each air sampling station should be collected at a height of $2 \mathrm{~m}$ above ground level (approximately the height of inhalation for adults), in a location free from unusual localized effects or other conditions (e.g., in proximity to a large building, vehicular traffic, or trees) that could result in artificially high or low concentrations. Locations should be selected to avoid areas where large-particle (nonrespirable) fugitive dusts can dominate the sample (Ludwig 1976).

A method similar to that developed (Waite 1973b) and evaluated by Waite (1973a) should be used to determine the number of air sampling stations and their placement. Waite's method entails examining demographic and meteorologic data for the site to determine the distance to local population centers, their population, and the wind frequency distribution and weighting factors that are scaled to equal the desired number of sampling locations. The application of this method to sites in coastal or agricultural areas requires only minor modification of the procedure illustrated (i.e., sites in coastal zones would adjust the number of radial divisions to the number required to cover the surrounding inhabited land mass). For agricultural areas, an equivalent population index is derived by multiplying the number of people who are direct recipients of produce, dairy products, etc., from the area by the biological discrimination factor for the critical radionuclide in the exposure pathway i nvol ved.

\subsubsection{Sampl inq Frequency}

In general, the frequency of collection for air samples is adjusted to take into account the limitations of the sample collectors, the capabilities of the air movers, and the physical problem of retrieving samples from each location on a fixed frequency, typically 1 to 2 weeks. However, the operational status of relevant facilities should also be considered. Unless otherwise justified, the maximum air particulate filter exchange frequency should 
be biweekly. Experience has shown that sampling rates of 30 to $120 \mathrm{~L}$ per minute can be used with moderate power requirements.

The common practice, especially for the longer-lived radionuclides, has been to composite filters for subsequent analysis from several locations and/ or successive time periods, taking advantage of the larger volume of air sampled to achieve the desired sensitivity. Use of compositing techniques assumes that the concentration of a given radionuclide at the locations or for the time composited is sufficiently constant for the end use of the data. For dose calculation purposes, the annual average concentration for a location or for a group of locations can still be compared against an annual average for a background location as an indication of potential facility impact during the year in question. Since the applicable standards are annual standards, comparison of annual averages to the standards is appropriate. Also, averages for successive years can be compared for detection of general trends. Requirements for sample collection and analysis, including the use of compositing, are shown in Table 5-2 as a function of effective dose equivalent to the maximally exposed individual.

For air sampling of nonparticulate material, the available tradeoff between sensitivity and frequency of sample removal is governed primarily by the fact that "breakthrough" can occur with the charcoal cartridges, silica gel, and molecular sieves used for radioiodine, noble gas, and tritium collection, respectively. These breakthrough phenomena can be based on flow rate, total volume, activity, or a combination of these. The sample exchange frequency for nonparticulate sampling should be determined on a site-specific basis and should* be documented in the enyironmental surveillance files. For facilities with a significant release of ${ }^{129}$ I, measurements can be made on an annual basis at site-perimeter and control stations to characterize the local site environs. It is also recommended that the relationship between 129 I and natural iodine ( 127 I) be determined However, it may be assumed that because of the extremely long half-life of 129 I, its accumulation (if any) in the environment will be better observed in milk than in air.

\subsubsection{Sampling Methods and Criteria}

Filtration is by far the most popular air-sampling method (Lee 1974) and the method generally required for air-particulate collection at DOE sites. Correct use of the International Commission on Radiological Protection (ICRP) lung model, as described by the Task Group on Lung Dynamics (ICRP Task Group 1986), requires a knowledge of the chemical state and the particle size distribution. The need for particle size measurements is especially important at those sites where resuspension of previously deposited material is or can be a significant factor in environmental air concentrations. Such particle size measurements will also be useful in distinguishing resuspended material from that of current emissions. Several methods, including the impactors (e.g., multistage cascade impactor) and electrostatic precipitators referred to above, can be used to classify particle size (ISO 1975). Particulate filters can be made of any fibrous material, and a variety of filter media (e,g., cellulose, glass fiber, membrane, polystyrene) are commercially available. № single filter type is best for all purposes, but the specific filter to be 
TABLE 5-2. Minimum Air Sample Collections and Analyses to Be Performed as a Function of Estimated Effective Dose Equivalent (EDE) to the Maximally Exposed Individual, as Determined from Effluent Releases

\begin{tabular}{|c|c|c|c|c|}
\hline & & & ole Col lection/Ana lys is Cr & \\
\hline & Sample/Analys is Tyoe & EDE $<1$ mrem ${ }^{(a)}$ & 1 mrem $<$ EDE $<5$ mrem $(a)$ & EDE $>5$ mrem ${ }^{(a)}$ \\
\hline & $\begin{array}{l}\text { Air particulate: } \\
\text { - Total beta } \\
\text { - Total alpha } \\
\text { - Gamma spectroscopy } \\
\text { - Other(c) }\end{array}$ & $\begin{array}{l}\text { yes, as indicators } \\
\text { yes, as indicators } \\
\text { yes. annual composite } \\
\text { no }\end{array}$ & $\begin{array}{l}\text { yes }(\mathrm{b}) \text {, as indicators } \\
\text { yes }(\mathrm{b}) \text {, as indicators } \\
\text { yes, quarterly composite } \\
\text { yes, quarterly or annual } \\
\text { composite }\end{array}$ & $\begin{array}{l}\text { yes }(\text { b) } \\
\text { yes }{ }^{(b)} \text {. as indicators } \\
\text { yes, monthly composite } \\
\text { yes, quarterly composite }\end{array}$ \\
\hline & $\begin{array}{l}- \text { Alpha spectro- } \\
\text { scopy }\end{array}$ & no & no & yes \\
\hline & $\begin{array}{l}\text { - Particle size } \\
\text { determinations }\end{array}$ & no & yes & $\begin{array}{l}\text { yes, one indicator sample } \\
\text { per quarter }\end{array}$ \\
\hline & $\begin{array}{l}\text { Noble gases: } \\
\text { - Direct radiation } \\
\text { measurement }\end{array}$ & no (e) & ${ }_{n o}(e)$ & yes \\
\hline Tـ & - Sample collection & no & no & $\begin{array}{l}\text { yes. one indicator sample } \\
\text { per quarter }\end{array}$ \\
\hline & $\begin{array}{c}\text { Halogens (radioiodine): } \\
\text { - Charcoal (XI- } \\
\text { impregnated) or } \\
\text { silver zeolite }\end{array}$ & no & yes & 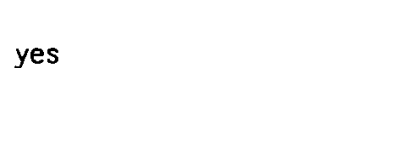 \\
\hline & $\begin{array}{c}- \text { Species differen- } \\
\text { tiation } \\
\left(\mathrm{I}_{2}+\mathrm{CH}_{3} \mathrm{I}+\mathrm{HOI}\right)\end{array}$ & no & no & $\begin{array}{l}\text { yes, one indicator sample } \\
\text { per quarter }\end{array}$ \\
\hline & Tritium & no & yes & yes \\
\hline & $\begin{array}{l}\text { (a) Implemented when } \\
\text { (b) Assess relationsh } \\
\text { (c) Some examples inc } \\
\text { separated prior tc } \\
\text { contribution to dc } \\
\text { (d) Only if actinides } \\
\text { (e) Routine environmer } \\
\text { not realistically }\end{array}$ & $\begin{array}{l}\text { EDE is estimated to ha } \\
\text { to } 5 \text { pecifje radionuc } \\
\text { e }{ }^{\mathrm{g}} \mathrm{Sr},{ }^{238} \mathrm{Pu}, 239 \mathrm{Pu}, \mathrm{U}- \\
\text { ounting; the nuclides ch } \\
\text { her than }{ }^{239} \mathrm{Pu} \text { contribut } \\
\text { l monitoring for increme } \\
\text { hievable, and levels }<5\end{array}$ & $\begin{array}{l}\text { been received during the } \\
\text { oncentrations or use radio } \\
\text { tural, or other radionucli } \\
\text { en must be based on site-s } \\
\text { significantly to the dose } \\
\text { al exposures of }<\mathrm{mrem} / \mathrm{yr} \\
\text { em/yr are questionable. }\end{array}$ & $\begin{array}{l}\text { ceding } 12 \text { mo. } \\
\text { mical analysis. } \\
\text { that must be chemically } \\
\text { ific effluent data and } \\
\text { ivalent as shown. } \\
\text { direct radiation are }\end{array}$ \\
\hline
\end{tabular}


used should be selected to meet site-specific requirements, such as high collection efficiency, particle size selectivity, retention of alpha emitters on the filter surface, or ease of radiochemical analysis. Any filter media used should retain a minimum of $99 \%$ of dioctylphthalate (DOP) particles with an aerodynamic mean diameter of $0.3 \mu \mathrm{m}$ at the air face velocity and pressure drop expected in use (American Conference of Governmental Industrial Hygienists 1974).

Airborne radioiodines should be collected with charcoal or silver zeolite cartridges in series behind the particulate filter, and analyzed by gamma spectrometry, the method suggested by the Intersociety Committee (1972). Compound filter canisters of several designs (for an example, see Keller et al. 1970) have been used to distinguish the several chemical forms of radioiodine that may be present in the atmosphere. Generally these canisters will contain a particulate filter and silver wire or mesh plus charcoal, each of which is analyzed separately. This type of collection device should be used if the levels of radioiodine or the cause of the release warrant.

Routine environmental surveillance for short-lived noble gases (e.g., ${ }^{41} \mathrm{Ar}$ ) should be performed by external radiation measurements. Laboratory analysis of periodic grab samples of ambient air (Denham et al 1974) should be performed for the longer-1 ived radionuclides, principally $85 \mathrm{Kr}$, when the critical pathway analysis indicates the potential dose exceegs the criteria given in Table 5-2. Suggested methods for radioactive gas $\left({ }^{8} \mathrm{Kr}\right)$ sampling, either grab or continuous, can be found in the Proceedings of the Noble Gases Symposium (Stanley and Moghissi 1974) and in more recent reports by Grossman and Holloway (1985) and Trevathan and Price (1985). Atmospheric stability and wind speed and direction during the period in which the samples were collected should be recorded to aid in interpreting and using the data for dose calculations.

Several methods are available for collection of atmospheric tritium, such as bubblers, molecular sieves, and silica gel (Denham et al. 1974). The Intersociety Committee (1972) method recommends the use of silica gel as a desiccant to remove moisture $\left(\mathrm{H}_{2} \mathrm{O}\right.$, HTO) from air, followed by re-evolution, collection as a liquid, and liquid scintillation counting. This procedure calls for a 30-cm-long by 3-cm-diameter cylinder filled with silica gel $(180 \mathrm{~g})$. Air is pumped at a flow rate of 100 to $150 \mathrm{~cm}^{3} /$ minute through the silica gel column, which collects essentially all of the moisture; the distillate is collected and counted using standard liquid scintillation techniques. Tritium gas (HT) is totally excluded by this procedure. Methods for differentiating and measuring separate concentrations of HT and HTO in air (MLM-2015; Griffin et al. 1972; Ostlund 1970) should be used when the critical pathway analysis indicates the need for differentiation. Where only intermittent sampling of HTO for short times (less than 30 minutes) is essential at a given site, the method of Osborne (1974) can be used. In this approach, HTO is removed from the air by bubbling moist air through a gas-washing bottle. Measurement of the specific activity of tritium in atmospheric moisture, using a passive device such as a container of silica gel suspended in air to collect tritiated water vapor, is considered satisfactory as a detection device only. 


\section{$\underline{\text { Precautions }}$}

A number of precautions should be taken when using the referenced methods and equipment for air sampling in the environment. Some of these relate to general air sampling and some relate specifically to the sampling of particulates, radioiodines, noble gases, or tritium:

1) Sufficient material needs to be obtained for analysis of samples in a time frame set to meet reporting and data-retrieval requirements. The requirements of sufficient volume of air and number of samples should be evaluated and the need for compositing samples considered (DOE/EP-0023).

2) Excessive material (sample or dust) collected on filters can invalidate the sample in several ways; the flow rate through the filter may be unknown, the pump may fail, the particulate material may penetrate the filter, the analysis for alpha emitters may be affected, or material on the surface may be lost when the flow is interrupted (DOE/EP-0023).

3) Excessive sampling velocity can invalidate the sample if too much sample is collected during a specific time period.

4) Collection efficiency of an air filter is affected by flow rate; too low an air sampling velocity can produce a reduced collection efficiency for specific filters (Keller et al. 1970).

5) Ambient levels of radon and thoron and their decay products can affect the analysis of a number of filter samples. These naturally occurring radon and thoron decay products are found on air particulate filters because they adhere to particulate matter and are thus efficiently trapped by the air sampling filter. Therefore, any masurement system for other alpha and/or beta emitters (e.g., ${ }^{\mathrm{SP}}, 239 \mathrm{Pu}$ must be able to discriminate against the typically much larger "background." Rather than resorting to spectroscopic or chemical separation techniques, the most common method of discrimination is to retain the filter from 1 to 7 days (American Conference of Governmental Industrial Hygienists 1974) after collection and before counting, to allow for decay of the short-lived radon and thoron decay products.

6) Too high a sampling rate reduces both the collection efficiency and retention time of charcoal filters, especially for the nonelemental forms of iodine (Bellamy 1974; Keller et al. 1970). The retention of iodine in charcoal is dependent not only on charcoal volume, but also on the depth of the charcoal bed.

7) The monitoring of airborne radioiodines is complicated by the occurrence of several species, including particulate iodine (bound to inert particles), elemental iodine vapor, and gaseous (usually organic) compounds. The monitoring program should take into 
account the probable occurrence of the different iodine forms, because their subsequent history in the environment will differ. While it may not be necessary to differentiate routinely between the various species, care should be taken so that no significant error results by neglecting one or more of them (DOE/EP-0023).

8) Charcoal cartridges (canisters) for the collection of radioiodine in air are subject to channeling, as with any packing of loose materials. Baffled-flow cartridge design, packing to a minimum required weight, and pretesting of randomly selected cartridges for pressure drop before operation in the field will minimize the problem. An alternative is to mount several cartridges in a series to prevent loss of iodine; each cartridge must be counted in this case (DOE/EP-0023).

9) For the short-1 ived radioiodines (mass numbers 132, 133, 135), environmental sampling is complicated by the need to obtain a sufficient volume for analysis while at the same time retrieving the sample soon enough to minimize decay (with half-lives ranging from 2 to 31 hours). Short-period grab sampling with charcoal cartridges is possible, with direct counting of the charcoal as soon as possible for gamma emissions, but radon and thoron will affect detection levels (00E/EP-0023).

10) Because of the extremely long half-1 ife and normally low environmental concentrations, ${ }^{129}$ I determinations are usually performed by neutron activation analysis after chemical isolation of the iodine.

The following operational criteria relate to environmental sampling instrumentation and methods:

- The linear flow rate across particulate filters and charcoal cartridges should be maintained between 20 and $50 \mathrm{~m} / \mathrm{minute}$ (DOE/ EP-0023) .

- The air sampling system should be protected as much as possible from the elements (i .e., weather, tampering, and theft).

- Air sampling devices, such as "quick-disconnect'' filter holders, should be designed so that the potential for loss of sample during the collection process is minimized.

- If impregnated, activated carbon is used as the adsorbent for radioiodine, the adsorber system should be designed for an average atmospheric residence time of $0.05 \mathrm{sec} / \mathrm{cm}(0.25$ second $/ 2$ in.) of adsorbent bed (NRC Regulatory Guide 1.52) .

- NRC Regulatory Guide 6.25 contains guidance relative to determining errors associated with the total volume of air sampled. 


\subsection{BASIS FOR SAMPLING TERRESTRIAL FOODSTUFFS}

If the preliminary analysis of public dose indicates that the annual effective dose equivalent from ingestion of terrestrial foods is 5 mrem or greater, then sufficient sampling and analysis should be carried out so that the foods and radionuclides contributing at least 90\% of this ingestion dose have been evaluated. If the annual effective dose equivalent is between 1 and 5 mrem, sufficient sampling and analysis should be carried out to provide reasonable assurance that the doses are within this range. When the annual effective dose equivalent is between 1 and $0.1 \mathrm{mrem}$, then sufficient surveillance should be done to show that the radionuclides are behaving in the environment as expected. The principal pathways by which foods become contaminated are deposition from airborne materials and crop irrigation from surface or ground waters. The relative contributions of various pathways, foods, and radionuclides to the total dose depends on several factors, including

- Agricultural uses of the land

- Farming and gardening practices

- Soil type

- Climate (e.g., temperature, rainfall, growing season)

- Dietary habits

- Quantities of specific radionuclides released to air and water and their chemical and physical forms.

\subsubsection{Possibility of Lona-Term Buildup}

Even in those instances where the annual effective dose equivalent from ingestion of terrestrial foods is less than $1 \mathrm{mrem}$, periodic sampling and analysis of indicator materials, such as soil or vegetation should be performed to determine if there is measurable long-term buildup of radionuclides in the terrestrial environment. Such long-term buildup could affect the relative contributions of certain radionuclides and foods to the total radiation dose of site origin. However, the availability of these radionuclides to plants grown in such soil may decrease with time as a result of several natural processes. These processes include changes in chemical or physical form of the radionuclides caused by weathering or the action of soil bacteria, fixation onto soil materials or the litter layer, migration below the root zone of the plant with irrigation water or rainfall, and removal of contaminated soil by wind or water erosion or by cultivation. Unless terrestrial foods or indicator organisms are being analyzed routinely, the pathway evaluation should be repeated annually to reaffirm the original evaluation. Foods to be considered in the pathway analysis, listed in approximate descending order of importance, are milk, vegetables, meat, eggs, grain, and fruit. If wild game, such as deer or game birds, are available locally, then these should also be considered in the pathway analysis. 


\subsubsection{Agricultural Products}

Representative samples of the pathway-significant agricultural products grown within $16 \mathrm{~km}$ of the site should be collected and analyzed for radionuclides potentially present from site operations. These samples should be collected in at least two locations: the place of expected maximum radionuclide concentrations, and a "background" location unlikely to be affected by radionuclides released from the site. Fresh produce, meat, poultry, and eggs can be purchased from local farmers or from commercial outlets if the origin can be identified. Under certain circumstances, sites and facilities have need to sample beyond $16 \mathrm{~km}$ to investigate and evaluate the effect of site-specific characteristics or peculiar meteorological conditions. Where warranted, and based on site-specific considerations, DOE will require individual sites for facilities to conduct sampling beyond $16 \mathrm{~km}$.

\subsubsection{1 $\underline{\text { Milk }}$}

Cow milk, and in certain localities goat milk, is widely consumed by all age groups. Therefore, milk is frequently one of the most important foods contributing to the radiation dose to people if dairy animals are pastured near a nuclear site. If dairy herds or "family" cows (or goats) are present in the vicinity of the site (within $16 \mathrm{~km}$ ), representative milk samples should be taken and analyzed for radionuclides potentially present from site operations. The frequency of sampling will depend on the magnitude of the radiation doses potentially receivgd viathis squrce ${ }_{137}$ Radionuclides of gotential

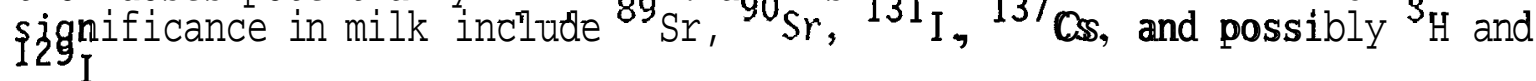

The number of locations to be sampled depends on the number and distribution of the dairy herds or family cows in the vicinity $(16 \mathrm{~km})$ of the site ( $i . e .$, one sample at highest annually averaged air concentration and in each area where estimated doses exceed the criteria in Table 5-1) but a minimum of one background and one potentially affected location should be sampled at least annually. For 131 I analyses, sampling should be at least biweekly during the local grazing season. The frequency should be increased if the $131 \mathrm{I}$ ${ }^{129} \mathrm{I}$, and ${ }^{3} \mathrm{Cs}$, quarterly composite samples are usual ly adequate.

Milk samples should be as representative of the location of interest as possible. Commercially available processed milk, while representative of consumption by the general public, may include milk produced in areas remote from the site. Information about the dates and distribution patterns of local milk production is essential if the analytical results are to be meaningful. Raw milk should be sampled for evaluation of potential radiation doses to individuals consuming milk produced by a family cow.

No particular sampling techniques are required, other than to guard against cross-contamination and souring or curdling of the milk. However, specific requests should be made to the milk producer so that techniques are in accordance with the protocol accepted by the appropriate State agriculture department. For the levels of contamination expected at most DOE sites, a 4-L sample is necessary to achieve the required detection level. However, for 
goat's milk, a 1-L sample may be all that can be obtained, especially from a single goat. Liquid milk samples should be refrigerated or otherwise preserved prior to analysis; however, the analytical procedure to be used should* be considered when choosing a sample preservation method. Radioanalysis of milk usually involves ion-exchange techniques (for concentration) followed by beta or gamma counting.

When fresh milk is not available, analytical results of leafy vegetable (or fresh forage) samples can be used to estimate concentrations in milk using transfer coefficients or concentration ratios for dose calculations.

\subsubsection{Veqetation}

Vegetation includes three categories: vegetables, grains, and fruit. [If vegetation ( $i, e$, vegetables, grains, and fruit) is not one of the contributing pathways involved in determining the dose to humans from the site, native vegetation can be used as indicator species.] Collection and analysis of vegetation samples can serve three useful purposes: evaluating the potential radiation doses received by people consuming such vegetation; predicting the possible concentrations in meat, eggs, and milk from animals consuming contaminated forage (and resultant radiation doses to consumers of the animal products) ; and monitoring trends in environmental contamination and possible long-term accumulation of radionuclides.

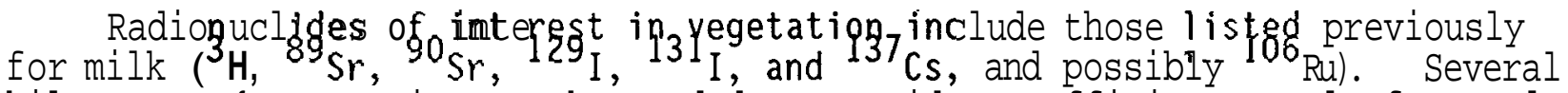
kilograms of vegetation may be needed to provide a sufficient sample for analysis, depending on the analytical sensitivities for the radionuclides of interest. The particular samples collected will depend on species availability, seasonal growth patterns, farming practices, and the reasons for sample collection. Where actual measurement of radioactivity cannot be made (e.g., radioactivity levels are below minimum detectable concentrations), dose calculations should include estimates of potential contributions.

The vegetable category includes common garden crops (i.e., corn, beans, potatoes, tomatoes, etc.). If the samples of garden vegetables are being collected for evaluation of radiation doses, then the edible portions of the vegetables should be analyzed.for the radionuclides of interest. Analysis may include direct gamma measurement, or alpha or beta counting after drying, ashing, and/or chemical separation of the desired radionuclide. The results should be expressed in terms of the radionuclide concentrations in the vegetables (consumed state) used in the dose calculation (e.g., fresh weight, peeled weight, etc.).

Samples of vegetables should be collected at local farms or from family gardens when the effective dose equivalent to individuals is being evaluated. When collective effective dose equivalents are being evaluated, fresh produce from commercial sources should be included in the samples. Care should be taken to collect vegetation from open, unshaded areas where radionuclide ground deposition would not be atypical. It is important that the origin of the materials sampled be within a 10- to $15-\mathrm{km}$ radius of the site and be 
identified. Analyses of commercial food items of known origin can also provide data on concentrations of naturally occurring or fallout radionuclides.

The grain category includes sweet corn, field corn, wheat, and other cereal grains. It is not likely that field corn would need to be sampled, since it is used for animal feeds, and animal products would be more logical items to sample for evaluation of intake of radionuclides by humans. With the exception of fresh sweet corn from local farms, most grains, by the time they are consumed, would not be likely to contain any radionuclides with halflives shorter than a few weeks. In addition, most pathway models use concentration ratios $(\mathrm{pCi} / \mathrm{kg}$ plant per $\mathrm{pCi} / \mathrm{kg}$ soil) that reflect the average concentration of radionuclides in the whole plant. Normally, concentrations in the kernel of the grain are lower than those in the stems and the leaves. As a result, ${ }^{9} \mathrm{Sr}$ and ${ }^{3} 7_{\mathrm{Cs}}$ are usually the only radionuclides of interest in cereal grains.

90. Radionyclides of potential interest in fresh sweet corn include ${ }^{65} \mathrm{Zn}$, ${ }^{90} \mathrm{Sr}$, and ${ }^{31} \mathrm{I}$. Local sweet corn should be sampled annually at harvest time from a "background" farm and a farm where there is a potential for contamination with radionuclides released from the site. A 1- to 2-kg sample of corn should be sufficient for analysis. Unless the pathway analysis indicates an unusually high potential for contamination, other grains will probably not have to be sampled.

The category of fruit includes tree fruits, berries, melons, and grapes. Unless the pathway analysis indicates that some unusual circumstances are present, it is normally not necessary to sample such fruit.

Samples collected for evaluation of intake of radionuclides by farm animals should be representative of the vegetation consumed by the animals. This includes silage and hay as well as fresh forage when available. Samples collected for monitoring of long-term trends in environmental contamination should be capable of accumulating the radionuclides of interest to permit detection at the desired level. Such samples should be collected from the locations of interest, including, but not necessarily limited to, a background location and a maximum location.

\subsubsection{Meat}

Because of the time delay for transfer of radionuclides from the point of release through vegetation to beef, pork, and poultry, samples of these meats are not good indicator materials. Therefore, frequent sampling of meat is normally required only when it is necessary to evaluate the radiation doses received via this foodstuff. With a few exceptions, radiation doses from ingestion of radionucljges in meat are of secondary importance. (One such exception occurs when ${ }^{4} \mathrm{C}$ from the facility's effluent is the predominant radionuclide present in the environment. In that instance, the doses from inhalation and external exposure would be small compared to those from ingestion of foods, and also the contribution from milk and vegetables would be less than that from meat.) The preliminary pathway analysis will determine whether frequent meat sampling is required. 
Because of the time lag mentioned above, shorter-1ived radionuclides (those with half-lives of less than 1 month) are not likely to be present in measurable concentrations in meat samples. The additional time lag (about 2 weeks for cattle and a few days for poultry) imposed between slaughter and delivery of the meat to retail outlets can be avoided by sampling directly at local farms or slaughterhouses. However, this time delay should be accounted for when the analytical results are used to calculate radiation doses from consumption of commercialfy avajlable meat. Radionuclides of potential interest in meat include ${ }^{4} \mathrm{C},{ }^{9} \mathrm{Sr},{ }^{3 /} \mathrm{Cs}$, and possibly ${ }^{129} \mathrm{I}$.

A 1 - to 2-kg sample of meat is usually sufficient for analysis. Meat may be purchased from local farms, retail stores, or slaughterhouses. All samples should be placed in plastic bags, sealed, and properly labeled before delivery to the analytical laboratory. Meat samples collected at farms or slaughterhouses should be reduced to edible portions in a manner similar to commercial and home preparation before analysis.

It should be noted that concentrations for several of the radionuclides of interest are generally lower in pork than in beef, despite the fact that many of the radionuclide concentration ratios $(\mathrm{pCi} / \mathrm{kg}$ meat per $\mathrm{pCi} / \mathrm{kg}$ feed) are somewhat higher for pork than for beef. The concentrations reflect the fact that the consumption rate of feed by swine is about 20 to 30\% that of beef cattle. Similarly, the radionuclide concentrations in chickens are generally lower than those in pork because chickens have a much lower feedconsumption rate than swine.

\subsubsection{Eqqs}

Under certain circumstances, eggs may make a contribution to radiation doses received from terrestrial foods. The preliminary pathway analysis will determine whether frequent sampling and analysis of eggs are required or whether annual sampling is sufficient. Eggs collected from small local farms where the chickens are free to range over open soil are more likely to contain detectable amounts of effluent radionucl ides than eggs from large poultry farms where the hens are confined. As with other foods, it may be difficult to determine the origin of commercially purchased eggs.

Several elements have relatively high concentration ratios in eggs ( $\mathrm{pCi}$ / $\mathrm{kg}$ egg per $\mathrm{pCi} /$ day intake) including phosphorus, rubidium, iodine, calcium, cesium, barium, tellurium, copper, iron, cobalt, and nickel. Many radionuclides of these elements have such short radioactive half-lives that they would not be detectable in eggs. In addition, some of the radionuclides would not likely be present in the effluents from most DOE sites. Cesium, iodine, and barium could be present in both liquid and gaseous effluents from many different types of facilities. Phosphorus-32 and -33, and iron, cobalt, and nickel could be released as activation products with liquid effluents from operating nuclear reactors.

One dozen large eggs, which have a combined weight of about 600 to $700 \mathrm{~g}$ (without the shells), is normally a large enough sample for analysis. Analysis should be done on the whole egg (without the shell). It is not necessary to analyze the yolk and white separately. Analytical results from local farm 
eggs, when available, should be used for individual dose calculations, while those from commercial eggs should be used for population dose calculations.

\subsubsection{Game Animals}

At some sites, animals such as deer, rabbits, and game birds are components of the diets of certain individuals. A review of the hunting habits in the local area should be included in the preliminary pathway analysis to determine if such game are important parts of the diet of the local population or of hunters from outside of the region. If the results of the preliminary survey indicate that local game could make an important dose contribution, then a more detailed survey of the amounts of each type of game harvested and the disposition of the meat should be made and documented.

It is also important to determine whether the meat is eaten, and if so, whether it is eaten fresh or frozen or given to others. If the results of the preliminary survey indicate that this pathway contributes an EDE of less than $1 \mathrm{mrem} /$ year, then annual sampling and analysis of two or three representative species will be sufficient to determine whether or not this pathway is still insignificant.

Radionuclides of interest ${ }^{\text {in }}$ wild game are similar 199 those listed under the discussion of meat: ${ }^{14} \mathrm{C},{ }^{9} \mathrm{Sr},{ }^{37} \mathrm{Cs}$, and possibly ${ }^{129}{ }_{\mathrm{I}}$. Again, 1- or $2-\mathrm{kg}$ samples should be sufficient for analysis.

Wild game samoles can be obtained from wildlife that is trapped, acquired by hunter; , or (for larger a imals, such as deer) collected after accidental road kills, or the samples can be obtained from an appropriate State agency. Wildlife that is relat vely rare locally should not be taken as environmental samples. When sampling deer and other game animals, it is important not to contaminate the meat sample with radionuclides that may be present on the animal's fur or in its gut.

\subsection{BASIS FOR SAMPLING SOIL}

Soil provides an integrating medium that can account for contaminants released to the atmosphere, either directly in gaseous effluents or indirectly from resuspension of onsite contamination, or through liquid effluents released to a stream that is subsequently used for irrigation. Hence, soil sampling and analysis should be used to evaluate the long-term accumulation trends and to estimate environmental radionuclide inventories. In addition to radionuclides that are specific to a particular operation or facjlity, naturally occurring (e.g., the uranium and thorium decay chains and Be) and fallout radionuclides can be expected in soil samples. The relative importance of these contributors is dependent on site operations and site conditions including site geography, geology, and metegrology Ragionuclides that are

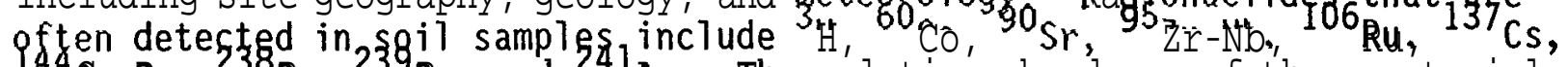

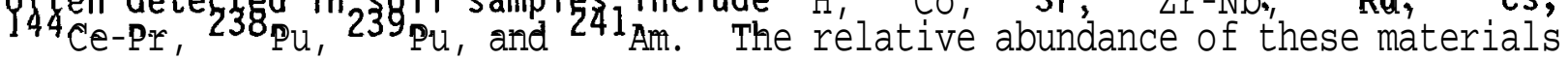
varies with the source and half-life of the materials. Analytical and sample preparation procedures should be tailored to the radionuclides of interest. As pointed out in the Summary of Selected AEC Contractor Environmental. 
Surveillance Techniaues and Capabilities (Denham et al. 1974), perhaps the greatest diversity among sites occurs in the techniques used for sampling and analyzing soil. Part of this diversity arises from different purposes for soil sampling and analysis (e.g., trend evaluation, projection of future plant uptake, contaminant inventory, comparison with applicable standards). Plutonium is one of the most commonly analyzed contaminants in soil. However, the limitations of sampling and analysis of plutonium in soil are many, as stated in NRC Regulatory Guide 4.5. Although concentrations of plutonium and other radionuclides in soil are generally readily detectable, the determination of their significance in terms of exposure to humans is loss readjly quantifiable, except perhaps for the gamma emitters, such as ${ }^{60} \mathrm{Co}$ and ${ }^{13} \mathrm{Cs}$. Therefore, it is desirable to assess, document, and periodically reassess the distribution and fate of radionuclides in the environment, especially plutonium in soil samples.

\subsubsection{Soi1 Sampling Location and Frequency}

Background determinations should be based on soil sampling and analysis at points corresponding to background (or control) air sampling locations. Where possible, soil sampling locations should be selected to coincide with air sampling stations, since the comparability of data may be important in achieving the objectives of the overall environmental sampling program. Except where the purpose of the soil sampling dictates otherwise, every effort should be made to avoid tilled areas or areas of unusual wind or precipitation influence when selecting soil sampling locations. An annual sampling frequency' is recommended for long-term accumulation trends. The sampling frequency of soil collected for purposes other than long-term environmental accumulation should be based on site-specific purposes and radionuclide halflife, with the purpose(s) and details documented.

\subsubsection{Soil Samoling Methods}

Several reports are available that should be used as guidance in sampling, preparing, and analyzing soil for plutonium (NRC Regulatory Guide 4.5; Fowler et al. 1971; Sill and Williams 1971), for radium (GJ/TMC-13; Meyer and Purvis 1985; Myrick et al. 1983), and for other radionuclides (ASTM 1986a; Mohrand and Franks 1982). In addition, Healy (1984) has proposed a standard for comparing observed to allowable concentrations of plutonium. It is recommended that trends in local environmental radionuclide levels be determined through routine soil sampling. Surface soil sampling should be conducted according to methods of NRC Regulatory Guide 4.5, ASTM (1986b), or HASL-300. Profile depths need to be established; ASTM C998-83 (ASTM 1986a) recommends profile depths of $30 \mathrm{~cm}$ to measure the total amount of a radionuclide deposited on the soil, during preoperational assessment, after a disturbance of the soil, and periodically as needed. Useful information about soil contamination levels can also be obtained using in situ gamma-ray spectrometry. Estimates of individual radionuclide contributions in soil can be made from field spectra, such as those developed by Anspaugh et al. (1974), HASL-195, and HASL-256, and reported by Friesen in NVO-213. The soil concentration estimates depend on distribution of radionuclides with depth, soil density, soil moisture, and chemical composition. 


\subsection{BASIS FOR SAMPLING WATER}

When liquid effluents are released to streams, rivers, or lakes, samples of these surface waters should be made according to the methods, locations, and frequencies specified in this section if the releases are projected to result in radiation doses exceeding the criteria given in Table 5-1. The principal exposure pathways to individuals and/or groups of individuals in the environment from waterborne radionuclides are consumption of fish and ducks (or other aquatic species), consumption of irrigated crops, and ingestion of drinking water. Of lesser significance is external radiation from surface water (swimming, water-skiing, boating). Ground water may accumulate detectable radioactive materials (particularly tritium) from liquid effluent storage systems (leakage) or discharges to surface water. Such accumulations are even more likely from facilities that discharge liquid effluents to the ground via cribs, pits, or trenches. Drinking water supplied from any source (surface or ground water) that receives effluents from nuclear facilities is a potential source of radiation exposure of humans. Experience at most DOE facilities (Hawley and Washburn 1985) indicates that waterborne radionuclide releases consist mostly of fission and activation products associated with reactor and supporting fuel-cycle operations. Routine laboratory analyses on water Samples should include those radionuclides, determined by pathway analyses, that represent a significant fraction of the potential dose from the water pathway (e.g., radiostrontium, gamma spectrometry) according to the radionuclides released from the site and other potential sources. Where documented operating experience and/or system design show that no release (or significant potential for a release) will be made to surface waters that could cause the dose criteria presented in Table 5-1 to be exceeded, this portion of the environmental surveillance program may be reduced accordingly. Potential for unpl anned releases, including those caused by runoff, leaching, flooding, or resuspension, should not be overlooked in planning for monitoring.

\subsubsection{Water Sampling Locations}

The basic recommendations that follow should be applied at all DOE sites where radioactive liquid effluents are discharged to surface streams (accessible to the public). Special studies, examining site-specific ground-water and surface-water flows, may be necessary to establish preferential sampling locations for ponds or lakes. Therefore, detailed hydrological and radiological studies should be conducted for each site on streams, ponds, and lakes to establish the best sampling locations and frequencies to determine radiological doses.

\subsubsection{Surface Water}

Surface waters can be divided into two basic types; that is, those that are constantly moving (e.g., rivers and streams) and those that are not constantly moving (e.g., ponds and lakes). The type of surface water must be considered when specifying surface-water sampling location requirements.

Representative surface-water background samples from rivers or streams should be collected routinely at locations expected to be unaffected by site 
operations (i.e., upstream locations). Such samples provide control data for comparison with data from downstream (potentially affected) indicator stations. Care should be taken to avoid eddy currents. If the receiving stream originates onsite, a counterpart stream in the vicinity may be used to collect background samples. However, an investigation should be conducted and documented to show that the counterpart stream is independent of local influence from radioactive materials. The other offsite sampling locations for surface water should be at the edge of the effluent mixing zone and at the nearest down-current point of withdrawal for domestic or other uses. Multiple sampling points, based on diffusion and transport studies of the mixing zone, may be necessary to obtain a reliable estimate for that location. Sampling at the first downstream point of withdrawal for public use provides an upper estimate of the amount of radioactive material in the water supply (for drinking or irrigation) of the potentially affected population group(s). Samples should be taken on a traverse, at more than one depth, and at a minimum of four to six points equidistant across the stream flow. Each sample should represent no more than $10 \%$ of the total stream flow (i.e., at least 10 samples should be taken across the traverse). This sampling strategy may not be applicable for very small streams. Traverse studies should be repeated whenever a significant change occurs either in the types or quantities of radionuclides (actual or expected) released or in the flow regime of the stream (such as from the addition of hydroelectric or flood-control dams).

Representative background samples from ponds or lakes should be collected routinely for these surface-water sources at locations expected to be unaffected by site operations. Such locations should be far enough from the point of discharge so that the facility effluent has no (or as little as possible) influence on the sample content. To provide that the latter is trule, the distance from the discharge point should be chosen to be at least 20\% of the length of the pond or lake, given that, for small ponds or lakes and those with limited water turnover, it may be impossible to find a background sample location unaffected by effuent discharge. Another possible solution is to sample from another nearby pond or lake with the same water source ( $i, e$, , fed by the same stream or located within a similar runoff regime). Such background samples provide control data for comparison with data from potentially affected indicator sampling locations. Care should be taken to avoid eddy currents in the sampling location. If the receiving pond or lake is onsite, an offsite counterpart pond or lake may be used to collect background samples. However, in either case an investigation should be conducted ( $8 . g$, , collection of substantial hydrologic and surface-flow data) and documented to show that a different pond or lake from the one 1 sed for liquid effluents is independent of local influence from radionuclides of possible facility origin.

Other offsite sampling locations for ponds or lakes should be at the edge of the effluent mixing zone (based on dye or other local transport studies) and at the nearest point of withdrawal for domestic or other uses. The close-in sampling location should be located near the discharge outfall, but beyond the turbulent area caused by the discharge. Multiple sampling points, based on diffusion and transport studies of the mixing zone, may be necessary to obtain a reliable estimate for that location. 
Sampling a lake or pond at the nearest point of withdrawal (i,e, , closest to discharge) for public use usually provides an upper estimate of the amount of radioactive material in the water supply (for drinking or irrigation) of the potentially affected population group(s). Samples should be collected at each location where water is withdrawn for public use. Samples on the traverse or axial sampling lines should be taken at more than one depth and at a minimum of three to five equally spaced points along each of four radials. Traverse or axial studies should be repeated whenever significant change occurs either in the types or quantities of discharges or in the water level of the pond or lake.

\subsubsection{Drinking Water}

Drinking water may be supplied from surface-water sources or from ground-water sources. Thus, the drinking-water sampling location requirements are presented according to the type of drinking-water source that is avai 1 able.

The sampling location for drinking water derived from surface-water sources should be of the treated water at the point of maximum probable effluent concentration in the surface water. Samples of untreated water from the same location should also be taken to determine any removal by water treatment and to improve the reliability of dose estimates. If surface-water sampling and analytical results indicate that the dose criteria given in Table 5-1 are not exceeded, further drinking-water sampling is not required. Such conditions should be documented and periodically (at least annually) reviewed to determine that the potential doses are still below the criteria in Table 5-1.

The sampling location for drinking water derived from ground-water sources should be at the nearest domestically used well downgradient from the surface (crib, pond, lake, or stream) discharge point. Another well upgradient from the discharge point should be used for the control or background sample. When comparisons with control wells are conducted, the sampling stations should be located in the same hydrologic unit. If significant numbers of shallow wells are used domestically in the vicinity of the plant site, it may be necessary to sample several wells to determine which (if any) are affected by surface-water discharges from the site.

\subsubsection{Ground Water}

DOE 5400.1 requires that ground waters that may potentially be affected by DOE operations be monitored to determine and document the effects of such operations on ground-water quality and quantity and to demonstrate compliance with applicable Federal and State laws and regulations. The ground-water monitoring programs should be conducted onsite and in the vicinity of DOE facilities to

- Obtain data for the purpose of determining baseline conditions of ground-water quality and quantity. 
- Demonstrate compliance with and implementation of all applicable regulations and DOE Orders.

- Provide data for the early detection of ground-water pollution or contamination.

- Identify existing and potential ground-water contamination sources and to maintain surveillance of these sources.

- Provide data upon which decisions can be made concerning land disposal practices and the management of ground-water resources.

The siting and number of ground-water monitoring stations should be governed by the nature of ground-water use and the location of known and potential sources of pollution. When possible, existing wells and historical data should be used. However, it is likely that new wells will be needed. Well siting should be directly related to pollutant pathways, but well locations must be chosen carefully and wells must be installed, developed, and operated with care to prevent a new well from providing an avenue for pollutants to reach the aquifer. Quality control in well construction is essential. Predicting contaminant pathways requires a three-dimensional geologic, hydrodynamic, and geochemical analysis. Mechanisms for subsurface pollutant dispersal are not fully understood. The rate and extent of contamination are controlled by 1) the characteristics of the pollutant source, 2) the nature of the geologic formations in the saturated and unsaturated zones, and $\mathbf{3}$ ) the physical and chemical properties of the contaminants. Phenomena that affect the fate of a pollutant include capillary action, decay, adsorption, dispersion, and diffusion. No comprehensive Federal statutes regulating groundwater quality and monitoring currently exist. Rather, ground-water requirements are drawn from a number of distinct laws enacted to protect other resources or to regulate specific sources of contamination. Specific legislation relevant to DOE nuclear operations includes the following:

- Atomic Energy Act (AEA) of 1954, as amended by the Uranium Mill Tailings Radiation Control Act (UMTRCA) of 1978

- Safe Drinking Water Act (SDWA)

- Federal Water Pollution Control Act (FWPCA), as amended by the Clean Water Act (CWA) of 1977

- Nuclear Waste Policy Act (NWPA)

- Comprehensive Environmental Response, Compensation, and Liability Act (CERCLA), as amended.

In addition to Federal statutes that authorize programs and activities for ground-water protection, many States are also developing and implementing ground-water policies, statutes, and strategies. Often States have the authority or "primacy" to administer several Federal environmental 1 aws. Under this authority, States may, and often do, impose more stringent requirements than the Federal government. In many States, State agencies, regional 
authorities, and local governments share responsibilities for protecting ground water. Contaminants covered by ground-water quality standards vary from State to State, and about half of the States have adopted or proposed some type of classification system for ground water. Thus it is important that DOE Operations Office and contractor staff work close y with state and regional agencies when determining the specific monitoring requirements for each facility.

\subsubsection{Water Samolina Frequency}

For drinking-water systems, the sampl ng frequency and volume should be chosen to provide adequate sensitivity for the analysis using the general criteria given in Table 5-1. At least 50\% of the data should be greater than the minimum detectable level for all water ana yses used for dose calculations.

\subsubsection{Water Samoling Methods}

Since most water measurements are made on samples taken in the environment and returned to the laboratory for analysis, the two major concerns in water sampling are the collection of a representative sample and the maintenance of radionuclides in their original concentrations before analysis. The general problem of the measurement of radioactive material in environmental water is discussed by Kahn (1972); water sampling procedures are also discussed in APHA (1985), ASTM (1986b), and EPA (EPA 625/6-74-003) manuals.

\subsubsection{Water SamDle Collection}

Waste management practices often result in periodic or batch discharges of liquid wastes, rather than a continuous release. The following factors should be considered when selecting water sampling equipment:

- Probability of significant fluctuations in concentration of the water sampled

- Potential for significant human impact (dose)

- Potential for contaminating the environment

- Applicability to radionuclide(s) of interest.

The recommended practice for surface- and drinking-water samples is automated continuous sampling followed by analysis of the unfiltered sample. When the data are to be used for dose calculations, the method should use a fixed-time sampling frequency, similar to that by which water is withdrawn for human consumption. (If the data therefrom are to be used for radionuclide transport or inventory purposes, these samples should be taken with timing proportional to flow rate.) When circumstances prohibit this type of automated continuous sampling (e.g., power restrictions, prohibitive pumping requirements, freezing temperatures, etc.), compositing should be performed by manual collection on a frequency based on effluent release and on information on the receiving body of water. An acceptable scheme is weekly grab samples of surface water composited for monthly analyses and daily grab samples of 
drinking water composited for weekly or monthly analyses. Because the flow of most ground-water systems is on the order of centimeters to meters per day (compared with tens or even hundreds of kilometers per day for surface stream flows), periodic grab sampling of ground water should be sufficient. Unless circumstances prohibit, ground-water grab sampling should be done by pumping, either with a pressure air lift or'with a submersible pump. In either case, the pump should be operated for a length of time sufficient to obtain a representative sample of water in the aquifer. To approximate conditions at the tap, finished drinking water conditions may require filtering of ground-water samples to remove well-casing effects.

\subsubsection{Sample Size}

The size of water samples will be determined by the analytical procedures (see Chapter 7) to be used. A 3.5-L (approximately 1-gal) sample is usually minimal for other than tritium or gross activity measurements. The sample volume must be increased where splitting of samples for replicate analysis or individual radionuclide determinations is planned.

\subsubsection{Representative Sampling}

Natural waters are frequently two-phased systems (i .e., sol id materials are suspended in or floating on the water). Therefore, all surface-water samples should be carefully taken from beneath the water surface to avoid floating debris and any bottom sediments or growths. The soluble fraction provides an indication of possible stream transport, while the insoluble fraction can be used as an indication of potential sedimentary material. So that data are comparable, both fractions should be added in reporting the total concentration. Filtration of ground-water samples is recommended because suspended material is usually an artifact of the sampling process (well-casing particles and dirt near water-soil interface) and is not representative of the ground water. Caution should be exercised to prevent water samples from different locations being cross-contaminated by reuse of sampling containers. When obtaining surface-water grab samples, the sample container should be rinsed twice with the water being sampled before the actual sample is taken. When extracting aliquots from a larger water sample, extra effort should be taken to provide that the aliquot is representative of the entire sample.

\subsubsection{Sample Preservation}

Continuing biological and chemical action in the sample during and after collection can cause changes in chemical form, deposition on container walls, and removal of radioactive material from solution by biological growths. Known phenomena include the following:

- Cations, at very low concentrations, can be lost from solutions $[\varepsilon, g .$, cesium can exchange with potassium in the container (glass) 1 . 
- Radionuclides can be absorbed by algae or slime growths in sample lines or on container walls, especially in sample containers that remain in the field for extended periods.

- Hydrolysis and sorption on container walls or on particles in the water can occur at low acidities (typical of many natural waters).

- Radiocolloidal phenomena may result in large flocculent particle formation or additional plate-out on container walls.

- Pretreatment may induce change in nuclide distribution (e.g., acidification can leach suspended particles in the original sample so that more radioactive material appears in solution).

- Acids used as biocides can oxidize iodide to iodine, resulting in its vol atilization.

- Acids may quench standard liquid scintillation cocktails.

- A change in counting geometry may occur for gamma-ray counting if finely divided particulate activity settles out or if soluble species become fixed on the container walls during counting.

Methods for Chemical Analvsis of Water and Wastes (EPA 625/6-74-003), Section 11 of the Annual Book of ASTM Standards (1986a), the Environmental Measurement Laboratory (EML) Procedures (HASL-300), and the Radiological and Environmental Sciences Laboratory procedures (IDO-12096) should be used for sample preservation, storage, and analysis methods. The first two references 1 ist various preservative methods and permissible storage times for water samples according to chemical species, while the ASTM (1986b) and EML (HASL-300) manuals provide methods for measurement of radioactivity and specific radionuclides. Radioiodine analyses should not be performed on an acidified sample because organic forms may be tranformed to elemental forms that are more volatile.

\subsubsection{Settleable Solids in Effluent Discharge}

DOE Order 5400.5, Chapter 11 , paragraph $3 \mathrm{a}(4)$ requires that the radioactivity in the settleable solids in liquid discharge streams be limited to $5 \mathrm{pCi} / \mathrm{g}$ above background for alpha-emitting radionuclides, and to $50 \mathrm{pCi} / \mathrm{g}$ above background for beta- and gamma-emitting radionuclides. The following method should be used to determine the radioactivity of settleable solids:

1. Use Standard Method 209 E, 3.b. gravimetric (APHA 1985) to determine settleable solids (SS) in $\mathrm{mg} / \mathrm{L}$ in the water sample. This method refers to Method $209 \mathrm{C}$ for determining both the total suspended solids (TSS) and nonsettleable solids (NSS). Retain the solid fractions of the TSS and NSS samples for later radioactivity measurements.

2. Determine the radioactivity of alpha-emitting radionuclides in picocuries per gram and the radioactivity of beta-emitting radionuclides in 
picocuries per gram in the recovered solid fraction of each of the TSS and NSS samples. Use the recommendations found in Section 6.4.

3. Determine the gross activity concentration of the settleable solids, using information obtained above and the equation

$$
A_{S S}=\frac{\left(M_{T S S} \times A_{T S S}\right)-\left(M_{N S S} \times A_{\text {NSS }}\right)}{M_{T S S}-M_{N S S}}
$$

where $A_{S S}=$ activity concentration of settleable solids, $\mathrm{pCi} / \mathrm{g}$

MTSS = mass concentration of total suspended solids, $\mathrm{mg} / \mathrm{L}$

ATSS = activity concentration of total suspended sol ids, $\mathrm{pCi} / \mathrm{g}$

$M_{\text {NSS }}=$ mass concentration of nonsettleable sol ids, $\mathrm{mg} / \mathrm{L}$

$A_{\text {NSS }}=$ activity concentration of nonsettleable solids, $\mathrm{pCi} / \mathrm{g}$

4. Since the sedimentation standard is presented as net settleable solid radioactivity, the activity of backaround settleable solids must be subtracted from the sample-SS activity Determine the background radioactivity from an appropriately se ected background water sample, using the same methods and equation.

Direct environmental monitoring of sed ments, as required under the site Environmental Monitoring Plan, will further verify that radionuclides are not accumul ating .

\subsection{BASIS FOR SAMPLING AQUATIC FOODSTUFFS}

Aquatic foods, including local fish, shellfish, and waterfowl, are eaten in relatively large quantities by residents of some regions of the country. Aquatic plants are not normally a component of the human diet in the United States. However, there are exceptions; for example, along the California coast a particular species of seaweed is harvested and processed into a thickener for foods, such as milkshakes. Aquatic plants can be vectors in the water-plant-animal-human pathway. If the preliminary analysis indicates that the potential annual EDE from ingestion of aquatic foods is 5 mrem or greater, then sufficient sampling and analysis should be carried out to provide that the foods and radionuclides contributing at least 90\% of this ingestion dose have been evaluated. If the potential annual EDE is between 1 and 5 mrem, then sufficient sampling and analysis should be carried out to provide reasonable assurance that the doses are in this range. When the annual EDE is potentially between 1 and $0.1 \mathrm{mrem}$, then sufficient surveillance should be done to show that the radionuclides are behaving in the environment as expected. Only one generic concentration ratio for aquatic organisms ( $\mathrm{pCi} / \mathrm{kg}$ organism per $\mathrm{pC} i / L$ water) is less than 1 ; namely, 0.5 for uranium in marine plants. As a result, any radionuclide present in the water will be present in aquatic organisms, and most, but not all, radionuclides detectable in water will be present at detectable concentrations in the organism. Aquatic organisms, sediments, and other predictive environmental media should be sampled and analyzed at least annually to provide compliance with the interim aquatic biota limit of $1 \mathrm{rad} /$ day. The required sampling program is to be 
determined on a case-by-case basis considering such factors as the estimated dose as determined from measured concentrations in organisms or predictive environmental media in comparison with the limit and any variation behavior of the contaminants involved.

\subsubsection{Freshwater Foods}

If the aqueous effluents are discharged into a surface body of freshwater (pond, lake, stream), then the background sampling point should be far enough from the discharge point for radionuclide concentrations in the water and sediment to be unaffected by the effluents. The indicator sampling location should be downstream of the discharge point(s) at a location in which the water is determined to be well-mixed (e.g., based on water-sample traverses). In choosing the locations to be sampled, consideration should be given to the possible migration of fish between upstream and downstream locations. Special permits from State fish and wildlife agencies are usually required for fish, shellfish, and waterfowl sampling for monitoring purposes. Concentrations of many elements in freshwater are highly site-dependent. This variation can affect the observed concentration ratios of radionuclides of these or biologically similar elements in freshwater organisms. (Except in estuaries, the elemental composition of seawater is relatively constant, and the concentration ratios of radionuclides in marine organisms are not nearly so sitedependent as they are for freshwater organisms.)

\subsubsection{1 $\underline{\text { Fish }}$}

The species of fish likely to contain the highest concentrations of radionuclides are those that feed at or near the bottom and do not migrate very far from the places having the highest water or sediment concentrations. These species are useful as indicator organisms for monitoring trends in aquatic contamination levels. However, they may not always be the ones that are consumed at the highest rate by the local population. Studies of fishing pressure and fish consumption, coupled with preliminary radiochemical analysis of the different types of available fish, should be used to define the proper species to monitor for the purposes of dose calculation.

Fish can be collected by using nets or rod and reel, or they can be purchased from commercial sources, if their origin can be determined. For use in dose calculations, the edible portions of the fish as prepared for human consumption should be analyzed. In most instances, that includes only the muscle. However, the whole fish should be analyzed if it is used for preparation of fish meal or fish burgers. It is also appropriate to analyze the whole fish when the data are used for trend indication. If fish are the critical pathway, then they should be analyzed by species. On the other hand, if the results are to be used as trend indicators, then the fish may be grouped by type for analysis (e.g., bottom feeders, insectivores, or predators).

The following factors should be considered when determining the frequency of sampling: variability of the radionuclide release rates; seasonal variations in the feeding habits of the fish and in the availability to consumers; and, if the freshwater habitat includes a flowing stream, the variability in the stream flow rate. 
Radionuclides of potential interest in fish include $3 \mathrm{H}, 32 \mathrm{p}, 33 \mathrm{p},{ }^{65} \mathrm{Zn}$ ${ }^{134} \mathrm{Cs}$, and 'Cs. Although the concentration ratio for $H$ is only 1 , it is' often present in high concentrations in aqueous effluents. Strontium-90 might be of importance in samples of whole fish, since it concentrates mostly in bones. Phosphorous ( ${ }_{\mathrm{P}}$ and $33_{\mathrm{P}}$ ) concentrates in fish flesh, as well as in bones. The sample size required for analysis will vary from $1 \mathrm{~kg}$ to several kilograms, depending on the specific radionuclides being measured and their concentrations.

\subsubsection{Shell fish}

Freshwater shellfish are usually not a significant diet item. They may, however, be eaten by some individuals in certain specific regions of the United States. A preliminary pathway analysis will determine if shellfish are a potentially important contributor to the EDE that might be received by residents of the region. Shellfish include mollusks, which live in or on the sediment, and crustacea, such as freshwater crayfish, which live on or near the bottom. Decisions on sampling locations and frequencies involve the same types of considerations as discussed above for fish (i.e., variability of radionuclide concentrations in water and sediment and inclusion of upstream and downstream locations). Radionuclide concentration ratios are generally higher in invertebrates than in fish, and in some cases significantly higher. Radionuclides of pgtential integest if fresplwater mollusks and crustacea include ${ }^{32} \mathrm{P},{ }^{33} \mathrm{P},{ }^{58} \mathrm{Co},{ }^{60} \mathrm{Co},{ }^{5 \mathrm{n}},{ }^{90} \mathrm{Sr},{ }^{106} \mathrm{Ru}$, and the rare earth radioelements. A 1 - or 2-kg sample is normally sufficient for analysis. Samples of shellfish may have to be purchased commercially to avoid the difficulties associated with field collection.

\subsubsection{Waterfowl}

Waterfowl, such as ducks and geese, may acquire radionuclides from their food sources. Some species are bottom feeders and tend to accumulate those radionuclides associated with sediments, such as ${ }^{60} \mathrm{Co},{ }^{65} \mathrm{Zn}$, and ${ }^{37} \mathrm{Cs}$. others feed predominantly on surface plants, insegts, $\beta_{r}$ fish. Bepending on the specific diet, these species may accumulate ${ }^{32} \mathrm{P}, 3{ }_{\mathrm{P}}, 6{ }^{2} \mathrm{Zn},{ }^{90} \mathrm{Sr}$, and $137 \mathrm{Cs}$.

The migratory habits of waterfowl species vary widely. Some may be year-round residents of the local waterways (and effluent ponds). These are usually species that are less desirable to hunters. Others may migrate long distances, and the limited amount of time spent in the local area may not be enough to cause significant contamination of their flesh. Because of these variables, it is often difficult to predict which species is most important in terms of potential exposure to local hunters.

The prel iminary pathway analysis should include consideration of the amount of waterfowl hunting, if any, in the local area and the number of birds shot. It should be remembered that even though some individuals may harvest a relatively large number of waterfowl, the collective EDE to the local population from waterfowl consumption may still be small. If the potential EDE is significant, a minimum of two or three birds of each type (bottom feeders, plant eaters, and fish eaters) should be sampled during hunting season. The 
most common method of collecting waterfowl is by hunting. Sampling of nonmigratory, nongame species can occasionally provide useful information on contamination trends.

During preparation of the samples for analysis, care should be exercised not to contaminate the edible portions with radionuclides present on the external surfaces of waterfowl. Analysis should include the radionuclides listed above plus any others that prove to be of special concern at a specific site.

\subsubsection{Marine Foods}

Sites that are located on the seacoast, an estuary, or a river upstream of an estuary should include consideration of the potential consumption of contaminated marine foods, such as sports and commercial fish and shellfish, in their preliminary pathway analysis. The considerations discussed for sampling of freshwater aquatic foods also apply to marine foods. These considerations include sample size and radionuclides of potential interest.

Sports fish and shellfish will be of interest primarily for calculation of radiation doses to the maximally exposed individual, while commercial seafoods are of interest for estimating the collective dose. Once again, it is important to document the origin of the commercial samples. It may be necessary to track the path of an effluent plume or contaminated river for many miles along the seacoast to identify the important locations for shellfish sampling. Arrangements can usually be made to buy seafood harvested at known areas from local packing houses.

Certain marine fish, such as salmon and tuna, that migrate over large areas of the ocean will not normally be measurably contaminated from aqueous effluents discharged along the shore or reaching the coast line. If they are found to be contaminated, it might be difficult to determine the exact source of radionuclides detected in them.

\subsection{BASIS FOR SAMPLING SEDIMENT}

The sampling of sedimentary material from streams or ponds can provide an indication of the accumulation of undissolved radionuclides in the aquatic environment. The accumulation of radioactive materials in sediment can lead to exposure of humans through ingestion of aquatic species, through sediment resuspension into drinking-water supplies, or as an external radiation source irradiating people fishing, wading, or sunbathing. Hence, the sampling and analysis of sediment, or the measurement of the external radiation emanating therefrom, provide indications of the potential for human exposure from these indirect pathways. Because of the accumulation of contaminants, sediment sampling is a more sensitive indicator of waterborne radionuclides than water sampling or, for some aquatic species, aquatic biota sampling. This sensitivity is especially true for radionuclides that are not significantly accumulated by fish or shellfish. Sediment sampling is particularly appropriate for 


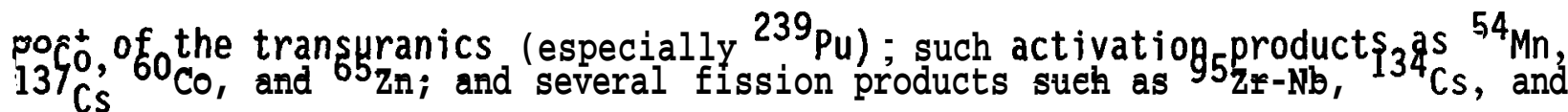

\subsubsection{Location and Freauency}

The need for sediment sampling and the choice of locations and frequency should be based on site-specific evaluations. These evaluations should consider the potential for offsite exposure of humans, as well as the potential dose to onsite or offsite aquatic organisms. Sediment samples are normally taken to detect the buildup of radionuclides by sedimentation. Sediment sampling locations should be based on the type of surface water receiving site liquid effluents. For moving bodies of water, such as streams or rivers, sediment sampling locations should include an upstream site beyond any possi ble facility influence and two downstream locations. The two downstream locations should be located such that one is near the discharge site and the other is in an area that favors sedimentation, such as the inner bank of a bend in the stream or river (ORP/SID 72-2), the region of a freshwater-saltwater interface, or at a dam impoundment. If liquid effluents from a nuclear facility are discharged to a lake, pond, or arroyo, a sediment sample should be taken near the outfall but beyond the turbulent area created by the effluents. Because sediments are usually not in a critical exposure pathway, an annual frequency for sediment sampling should be sufficient. For rapidly moving streams (e.g., rivers), sediment sampling should be considered in conjunction with the spring freshet (i.e., just before or just after), if one occurs locally. For arroyos, the sampling should take place after cessation of water flow (i.e., upon first drying in the spring). For ponds or lakes, the timing of sediment sampling should be considered on a site-specific basis, but normally at about the same time each year.

\subsubsection{Sediment Sampling}

Samples of deposited sediments in water can be collected manually (by hand in shallow water or by diving in deeper water) or mechanically (by dredge or with a core sampler). The manual methods are recommended where conditions permit, because the location and depth of the sample can be well-defined. The dredge and coring methods use a sampling device dropped from a boat that is activated when the device contacts the sediment (benthos).

Except for cases where an inventory estimation is desired, representative surface (top 5 to $10 \mathrm{~cm}$ ) sediment samples should be collected along with water depth and stream flow (or pond/lake elevation) data at the time of sampling. Characteristics of the sample, such as particle-size distribution, sediment type, stream type (i.e., intermittent, creek, pond, river, reservoir, etc.), ion-exchange capacity, and organic content, may be useful for proper interpretation of the analytical results.

Every few years, core samples should be taken in areas in which sediments have been most heavily deposited to determine the profile of the historical depositions and to determine trends and changes in control of effluents and their impacts. 
All sediment samples should be oven-dried, homogenized (by grinding and blending, as appropriate in accordance with procedures used) and the radioanalytical results reported on the basis of activity per unit dry weight (g or $\mathrm{kg}$ ). To prevent cross-contamination, thorough cleaning of equipment between samples is necessary. Portions of the detailed EML procedures (HASL-300) for preparing soil samples for analysis are equally applicable to sediment samples.

\subsection{QUALITY ASSURANCE}

As they apply to environmental surveillance activities, the general qual ity assurance program provisions of Chapter 10 should* be followed. Specific quality assurance activity requirements for the site's environmental surveillance program are to be contained in the Quality Assurance Plan associated with the facility. 


\subsection{LABORATORY PROCEDURES}

The establishment of good laboratory practices is paramount to obtaining quality results from samples collected under the effluent monitoring and environmental surveillance program specified in DOE 5400.5. Laboratory procedures and practices should* be documented in the site Environmental Monitoring Plan (in compliance with DOE 5400.1) to show

- Sample identification systems

- Cross-contamination prevention measures

- Sample preservation and handling practices

- Analytical methods (standard methods)

- Modifications to any standard analytical methods

- Analytical capabilities (in-house and outside analytical ontract capabilities)

- Equipment-calibration and reference-source (check-source) practices (including procedures, frequencies, and methods for track ng/ managing)

- Other quality assurance procedures.

\subsection{SUMMARY OF LABORATORY PROCEDURE REOUIREMENTS}

The summary presents the 1 aboratory measurement procedural requirements necessary for a DOE site. A site does not have to maintain a full laboratory, but it does need to have the necessary laboratory capabilities available to it.

\subsubsection{Sample Identification System}

Each monitoring and surveillance organization should* have a sample identification system that provides positive identification of samples and aliquots of samples throughout the analytical process. The system should" incorporate a method for tracking all pertinent information obtained in the sampling process.

\subsubsection{Procedures Preventing Cross-Contamination}

To prevent incorrect analysis results caused by the spread of contamination among samples, each laboratory should* establish and adhere to written procedures to minimize the possibility of cross-contamination between samples. High-activity samples should" be kept separate from low-activity samples. In addition, the integrity of samples should* be maintained; that is, 
the degradation of samples should* be minimized by using proper preservation and handling practices that are compatible with the analytical methods used.

\subsubsection{Documentation of Methods}

To provide that the analyses performed are consistent and of the highest quality, specific analytical methods should* be identified, documented, and used to identify and quantify all radionuclides in the facility inventory or effluent that contribute $10 \%$ or more to the public dose or environmental contamination associated with the site. Standard analytical methods should* be used for radionuclide analyses (when available), and any modification of a standard method(s) should* be documented. In addition, methods, requirements, and necessary documentation should* be specified in any analytical contracts established with outside laboratories.

\subsubsection{Gamma-Emitting Radionuclides}

All sites that release or could release gamma-emitting radionuclides should* have the capability (either in-house or outside) of having samples analyzed by gamma-ray spectroscopy systems. This requirement applies to all samples whether they are routine, special, or emergency samples.

\subsubsection{Calibration}

Counting equipment should" be calibrated using, at a minimum, the calibration frequency recommendations of the manufacturers so that accurate results are obtained. In addition, check sources should" be counted periodically on all counters to verify that the counters are giving correct results.

\subsection{HANDLING OF SAMPLES}

To comply with the sample-identification system requirement, all pertinent information on the samples and their analysis should be recorded in a permanent 1 aboratory record book and/or computer system with hardcopy backup. The sample identification number should enable tracking of the exact location of the record entry or computer file and indicate the chain of custody for the samples.

\subsubsection{Measurement (Screening) of Activity Levels Using Monitorins Equipment}

Environmental samples collected in the vicinity of nuclear facilities could have widely ranging levels of radionuclides. They could also have radionuclide contamination in forms and levels that could contaminate materials and equipment with which they come in contact. Therefore, except for control samples or samples that historically have had very little or no activity, such environmental samples should be surveyed to determine activity levels and to detect transferable contamination before they are brought into the laboratory. Special precautions, such as the use of lead shielding or extra PVC bags, should be taken with samples that show elevated activity levels. 


\subsubsection{Shipoing, Unoacking, and Reoackaqing of Samples}

Samples that are sent offsite for analysis or for laboratory intercomparison should* be monitored for contamination and radiation levels and packaged in a manner that meets applicable transportation regulations and requirements. Samples that have been prepared with nitric acid may be considered to be hazardous substances and should be transported accordingly. Samples that show measurable surface contamination should be repackaged in uncontaminated containers before they are brought into the laboratory. This repackaging is necessary to prevent the spread of contamination or the loss of sample constituents. Even samples that do not show measurable surface contamination, using survey instruments, can have activity levels that can result in serious contamination of laboratories and counters. Also, sample containers prepared in the field are often poorly sealed, which can result in portions of the sample leaking out of the container. Therefore, all inadequately packaged samples should be repackaged before they are brought into the laboratory. The repackaged samples should be packaged in at least double containers to prevent contamination if one of the containers leaks. The outer container should be handled only by a person who has had no contact with the sample or other contaminated materials. For example, a water sample can be. sealed in a plastic bottle by a person who is believed to be uncontaminated. The bottle can then be placed into a plastic bag held by a person who has had no contact with the sample or other radioactive materials. The plastic bag should then be sealed airtight. In cases where the samples could have high levels of radioactivity, it would be prudent to heat-seal the bottle and plastic bag in another plastic bag to help prevent the escape of radioactive materials from the package.

\subsubsection{Prevention of Cross-Contamination}

High- and low-activity samples should be treated in different laboratories, or at least in separate, distinct locations of the laboratory. The measurements made during sample screening with survey instruments should be among the criteria used to determine which laboratory (location) will receive the sample. Laboratory glassware that has been used in processing highly radioactive samples should be appropriately discarded and not reused. A clean material, such as bench paper, should be used to cover laboratory benches before processing a set of samples. Periodic surveys of gross activity levels in the laboratory should be conducted to detect any contamination that might occur. Detected contamination should be removed by proper decontamination practices. Following physical and chemical treatment of the original samples, the resulting samples should again be sealed in plastic bags before being transported to the counting room for counting.

\subsubsection{Selection of SamDle Sizes According to Gross Beta and Gross Alpha Activities}

The size of the sample counted will depend on the activity of the sample. If the activity of the sample is near background levels, it could be necessary to count as large a portion of the sample as is practical for as long as is practical to obtain measurements with the desired degree of sensitivity and 
precision. Other samples may produce counting rates that are too high for the counter, producing coincidental readings that are inaccurate. These will produce artificial peaks with energies that are the sum of the energies of other peaks. Very high counting rates can also produce unacceptable counter dead times. In this case, it may be necessary to count only a small (representative) portion of the sample for a short period of time. Gross beta, gross alpha, and gross gamma measurements should be used to determine the most suitable sample size.

\subsubsection{Preparation of Samoles}

The chemical separation procedures, if any, that will be necessary to prepare samples for counting will depend on the nature of the sample and the radiation emitted by the radionuclide of interest. Radionuclides that emit gamma radiation will generally not require chemical separations, but alpha or beta emitters generally will. Chemical separations should be avoided whenever possible because of the time and expense involved and because of the errors that can result from radionuclide losses during chemical separations. Carriers and/or tracers should be introduced at an early stage of any procedure requiring chemical separations under conditions that will maximize isotopic exchange so that chemical yields can be calculated. The following subsections present the general types of separation procedures that might be required for different types of samples.

\subsubsection{Air}

Atmospheric concentrations of radionuclides attached to (or in the matrix of) aerosol particles should be measured by directly counting air-filter samples using low-background detector systems without any chemical separation. Photon emitters should be measured directly using germanium diodes without chemical separation. Chemical separations should be used only in cases where the concentrations or the photon energies are very low. If the particulate material is collected on the filter surface, the deposit does not become too thick, and interfering radionuclides are not present, then concentrations of alpha emitters should be measured directly from an air filter using alpha spectrometers. Samples collected using membrane filters should be counted directly for alpha emitters because membrane filters collect particles on the surface. However, the air flow rate that is possible through membrane filters is much less than that through fibrous filters, which causes the membrane filter to plug more rapidly. Therefore, alpha emitters that are present in low concentrations in the atmosphere often cannot be detected using membrane filters. Samples containing low concentrations of alpha emitters should be collected at high flow rates on fibrous filters and chemically separated before counting. High concentrations of naturally occurring short-lived radon and thoron decay products on air-filter samples can seriously affect the measurement of other radionuclides. The concentrations of the thoron decay products are generally 1 to $\mathbf{3}$ orders of magnitude lower than those of radon decay products. The short-lived radon decay products decay with an effective halflife of about 30 minutes, and the thoron decay products decay with a halflife of about 11 hours. Therefore, air-filter samples should be allowed to stand several hours before counting to allow the radon decay products to 
decay, or several days to allow both radon and thoron decay products to decay, rather than chemically separating the radon and thoron decay products. Many radionuclides in the atmosphere are in the gaseous phase and are not attached to (or in the matrix of) aerosol particles. These radionuclides are measured in whole air samples, in samples collected in cold traps, or in materials that have been used to chemically or physically absorb the radionuclides from the air. Unless the concentrations are too low, photon-emitting radionuclides collected on absorbent materials can be measured directly without chemical separation. Alpha and beta emitters generally require chemical separations. Noble gases are usually present in the gaseous effluents of nuclear facilities, such as nuclear reactors and fuel reprocessing plants, and are typically measured in whole air samples. For reactors, the shorter-1ived radionuclides such as ${ }^{41} \mathrm{Ar},{ }^{13} \mathrm{Xe}$, and ${ }^{135} \mathrm{Xe}$ will usually be the most important. Irradiated fuels are typically stored 6 mopths or more before reprocessing, so only the longer-lived nuclides, such as ${ }^{85} \mathrm{Kr}$, are expected to be found in the environment around a reprocessing plant. Krypton-85, $4 \mathrm{I}_{\mathrm{Ar}}, 133 \mathrm{Xe}$, and ${ }^{135} \mathrm{Xe}$ are measured by gamma coypting. For facilities involving ${ }^{226} \mathrm{Ra}$ or thorium, the release of ${ }^{222} \mathrm{Rn}$ or ${ }^{22} \mathrm{Rn}$ will need to be considered.

\subsubsection{Water}

A major concern in the measurement of radionuclides in water is the preservation of the samples before counting, especially if the distribution of radionuclides between an aqueous and a solid phase is desired. Continuing chemical and biological action in the samples can cause changes in the chemical and physical form, deposition on the container walls, and removal of the radionuclides to biological growths. Phenomena that should be considered incl ude

1) Ion exchange of cations between the sample and the container wal $\mathbf{s}$ (cesium, for example, can exchange with potassium in glass)

2) The absorption of radionuclides by algae or slime growths on con tainer walls or particulate materials

3) The hydrolysis and resulting sorption of radionuclides on container walls or particulates (this is especially likely at the low acidities typical of natural waters and some process streams)

4) The formation of large flocculent particles from radiocolloids resulting in additional plate-out

5) Change in the distribution of radionuclides between aqueous and solid phases as a result of sample pretreatment (e.g., acidification leaching radionuclides from suspended particles)

6) The conversion of iodides to iodine by biocides, followed by the loss of iodine by vaporization

7) The quenching of liquid scintillation cocktails by acids 
8) The change of counter geometries by the settling of particles or by their fixation on container walls.

The report EPA 625/6-64-003 1 ists various preservation methods and permissible storage times for water samples according to chemical species. Current practice at most nuclear installations is to predose the sample container with an acid [typically 2 to $3 \mathrm{~mL}$ concentrated $\mathrm{H}_{2} \mathrm{SO}_{4}$ or $\mathrm{HNO}_{3}$ (depending on compatibility with subsequent chemistry) per litêr of samplë], to inhibit biological growth and plate-out of dissolved ions on the container wall. Pretreatment of the sample container with a salt solution of the same chemical species as the radionuclide to be measured can help minimize wall adsorption. Keeping the sample container refrigerated and shielded from 1 ight inhibits biological growth. Filtration during sample collection can be effective for some situations. The radioanalytical procedures to be used and the purpose of the measurements should govern what, if any, pretreatment is used, because the procedures can be adversely affected by additives used to preserve other radionuclides. Optimum preservation procedures should be determined by local testing. The concentrations of gamma-emitting radionuclides in whole water samples should be measured directly by gamma-ray spectrometry, if such concentrations are high enough for determination. For accurate measurements, the radionuclide distribution should be uniform throughout the sample. If solids settle out of the sample, the geometry of the sample is changed, which makes it necessary to filter the water and count both the filter and the filtered water. If the distribution of the radionuclides between the solid and the aqueous phases is desired, the water sample should be filtered during or as soon as possible after collection, before acidification, and the water and filter counted separately. If additional precipitate develops later, the water should be filtered again just before counting. However, the precipitate in this case should still be considered to be part of the liquid phase. If concentrations of gamma emitters are too low to be measured in the whole sample, the sample should be concentrated by evaporation or placed in a 2-Pi counting configuration to maximize detector efficiency. If the concentrations are still too low to be measured in an evaporated sample, or if beta or alpha emitters are to be measured, the radionuclides to be measured should be chemically separated using procedures that will be determined by the radionuclides requi red.

\subsubsection{Soil and Sediments}

Since the water content of samples can vary widely, soil and sediment samples should be dried according to procedures that have been established for the measurement program, and the measured radionuclide concentrations reported on a dry-weight basis. Oven-drying temperatures ranging from $80^{\circ} \mathrm{C}$ to $130^{\circ} \mathrm{C}$ can be used; however, a fixed temperature, such as $110^{\circ} \mathrm{C}$, should be used for all samples. The oven temperature should be set according to the substance being analyzed for; $8, \mathrm{~g}$., use an oven temperature of $100-105^{\circ} \mathrm{C}$ for samples containing volatile organic compounds. Freeze-drying (drying under vacuum) is an excellent but expensive alternate method for drying samples. It is especially useful for large samples that contain considerable organic matter, which could undergo combustion during oven-drying. The loss of radionuclides by volatilization and by frothing and spattering during drying is also 
minimized by freeze-drying. Soil and sediment samples can be counted directly for some gamma-emitting radionuclides if the concentrations are high enough. However, to obtain accurate results, the samples should be homogeneous. So that soil samples are homogeneous, they should be ground to a small particle size and homogenized before counting. To determine the particle size distribution of the radionuclides, sieves can be used to separate the original sample into particle-size fractions. Small rocks and pebbles should be separated from the sample before counting. Radionuclides of interest in soil and sediment samples should be chemically separated where necessary to obtain the desired sensitivity. High concentrations of gamma-emitting radon and thoron decay products in soil can interfere with the measurement of low concentrations of other gamma-emitting radionuclides. Alpha and beta emitters cannot be measured directly, unless they are present in high concentrations, because of the short range of the alpha and beta particles and the high concentrations of alpha and beta emitters in the uranium and thorium decay chains.

\subsubsection{Biological Materials}

In some cases gamma-ray spectrometers can be used to measure gammaemitting radionuclides in biological samples without performing chemical separations. Where appropriate, freeze-drying can be used to decrease the weight of the sample. However, when large amounts of biological material are present, wet-or dry-ashing and chemical separations should be performed before counting the samples, especially in the case of alpha- or beta-emitting radionuclides. The choice of whether to wet- or dry-ash a sample is dependent on its properties, such as mass, bulk, physical form, oxidation resistance, and volatility of the desired constituents. Dry-ashing is simpler but could result in the loss of elements that are volatile at ashing temperatures. Also, refractory residues can form, and part of the desired material could even combine with the container. Porcelain, silica, nickel, and platinum all have an affinity for certain elements at ashing temperatures. These problems can be minimized by ashing at lower temperatures, such as $400^{\circ} \mathrm{C}$ to $450^{\circ} \mathrm{C}$, but this prolongs the ashing process. Also, many samples can ignite, producing local temperatures that are far in excess of furnace temperatures (HASL-300). Wet-ashing is more tedious, particularly for large samples, but volatilization during wet-ashing will occur only with extremely volatile elements such as iodine or bromine. Therefore, wet-ashing is preferable when there is no direct evidence that dry-ashing is suitable for the particular sample. Wetashing also has the advantage that carriers can be added directly during the ashing process (HASL-300). The major oxidizing agent used is nitric acid, and frequently the complete oxidation can be carried out with this agent alone. The addition of sulfuric or perchloric acid to assist oxidation is sometimes useful, but it can lead to the formation of insoluble compounds such as barium sulfate, calcium sulfates, or potassium perchlorate. In addition, high temperatures are reached when these acids are evaporated, which can lead to increased volatilization loss. Kjeldahl treatment can provide rapid ashing in cases where the added sulfuric acid does not present a problem (HASL-300). 


\subsubsection{Sample Preservation}

It is essential to maintain the integrity of samples ( $i, e$, , to minimize degradation of samples by using proper preservation and handling practices that are compatible with analytical methods). Degradable biological materials should be kept frozen until they are processed. A small amount of acid should generally be added to water samples to inhibit biological growth and the plate-out of dissolved materials on the container walls. However, acid should not be added in cases where the sample contains radionuclides that are volatile in acid solutions. A reducing agent, such as $\mathrm{Na}_{2} \mathrm{SO}_{3}$, should be added to solutions containing I or I I prevent the formation and loss of $I_{2}$. Refrigeration, shielding from light, and filtration should be used when necessary to prevent biological growth and deposition on container walls.

\subsubsection{Sample Archiving}

Sample archiving refers to the storage of samples for a period longer than is normally required to perform the routine sample analysis and result verification. Samples may be archived either before or after sample preparation and analysis. Routine sample analysis and result verification should normally be completed within 90 days of collection. However, special conditions might exist any time that routine sample analysis activities are disrupted. In these cases, it may be necessary to consider the factors listed below even for routine samples.

Decisions to archive environmental samples should be based on an identified future need for the sample. The decision to archive samples should be documented and re-evaluated on an annual basis for archive periods greater than one year.

For most cases, long-term archiving may not be required. However, special samples (e.g., those associated with accidents or those obtained to respond to public concerns) might be candidates for archiving. For periods when routine analysis activities may be interrupted or otherwise incapable of providing analysis results, the need for short-term archiving (i.e., months to a few years) of representative samples from routine environmental surveillance should be considered. The need for archiving special samples for longer periods (i,e, tens of years) should also be addressed.

The following factors should be considered when making a decision to archive samples:

1) Suitability of analyte - Determine the suitability of the radionuclide for archiving. For example, short-lived nuclides can be stored for only a short time before radioactive decay makes the sample unusable for analysis. The minimum detection limit of the analytical methods should be considered. Radionuclides that are in a volatile physical form, such as organics, also may not be appropriate for archiving. These factors should be considered in conjunction with the archive period expected. For example, the archiving of charcoal filters for analysis of 1-131 
(8-day half-life) would be inappropriate, in contrast to archiving them for analysis for $1-129$ (1.6 $\times 10$-year half-life).

2) Media compatibility - Determine whether the medium can be archived and for what period of time. For example, milk can be very difficult to store, as it spoils on the shelf and thickens when frozen and thawed. Normally, liquid samples are not suitable for archiving over long periods. Consequently they should normally be retained for short periods only. In most cases, only solid samples or filters can be archived for extended periods. These types of samples are generally ashed or require no special treatment prior to analysis, and media compatibility is less of a concern.

3) Special sample preparation for storage - Prior to archiving, special sample preparation that is different from that normally used in preparation for analysis may be required. It may be necessary to partition the sample before archiving for subsequent evaluation of different radionuclides. For example, water samples may be acidified to prevent algal growth or plateout of particulate radionuclides. However, acidification may cause the loss of any tritium and radioiodines present. Vegetation may be carefully dried to prevent decay; however, volatile substances may be lost during drying. It may be necessary to place heavily loaded air filters on metal planchets inside Petri dishes to he $\mathrm{P}$ prevent dust loss during handling and storage.

4) Type of container - Consideration should be given to the suitability of the container for long-term storage. Nuclides may tend to plate out or be absorbed into the walls of some types of containers. Containers must not degrade during the expected archive period and should be resistant to attack from insects and mice, the problem of mice being of particular concern for plastic storage bags. Containers may be required to prevent light from reaching and degrading the sample, or double containment may be necessary to guard against breakage and loss of sample or spread of contamination.

5) Sample analysis - The type of analysis performed on a sample that has been archived may be quite different from that performed on fresh samples, and special laboratory procedures may be needed. For example, particulates may settle out of liquids that have been stored for long periods and may have to be resuspended. It may be necessary to rinse the planchet holding heavily-loaded air filters with nitric acid to collect dust shaken loose from the filter. Analysis of milk may normally be done by passing it through a resin column; however, analysis of an archived, thickened product would necessarily be quite different, and the difference may limit the types of radionuclides that could be analyzed for. The possible ingrowth of radioactive decay products should be considered.

6) Quality assurance - Ensure that samples are properly logged and stored, and that sample accountability is maintained and documented. Maintaining sample accountability is critical in determining the future usefulness of 
the sample, regardless of sample storage or analysis capabilities. Sample archiving should be addressed in the Quality Assurance Plan associated with the facility.

7) Storage capability - The quantity of shelf space, freezer space, or special storage needed, as well as light or darkness requirements, should be determined based on the period over which samples are to be collected and archived. The need for physical security and restricted access should also be considered.

8) Impact on routine program - For ongoing analysis programs, consider the impact that future analysis of archived samples will have on the capacity for routine analyses under way in the future. Analyzing archived samples may adversely impact future routine analyses of samples by overloading laboratory capacity.

9) Data compatibility - Data obtained from archived samples should be compatible with and comparable to existing data. Any proposed change in analytical techniques or data analysis methods should be evaluated and their effect determined before they replace current methods on actual samples or sample data. A side-by-side comparison of the current and proposed methods on sample aliquots or duplicates should be considered.

10) Sample disposal - Determine the possible impact of disposal of samples that have been archived but not analyzed. Consider whether the samples will be disposed of as low-level radioactive waste, hazardous waste, .or mixed waste, and any special disposal or storage requirements under RCRA.

\subsection{ANALYSIS METHOD AND CAPABILITIES}

Excel lent references for analytical methods are APHA (1977, 1985), IDO-12096, EMSL-LV-0539-17, EPA-R4-73-014, EPA-600/4-80-032, EPA-520/5-84-006, and HASL-300. Drinking-water samples should be analyzed using EPA procedures where such methods are available and adequate for the radionuclides of interest. Alternate methods can be used in cases where satisfactory EPA-approved methods are either not available or not adequate. However, such alternate methods should have documented or documentable evidence showing that they give reliable results.

\subsection{GROSS ALPHA, BETA, AND GAMMA MEASUREMENTS}

Gross alpha and beta measurements should not be used to characterize a sample. Sample characterization should be done using radionuclide-specific analyses. However, gross alpha and beta measurements can be useful in determining the general activity level of the sample so that proper choices can be made regarding the size of the sample and the appropriate chemical separation procedures. Gross alpha and gross beta measurements should be made using a gas-proportional counter. Gross gamma measurements should be made using gamma-ray spectrometers. 


\subsection{DIRECT GAMMA-RAY SPECTROMETRY}

Gamma rays should be measured directly using sodium iodide thallium activated crystals [ $\mathrm{NaI}(\mathrm{Tl})$ ], lithium-drifted germanium diodes [Ge(Li)] or hyper-pure germanium type detectors (HPGE). The energy resolution of $\mathrm{NaI}(\mathrm{Tl})$ crystals is much poorer and the background is much higher than those of germanium diodes, which severely limits the number of radionuclides that can be measured in complex mixtures using $\mathrm{NaI}(\mathrm{Tl})$ crystals. However, $\mathrm{NaI}(\mathrm{TI})$ detectors are stili useful on samples that have relatively simple spectra or on radiochemically separated samples. For low-energy photons, IG diodes are somewhat more efficient than $\mathrm{Ge}(\mathrm{L} \mathrm{i})$ diodes.

\subsection{BETA COUNTERS}

Beta-emitting radionuclides should be measured using ionization, gasproportional, or liquid scintillation counters. Carbon-14 is often converted to a gas, such as $\mathrm{CO}_{2}$ or $\mathrm{CH}_{4}$, which is used as the counter gas during counting. Most beta emitters are counted with the sample outside the counter. A commonly used counter consists of a hemispherical chamber with a window on the flat end. The counter window can be covered with a thin polyester film. If the window is not covered with a polyester film, the sample holder must be attached to the counter in such a manner as to prevent the escape of gas through the window. In a liquid-scintillation counter, the sample is dissolved in scintillating liquid and placed in a standard-sized vial. Beta particles impinging upon the scintillating liquid in the vial produce light flashes that are measured using photomultiplier tubes.

\subsection{ALPHA-ENERGY ANALYSIS}

High-resolution alpha spectrometry using silicon surface barrier detectors should be used to determine the concentrations of alpha-emitting radionuclides in thin, uniform samples or in samples that can be deposited as thin, uniform sources. The accuracy and sensitivity of the measurements decrease considerably with increasing sample thickness because the matrix absorbs and scatters alpha particles. Therefore, chemical separations followed by the formation of thin deposits are necessary for more massive samples. Chemical separations are also necessary to resolve radionuclides that emit al pha particles with energies that differ by less than about $50 \mathrm{keV}$. Electrodeposition is the method that should be used to produce thin, uniform sources. However, the wide range of environmental and biological samples makes it difficult to develop electrodeposition procedures that can handle all types of samples. A coprecipitation method using rare earth compounds, such as neodymium or lanthanum fluoride, to separate actinides can provide a sample mount that in many cases is equivalent to an electrodeposited sample. Alpha spectrometry should be used primarily for the analysis of actinide radionuclides because the concentrations of these radionuclides in environmental samples are often near the detection limits of the alpha spectrometer, and because large samples are often needed to produce detectable counting rates. Therefore, very efficient separation procedures are needed to decrease the concentrations of 
impurities in the deposited samples. Most deposition procedures are very sensitive to hydrolytic losses; even microgram quantities of impurities can cause problems wi th yield and resolution.

\subsection{RADIOCHEMICAL SEPARATION PROCEDURES}

Innumerable radiochemical separation techniques have been used by various investigators to separate the radionuclides being evaluated from interfering radionuclides. No general set of separation procedures can be specified that will apply to all conditions at all DOE sites. However, standard (professionally accepted) methods should be used when separating radionuclides from interfering radionuclides.

\subsection{REPORTING OF RESULTS}

The reported analytical results should include the $2 \sigma$ uncertainty limits. The reported uncertainty limits should be calculated from the statistical counting error and as many other sources of error as can be identified. Each random error should be reported separately. The concentrations should be reported as calculated even when they are less than the error limits or negative, because such concentrations are required for the statistical analysis of the data. Values that are negative or below detection limits should be reported using a symbol and stating, in a footnote to the table, that the value is below the lower i imit of detection. In all cases, the error limit should be given so that a detection limit can be inferred. The results for short-lived radionuclides should be decay-corrected to the midpoint of the sample-collection interval.

\subsection{COUNTER CALIBRATION}

Proper and timely calibration of counting equipment is essential if accurate analytical results are to be obtained. Except in gamma-ray spectrometry when NIST-traceable standards are used to prepare counting efficiency curves, each counter should be calibrated for each radionuclide to be measured using standards traceable to the NIST. The standard should have the same geometry and matrix as the sample to be counted, and the standard should be well-mixed and remain well-mixed throughout the matrix that is used to produce the standard geometry. Many different procedures have been used to produce standards of different shapes and sizes. A recommended procedure for calibrating a gamma detector for solid samples is one in which the standard is pipetted onto $\mathrm{Al}_{2} \mathrm{O}_{3}$ powder. After the standard has dried, the $\mathrm{Al}_{2} \mathrm{O}_{3}$ powder is mixed thoroughly. The powder is then mixed thoroughly with an epoxy resin, which later solidifies to produce a solid that is very resistant to breakage and will not allow the standard to migrate. If a gamma counter is calibrated for several radionuclides, a plot of efficiency versus energy should be prepared and used to identify errors in the calibration of individual radionuclides and to determine the efficiencies of radionuclides for which standards are not available. 


\subsection{INTERCALIBRATION OF EQUIPMENT AND PROCEDURES}

Interlaboratory exchanges of samples should be carried out to determine whether the laboratories are obtaining the same results, and to eliminate any problems that are causing discrepancies. If samples are available that have not been chemically separated but are still known to be homogeneous, aliquots of these samples should be exchanged so that both the separation procedures and the counting equipment can be compared.

\subsection{COUNTER BACKGROUND}

One of the major factors that determines the sensitivity of the measurement procedures is the background of the counter. Therefore, the counter background should be reduced as much as possible. The counter should be shielded with lead or other materials, such as borated paraffin (to absorb neutrons). However, lead shielding will not significantly reduce the background caused by high-energy cosmic rays. The background from cosmic rays can be reduced by surrounding the sample counter with an anticoincidence counter(s). When primary cosmic rays interact with atmospheric gases, they produce showers of secondary cosmic rays that will produce simultaneous counts in the sample counter and the anticoincidence counter(s). Radiation that is emitted by the sample generally will not produce pulses in both the anticoincidence and the sample counters. The pulses in the sample counter that are simultaneous with pulses in the anticoincidence counters are then automatically rejected. The background of the counter should be kept low by preventing the contamination of the counter by radioactive materials. Such contamination not only would raise the background, but also would result in spurious measurements. Therefore, backgrounds should be measured regularly, and the counter decontaminated if background measurement shows evidence of contamination.

\subsection{QUALITY ASSURANCE}

As they apply to laboratory procedures, the general quality assurance program provisions of Chapter 10 should* be followed. Specific quality assurance activity requirements for laboratory operations at a site should be incorporated in the facility's plan for quality assurance. 


\subsection{DATA ANALYSIS AND STATISTICAL TREATMENT}

Good data analysis and statistical treatment practices are essential for the production of quality results from the effluent monitoring and, environmental surveillance program required by DOE 5400.1 and DOE 5400.5. The goals for analyzing effluent monitoring and environmental surveillance data should be

- To estimate radionuclide concentrations at each sampling and/or measurement point for each sampling and/or measurement time, and estimate accuracy and precision

- To compare the estimated radionuclide concentrations at each sam$\mathrm{pl}$ ing and/or measurement point to previous concentration estimates at that point to identify changes or inconsistencies in radionuclide levels

- To compare the radionuclide concentrations at each sampling and/or measurement point to the established limit(s), or concentrations related to the applicable dose limit, for those radionuclides

- To compare radionuclide concentrations at single sampling and/or measurement points or groups of points to those at control or other points and evaluate the reliability of those comparisons.

The statistical techniques used to support the concentration estimates, to determine their corresponding measures of reliability, and to compare radionuclide data between stations and times should* be designed with consideration of the characteristics of effluent and environmental data. These characteristics include a time series of data with skewed distributions (usually lognormal), a high degree of variability, and often large amounts of missing data and readings that are below the detection limit of the sample analysis technique. Documented and approved sampling, sample-handling, analysis, and data-management techniques should* be used to reduce variability of the results as much as possible. Data generated by the effluent monitoring and environmental surveillance program form the bases from which site management decisions are made. Thus, adequate attention to estimating the accuracy and precision of the data is necessary to determine whether such management decisions and actions are supported by valid and reliable data.

\subsection{SUMMARY OF DATA ANALYSIS AND STATISTICAL TREATMENT REOUIREMENTS}

The data analysis and statistical treatment procedures that are required to be incorporated into the radiological effluent monitoring and environmental surveillance program at a DOE site are presented in the summary. The level of confidence in the data due to the radiological analyses should* be estimated by analyzing blanks and spiked pseudosamples and by comparing the resulting concentration estimates to the known concentrations in those samples. The precision of radionuclide analytical results should* be reported as 
a range, a variance, a standard deviation, a standard error, and/or a confidence interval. Analytical precision estimates for radiological analyses should be made from replicate samples. Data should* be examined and entered into the appropriate data bases promptly after analysis. When selecting the data to be considered; outliers should* be excluded from the data only after investigation confirms that an error has been made in the sample collection, preparation, measurement, or data analysis process. As each data point is collected, it should* be compared to previous data, because such comparison can help identify unusual measurements that require investigation or further statistical eval uation.

\subsection{VARIABILITY OF EFFLUENT AND ENVIRONMENTAL DATA}

The variability of the effluent data will determine the degree of precision and accuracy that can be achieved with the results. Careful design and execution of the monitoring program can substantially improve the quality of the effluent monitoring and environmental surveillance results.

\subsubsection{Sources of Variabilitv in Effluent/Enyironmental Data}

The sources of variability in effluent data are listed in Table 7-1. These sources can be divided into three types: environmental, sampling, and recording. The analyses performed to determine and reduce the sources of variability should consider the relevancy of the variability source with respect to the actual conditions at the sampling and/or measurement point.

\subsubsection{Estimating Accuracv and Precision}

An estimate of the levels of accuracy and precision required for the data, based on previous site monitoring and surveillance experience, should be used to develop data analysis and handling strategies for the effluent monitoring and environmental surveillance programs. These strategies should then be re-evaluated periodically (or after significant modification to site conditions) to determine whether they are adequate for the present site conditions.

\subsection{SUMMARIZATION OF DATA AND TESTING FOR OUTLIERS}

Often, a measure of central tendency is needed to summarize the information in a data set (e.g., in the calculation of a yearly average concentration). In addition, an estimate of precision is required for that summary statistic. Assumptions about the underlying data distribution are inherent in the calculation of most statistical parameters; therefore, the distribution of the radionuclide concentration data should be established before the calculated parameters are considered valid.

\subsubsection{Distribution Analysis}

The assumption of a normal data distribution is implicit in the calculation of most statistical parameters. Radionuclide distributions are typically 
TABLE 7-1. Sources of Variability in Effluent Monitoring Data (00E/EP-0023)

\begin{tabular}{|c|c|c|}
\hline Type & Source & Examples \\
\hline \multirow[t]{3}{*}{ Environmental } & Space & $\begin{array}{l}\text { Distance from emission source, eleva- } \\
\text { tion, heterogeneous dispersion of } \\
\text { material }\end{array}$ \\
\hline & Time & $\begin{array}{l}\text { Variation in rates of emissions, } \\
\text { variation in rates of dispersion }\end{array}$ \\
\hline & Space $x$ Time & $\begin{array}{l}\text { Nonstationary differences between } \\
\text { sampling stations over time }\end{array}$ \\
\hline \multirow[t]{5}{*}{ Sampl ing } & $\begin{array}{l}\text { Sample } \\
\text { Collection }\end{array}$ & $\begin{array}{l}\text { Nonrepresentative sampling, incon- } \\
\text { sistent sampling techniques, sampling } \\
\text { equipment failure }\end{array}$ \\
\hline & Sample Handling & $\begin{array}{l}\text { Chemical reactions, nonuniform storage } \\
\text { conditions, container effects }\end{array}$ \\
\hline & $\begin{array}{l}\text { Sample } \\
\text { Processing }\end{array}$ & $\begin{array}{l}\text { Volume or weight measurement errors, } \\
\text { insufficient sample mixing, nonrepre- } \\
\text { sentative subsampling }\end{array}$ \\
\hline & Measurement & $\begin{array}{l}\text { Calibration errors, instrument errors, } \\
\text { readout errors }\end{array}$ \\
\hline & $\begin{array}{l}\text { Cross- } \\
\text { Contamination }\end{array}$ & $\begin{array}{l}\text { Residual contamination of containers } \\
\text { and work areas, imperfect sealing of } \\
\text { containers for transport, surface con- } \\
\text { tamination from transport, separation } \\
\text { of high- and low-activity samples, } \\
\text { decontamination practices }\end{array}$ \\
\hline Recording & $\begin{array}{l}\text { Data Recording } \\
\text { and Transfer }\end{array}$ & $\begin{array}{l}\text { Errors in data entry, errors in } \\
\text { transfer of data from lab books to } \\
\text { computer files }\end{array}$ \\
\hline
\end{tabular}

lognormal, and when appropriate, the raw data should be transformed to logarithms before calculating summary statistics.

Data sets with more than $\mathbf{1 0}$ points should be tested for normality. (Data sets containing fewer than $\mathbf{1 0}$ points can be treated as either normal or lognormal.) The simplest and most straightforward test involves plotting the data points on commercially available normal or lognormal probability paper. If the data form an approximately continuous straight line, it can be concluded that the data are homogeneous and from a distribution of the same type as the probability paper (normal or lognormal) on which they are plotted. 
Severe discontinuities in the straight line indicate that different subsets of the data, coming from different distributions, are involved. When such conditions occur, the data should be reexamined and identifiable subsets analyzed separately. Curvilinearity in the plot indicates that a data transformation is required before statistics based on the normal distribution are calculated.

Other acceptable methods of assessing normality are to plot all of the data in a frequency distribution and perform a $\chi^{2}$ test for normality, or to visually inspect a histogram of the data. The method of assessing normality should be presented in reports of the data.

\subsubsection{Measures of Central Tendencv}

The appropriate measure of central tendency depends on the characteris tics of the radionuclide concentration data collected. For normally distributed data with only a small number of extreme or less-than-detectable values, the arithmetic mean is the appropriate estimator of central tendency. When the data set contains large numbers of extreme values or concentrations below the analytical detection limits, the median, which is less sensitive to extreme values than the mean, should be used to summarize the data. Trimmed means (arithmetic means calculated while excluding some percentage of the upper and lower data values) can also be appropriate in these cases.

The data should be transformed to approximate a normal distribution before the central values are calculated. Most often a log transformation will normalize environmental data.

The mean of a distribution can be read from a plot of the data on probability paper. The mean (which in the case of the normal distribution is equal to the median) is the 50th percentile intercept on the probability plot.

\subsubsection{Measures of Dispersion}

Dispersion in normally distributed data, without large numbers of outliers and less-than-detectable values, should be represented as a variance, a standard deviation, a standard error, or a confidence interval. Again, data should be transformed if necessary to approximate a normal distribution.

For data with substantial numbers of extreme values, other measures should be used to estimate the dispersion around the central value. The full range of data values or the interquartile range (the range of data between the 25th and 75th percentiles) and the median absolute deviation (the median of the differences between each data point and the indicator of central tendency) are also acceptable measures.

The slope of the line drawn through the data points plotted on probability paper is the standard deviation of the data. 


\subsubsection{Less-Than-Detectable Values}

Monitoring programs often include measurement of extremely low concentrations of radionuclides, below the detection limit of the counting instruments. Data sets with large numbers of less-than-detectable values need special consideration in the statistical analyses (Gilbert 1987).

Less-than-detectable data will produce numerical measurements with values below the detection limit and sometimes negative values. All of the actual values, including those that are negative, should be included in the statistical analyses. Practices such as assigning a zero, the detection limit value, or some in-between value to the below-detectable data point, or discarding those data points can severely bias the resulting parameter estimates and should be avoided.

When analytical instruments or laboratories do not supply the actual values for readings less than the detection limit, but make some designation such as "NO," the actual values for those data points should be obtained. When obtaining these data points is not possible, at least the number of lessthan-detectable values should be obtained. Data from censored distributions (for which the number of less-than-detectable values is known) are more amenable to standard statistical analyses than are those from truncated distributions (for which the number of values below the detectjon limit are not known), which require special statistical techniques (Gilbert and Kinnison 1981).

\subsubsection{Testing for Outliers}

An outlier is defined as an abnormally high or low data value. It can represent a true extreme value, or it can indicate data errors or equipment malfunctions or errors. It is important to compare each data point to previous data to determine whether the point is an outlier or a true data point that is to be included in the data set (Gilbert 1987).

Several statistical tests are available to test for outliers. Most of these tests assume a normal distribution, so data should be transformed to approximate the normal distribution before outlier tests are performed. Outliers can be identified qualitatively by adding the new data point to the data probability plot and noting if the point falls on an extreme end of the plot line; alternatively, a 2- or 3-standard-deviation probability ellipse can be constructed around a scatterplot of all of the data, with points falling outside of that ellipse considered outliers. These tests, while statistically valid (as long as their assumptions, e.g., normality, are met), determine only whether the new point is extreme with respect to the mean or median of the entire data set and do not detect temporal irregularities (for example, data values that are close to a yearly average but highly unusual for the season or time of day at which they occurred). Therefore, these tests are not adequate to serve as the sole justification for the inclusion or exclusion of data from the set. A better procedure that takes into consideration the temporal 
pattern of the observations involves the development of a time plot of the data, with each new data value being entered promptly after collection. Outliers can be identified by inspection of the time plot. Control charting can also be a useful technique for identifying outliers. Control charts are time plots on which the center line represents the mean or median concentration value, and 1-, 2-, and 3-standard-deviation bands are marked. Data points falling outside of the 2- or 3-standard-deviation confidence bands are considered outliers. The position of the center line can differ diurnally, seasonally, or yearly. The central values should be calculated separately for identified subgroups of the data. Control charting is not useful for some new monitoring programs because they require sufficient amounts of data to adequately estimate the mean value and standard deviation for each subgroup. Graphs of moving averages of the data should also be plotted for each station, as soon as sufficient amounts of data (at least 10 points) are acquired. These plots will indicate overall trends in the data, identification of which aids in data interpretation as well as in detecting sampling or equipment errors.

When outliers are identified, a decision must be made whether to include those numbers in estimates of radionuclide concentrations or in comparisons between data sets. Outliers can represent true extreme values or can indicate malfunctions or failures in sampling equipment or variability in sample quality. Most often what at first appear to be outliers prove to be data transcription errors. The presence of outliers can, however, severely affect the value of the estimated mean or the outcome of statistical comparisons. When outliers that are not attributable to errors are contained in the data set, estimators and statistical tests should be computed with and without the outliers to see if the results of the two calculations are markedly different. If the results differ substantially because of outliers in the data, then both results should be reported.

\subsubsection{Elements of Good Practice}

Certain procedures should be followed that will aid in the interpretation of the effluent monitoring data and improve the quality of the results

from the program by helping to detect erroneous measurements. Comments on the quality of the samples taken should be entered into the data base with the sample radionuclide concentration measurements. In addition to the data collected during the regular sampling program, logs of events that might affect radionuclide concentrations (e,g, , precipitation) should be kept.

\subsection{TREATMENT OF SIGNIFICANT FIGURES}

Often, calculations involving measured values result in numbers with more significant figures than were in the original measurements and give an erroneous impression of the precision and accuracy of results. The number of significant figures in reported data should reflect the precision of the measured values. A larger number of figures may be carried during the calculations for computational accuracy. The number of significant figures reported for raw data should reflect the true precision of the measurement technique. 
When measurements are multiplied or divided, the number of significant figures in the product or quotient should not exceed that of the least precise measurement used in the calculations. When measurements are added or subtracted, the recorded precision of the result should not exceed that of the least precise measurement.

\subsection{PARENT-DECAY PRODUCT RELATIONSHIPS}

A common practice in the monitoring of radionuclide concentrations is to measure the activity of the parent radionuclide and calculate the amount of the decay products present from the known physical relationships. As an alternative, the concentrations of parent nuclides may be calculated from the measurement of the decay products. These calculations are relatively straightforward when the parent and decay products are at equilibrium, and in the absence of contrary data. Corrections should be made for calculations performed during the transitory period before equilibrium is reached. Correct estimation of the amount of the decay product (or parent) material present requires definite knowledge of the difference between the time of measurement and the time of the initiation of parent decay. The recorded accuracy and precision of the calculated radionuclide concentration estimates, as indicated by number of significant figures, should not exceed those of the original measured concentration. Uncertainties in the length of time between measurement and the initiation of parent decay should be reported and incorporated into the precision estimates for the calculated concentrations.

\subsection{COMPARISONS TO REGULATORY OR ADMINISTRATIVE CONTROL STANDARDS AND CONTROL DATA}

The object of obtaining reliable estimates of radionuclide concentrations at the monitoring stations is to compare those values to regulatory or administrative control standards or values at control stations to determine whether action must be taken to reduce the radionuclide levels in the effluents.

\subsubsection{Sinqle Concentration Measurements}

Statistical tests are not appropriate for comparisons of single values, such as when a single radionuclide concentration measurement is compared to its regulatory 1 imit. Single values can have a large associated uncertainty, and they are not necessarily an accurate representation of how well the facility is complying with the limit. Thus, additional sampling and/or measurement should be considered to provide an accurate representation of compliance status.

\subsubsection{Groups of Measurements}

Concentration estimates from groups of sampling and/or measurement points should be compared using standard (parametric) analysis of variance techniques (Winer 1971) when the data meet the underlying assumptions of those 
tests. Standard nonparametric statistical comparison techniques (Hollander and Wolfe 1973) should be used when the assumptions of the parametric tests are not met by the data. Caution should be used when comparing groups of readings from single points over time, because of the likely strong autocorrelation in the time series of data.

\subsection{QUALITY ASSURANCE}

As they apply to data analysis and statistical treatment activities, he general quality assurance program provisions of Chapter 10 should* be followed. Specific quality assurance activity requirements for data analysis and statistical treatment activities at a site should be incorporated in the Quality Assurance Plan for the facility. 


\subsection{DOSE CALCULATIONS}

For operating DOE-controlled facilities, DOE 5400.1 and DOE 5400.5 describe the annual reporting requirements for releases of radioactive materials to the environment. In addition to the summary of total curies (by radionuclide) in airborne and liquid effluents released to the offsite environment, these Orders require the reporting of estimates of the effective doses to the population and to the maximally exposed individual in the vicinity of DOE-controlled facilities. The offsite dose estimates require detailed knowledge (or estimates) of the concentrations of radionuclides in the facility effluents and emissions and in various environmental media resulting from site operations. Samples of air, soil, water, and vegetation, and direct readings of external radiation can be used to determine these offsite concentrations. However, in most cases these concentrations are very low and challenge the sensitivity of the analytical techniques used. As a result, estimates of environmental concentration and human exposure and the resulting estimated radiation dose are frequently made using mathematical models that represent various environmental pathways. For situations where available environmental data are sufficiently accurate to determine radionuclide concentrations, their use in the dose assessment process is encouraged. For the purposes of this Order, the following basic definitions are used:

- Hodel - A mathematical formulation or description of a physical, ecological, or biological system, which includes specific numeric values or parameters

- Computer Program - The logical computer language statements in an executable form on a digital computer that represents the model (mathematical formulation) and appropriate data.

\subsection{PERFORMANCE STANDARDS FOR PUBLIC DOSE CALCULATIONS}

\subsubsection{Required Standards}

The requirements to be followed when calculating public radiation dose are listed in the summary. DOE programs for surface- and ground-water monitoring, reporting, and modeling are under consideration by the DOE Office of Environmental Guidance and Compliance; thus, few details on these subjects are provided in this guide. These requirements will be broad enough to define conditions for radionuclides and associated chemicals that could enter surface or ground waters. Except where mandated otherwise (e,g., compliance with 40 CFR Part 61), the assessment models selected for all environmental dose assessments should* appropriately characterize the physical and environmental situation encountered. The information used in dose assessments should* be as accurate and realistic as possible. Complete documentation of assessments of the radiation dose resulting from the operation of DOE-controlled facilities should* be provided in a manner that supports the annual site environmental 
monitoring report, Environmental Monitoring Plan, or other application, and show the 1) models used, 2) computer programs used, and 3) input data and data source assumptions made.

\subsubsection{Documentation and Conformance with Other Reauirements}

Default values used in model applications should" be documented and evaluated to determine appropriateness to the specific modeling situation. When performing human foodchain assessments, a complete set of human exposure pathways should* be considered, consistent with current methods (IAEA 1982; Moore et al. 1979; NCRP Report No. 76; NUREG/CR-3332). Surface- and ground-water modeling should* be conducted as necessary to conform with the applicable requirements of the State government and the regional office of the EPA.

\subsection{MAJOR CONSIDERATIONS}

The basic considerations in performing an analysis of dose to the genera public for the annual releases of radioactive materials from DOE facilities are shown in Figure 8-1. Source-term estimates (box 1 in Figure 8-1) are obtained from the effluent monitoring programs established for each site, as described in Chapters 2 and 3 of this Order. Models (boxes labeled 2 in Figure 8-1) are then applied for atmospheric, surface-water, and ground-water transport. Environmental pathway analysis models (box $\mathbf{3}$ in Figure 8-1) are then used to account for bioaccumulation in food products and the annual usage or uptake of materials by members of the public. The dose-rate factors (boxes labeled 4 in Figure 8-1) to be used are the standard factors listed in the EPA publication Limiting Values of Radionuclide Intake and Air Concentration and Dose Conversion Factors for Inhalation, Submersion, and Inqestion

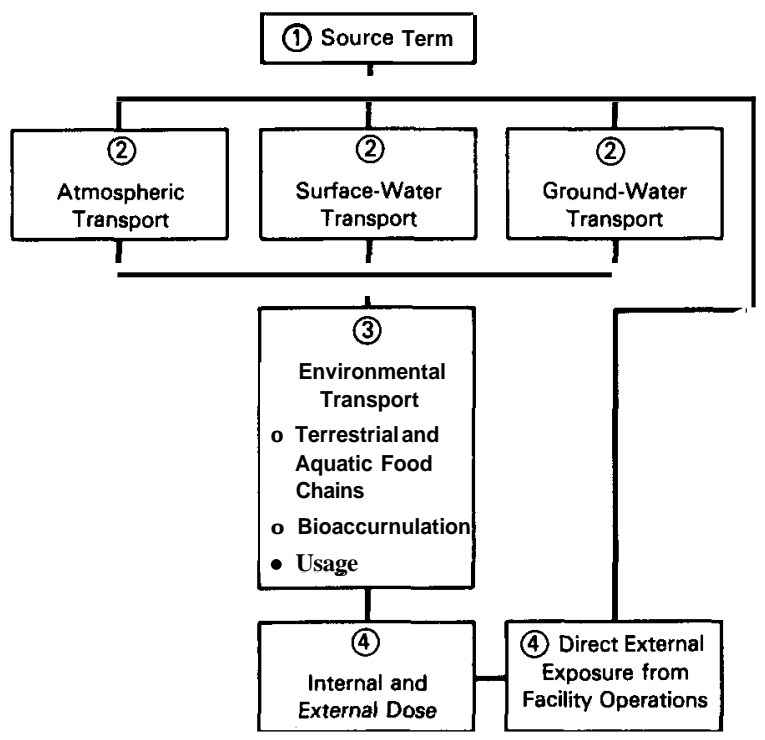

FIGURE 8-1. Major Steps in Performing Pub ic Rad ation Dose Calculations 
(EPA-520/1-88-020) and in the DOE documents entitled Internal Dose Conversion Factors for Calculation of Dose to the Public (DOE/EH-0071) and External DoseRate Conversion Factors for Calculation of Dose to the Public (00E/EH-0070).

\section{$8,2,1$ Considerations for Selection}

In applying models and computer programs for estimating public radiation doses, the following three critical assumptions should be evaluated for each application (Hoffman and Baes 1979): 1) the data available for the input parameters represent the true populations of the parameters ( $i, e_{1}$, the data represent reality), 2) the model parameters are statistically independent (i.e., no coupled parameters), and 3) the structure of the model is an approximation of reality (i.e., the model fits the situation encountered). Although these three conditions can never be completely met, reasonable efforts should be made to evaluate these assumptions in light of the models and data sets selected for site-specific applications.

\subsubsection{Misuses of Models}

The three most common misuses of these types of models are "overkill," inappropriate prediction, and misinterpretation (NCRP Report No. 76). "Overkili" occurs when the level of available data or the use of the results do not support the sophistication of the model selected. The National Council on Radiation Protection and Measurements (NCRP) was responding to "overkill" in models used for radiological assessments when they made the following comment (NCRP Report No. 76, p. 239) :

In recent years, the trend has been toward more complex models; however, the increased complexity has not necessarily improved the accuracy of estimates of dose and, in certain cases, has had the opposite effect.

Inappropriate prediction occurs when sophisticated models and detailed analyses are used too early in the assessment process. Initial assessments should be conducted with very simple models; more detailed models and more detailed assessments should be made as data and knowledge of the system being modeled improve.

Modeling results can be easily misinterpreted when inappropriate boundary conditions or assumptions have been used. The results of any modeling application should be viewed as estimates of reality, and not reality itself. In many cases, seemingly minor changes in assumptions or input can cause drastic changes in the results obtained (NCRP Report No. 76).

\subsection{TRANSPORT MODELS}

Radioactive materials released in the liquid effluents or airborne emissions from an operating DOE-controlled site or facility and transported through the environment might result in radiation exposures to members of the public. As shown in Figure 8-1, the three major types of transport considered in evaluating the effects of radionuclides released to the environment are 
1) atmospheric transport, 2) surface-water transport, and 3) ground-water transport. To estimate the concentrations of radioactive materials in the air or water at locations offsite, a number of mathematical models and computer programs are available. Examples of the methods for documenting computer programs are presented by the American National Standards Institute (ANSI N413) and the Federal Information Processing Standard FIPS Pub. 38. The correct operation of computer programs selected for performing the transport calculations for all environmental dose assessments should be verified on a specific computer system. This verification can be done by comparing the program results for sample problems against either documented sample problem results or against hand calculations. Complete validation of all models (testing the computer program against actual field or laboratory data) is not feasible because of the size of some data sets and the inability to fully characterize most sites. Thus, limited comparisons against field or laboratory data are typically conducted during development of the computer program. As a result of these limited tests, modifications are often made to key parameter values to make the results compare more closely to measured conditions. This comparison process is called "model calibration" and is often used when sitespecific model applications are desired. In many situations, site-specific data are not available, so default parameters or data sets are typically used in the transport calculations. These default values are often obtained from generic data sets and are designed to give conservative dose overestimates.

\subsubsection{Atmosoheric Transport and Dispersion Models}

Atmospheric dispersion models are typically applied to model the transport of airborne releases of radioactive materials. The modeling results obtained are useful to 1) assess the potential consequences of releases from proposed facilities or facility modifications, 2) assess the consequences of actual routine releases, 3 ) demonstrate compliance with regulations and standards, and 4) assess the consequences of actual accidental releases.

Atmospheric dispersion models and meteorological data that are most useful in making these calculations will vary in sophistication and complexity (depending upon the magnitude of the release) from relatively simple computations to extensive computations that require computers. Use of simple compl iance assessment models, based on conservative assumptions and 1 ittle or no meteorological data, could be sufficient for some DOE facilities. As the potential magnitude of the release increases, more realistic models become necessary to assess the potential consequences.

Selection of an adequate atmospheric dispersion model for estimating public radiation doses resulting from atmospheric releases of radioactive materials at DOE sites first requires the determination of site-specific data for a variety of parameters. These data are typically collected through a meteorological measurement program, as described in Chapter 5. The types of parameters required include horizontal and vertical diffusion parameters, wind data, plume-rise parameters, and plume deposition and depletion factors (Randerson 1984c). For the purposes of routine dose assessment, it is assumed that 1) the atmospheric releases occur over a long period of time (i.e., they are chronic releases from routine facility operation and not short-term accidental 
releases), 2) the purpose of estimating ground-level concentrations is to conduct annual public dose assessments, and 3) local terrain is not a complicating factor.

On December 15, 1989, the EPA published the revised "National Emission Standards for Hazardous Air Pollutants; Standards for Radionuclides" (40 CFR Part 61, Subpart H). This regulation applies to operating DOE nuclear facilities and sites. For DOE facilities, subpart $\mathrm{H}$ establishes radiation dose limits for the maximally exposed member of the public from all airborne emissions and pathways. The dose to the maximally exposed member of the public must be calculated using only the AIRDOS-EPA (Moore et al. 1979) and RADRISK (Dunning et al. 1980) computer programs (currently referred to as CAP-88), or other methods specifically approved by EPA as specified in 40 CFR Part 61 . Other approved methods could include the use of environmental data in the evaluation.

In their Annual Site Environmental Reports, most DOE sites have historically provided radiation doses determined by the ratio to the DOE concentration guides or by using the total emissions to model the downwind transport and subsequent exposure through environmental pathways (Kennedy and Mueller 1982). To apply for continued use of site-specific methods and models for demonstrating compliance with $40 \mathrm{CFR}$ Part 61, it is necessary for DOE and its contractors to show that the atmospheric transport and dispersion models used are "equivalent" to those in AIRDOS-EPA (CAP-88) or AIRDOS-PC (version 3.0) and that the environmental transport assumptions and dose conversion factors used are equivalent to or more conservative than those used in RADRISK or that, for some site-specific reason, AIRDOS and RADRISK are not applicable to the site. Atmospheric transport modeling should be conducted by a professional meteorologist or equivalent with modeling experience.

\subsubsection{Surface- and Ground-Water Transport Models}

The annual reporting requirements for DOE-controlled facilities include information on liquid releases (DOE 5400.1). The information reported is required to include statements concerning the quantity and type of radioactive materials discharged to receiving streams or aquifers and assessments of the potential radiation dose to the public that could have resulted from these discharges during the previous calendar year. Decisions about which model or models will be used in performing a specific assessment depend on the local site conditions, the receiving stream or aquifer characteristics, the duration of the release, the potential exposure pathways, the magnitude of the potential doses that result, and other factors. The variety of modeling approaches indicates that there is much uncertainty in modeling surface- and ground-water systems, and that many unanswered questions about radionuclide transport through surface- and ground-water systems remain. Additional questions about surface- and ground-water dispersion models have arisen from the need to identify the parameters that can be measured in the field that correspond to the parameters used in the models. Surface- and ground-water modeling in support of the operation of DOE facilities should be conducted by a professional geohydrologist or equivalent with modeling experience. This modeling should be done using site-specific data and taking into consideration the important characteristics of the site. 


\subsection{ENVIRONMENTAL PATHWAY MODELS}

Emission or effluent data and data from estimates of atmospheric, surface-water, and ground-water radionuclide concentrations are used as input to environmental pathway analysis models. These models predict the environmental transport of radionuclides in the human environment. For most facilities and environmental media, the concentrations in the environment are too low to adequately measure; thus, modeling is used to predict values. A summary of the major environmental radiation exposure and transport pathways relevant to operating DOE facilities that should be considered is given in Figure 8-2. In this figure, processes or steps that are typically modeled are shown in boxes. Processes or steps that can be either modeled or obtained from monitoring data are shown in hexagons. A more complete listing of the potential individual pathways that should be considered in environmental pathway modeling is given in Table 8-1. Pathway analysis and transport models should be compared or calibrated with field data when such information is available. To assess the operational releases from nuclear facilities, NRC Regulatory Guide 1.109 (NRC 1977) provides terrestrial foodchain transport models that address most of the steps shown in Figure 8-2. These models were adapted from the HERMES model (Soldat and Harr 1971) and are representative of the types of models that are frequently used (Hoffman and Baes 1979; Hoffman et al. 1977; IAEA 1982; Moore et al. 1979; NCRP Report No. 76; NUREG/CR-3332, Whelan et al. 1987; Napier et al. 1988; Gilbert et al. 1989; Droppo et al. 1989).

\subsection{INTERNAL DOSIMETRY MODELS}

DOE 5400.5 requires the use of the standard dose conversion factors published by DOE for both internal and external radiation (DOE/EH-0070 and DOE/ EH-0071) or those published in EPA publication EPA-520/1-88-020, Federal Guidance Report No. 11. These methods are based on the most recent recommendations of the ICRP (ICRP Publications 23 and 30). This requirement does not apply to the use of the EPA CAP-88 and AIRDOS-PC Codes (EPA-520/6-89-035; EPA 1990).

\subsection{DOSE TO NATIVE AOUATIC ORGANISMS}

DOE 5400.5, Chapter 11, paragraph 2a(5) contains an interim absorbed dose limit of $1 \mathrm{rad} /$ day to protect native aquatic organisms, other than plants, from exposure to radioactive material in liquid wastes discharged to natural waterways. So that DOE-controlled sites are in compliance with this limit, an assessment of the potential dose to native aquatic organisms should be conducted and included as part of the site Environmental Monitoring Plan. Dose evaluations for aquatic biota require the identification of important pathways and species for a given environment. Because of the diversity of organisms and the variety of pathways and radionuclides that must be considered, it is not possible to develop a single generalized model that can be assumed to cover all possible conditions. Instead, a site-specific assessment, using the best available data for a given facility and environment, should be conducted. 


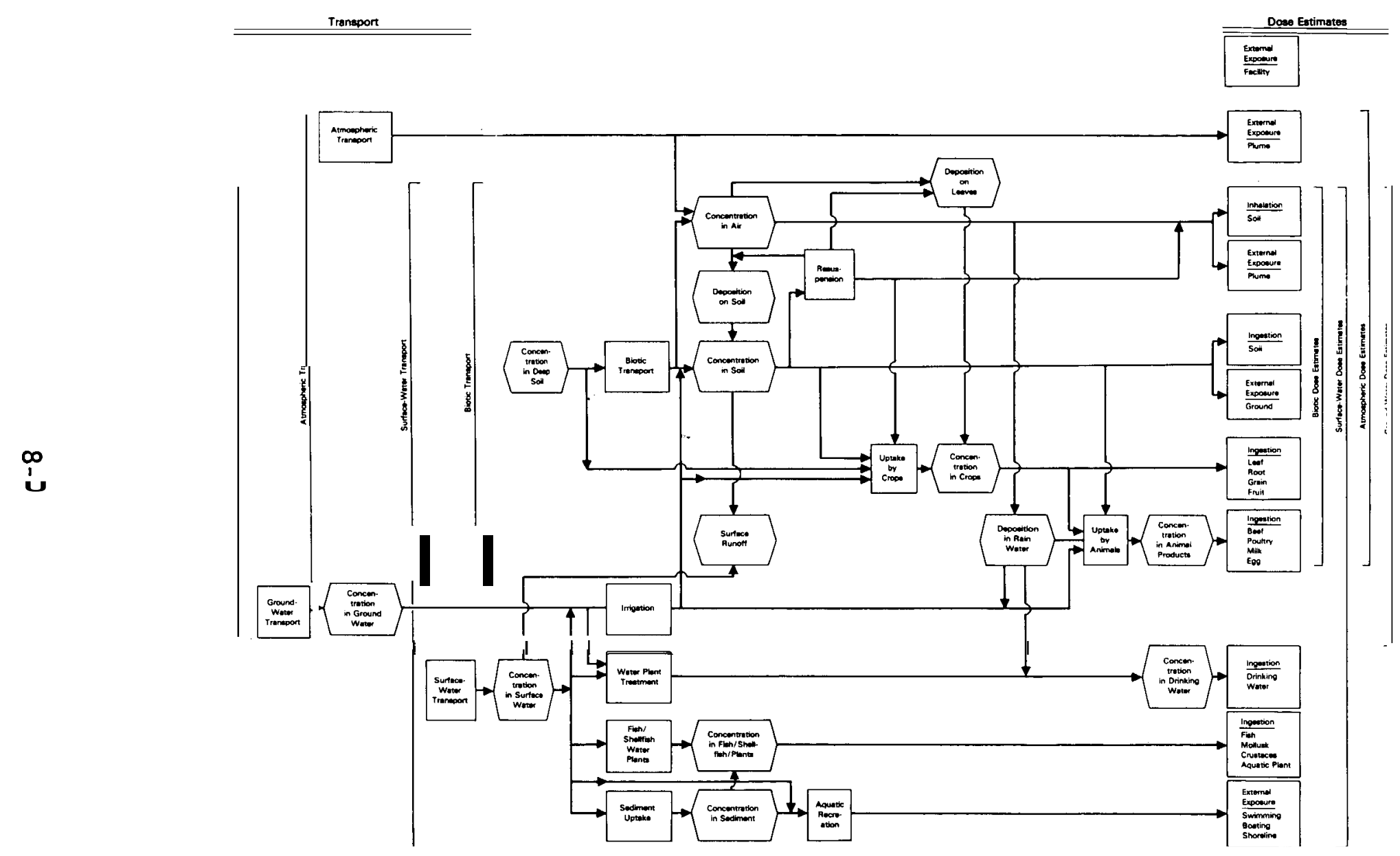

FIGURE 8-2. Potential Steps in Performing Public Radiation Dose Calculations for Various Environmental Pathways 
TABLE 8-1. Potential Pathways to Be Considered in Environmental Pathway Analyses

\section{Exposure Category}

External

Inhalation

Ingestion of

Terrestrial Foods
Environmental Pathwav

Direct Facility Radiation

Submersion in an Airborne Plume

Contaminated Land

Aquatic Recreation (Swimming/Shoreline/8oating)

Submersion in an Airborne Plume

Resuspended Materials

Vegetables:
Potatoes
Other Root Vegetables
Leafy Vegetables
Other Vegetables
Fruits
Cereal Grains
Animal Products:
Liquid Milk
Cheese
Meat and Meat Products (Beef, Pork, Poultry)
Eggs
Ingestion of

Aquatic Foods

Ingestion of Soil

Ingestion of

Drinking Water
Fish

Seafood (Shellfish)

Grazing Animals

Humans (Children)

Surface Water (Raw or Treated)

Well Water (Raw or Treated)

Rain Water

To assist in the dose calculations, a variety of computerized models may be used, including CRITR (Soldat et al. 1974) and EXREM III and BIORAD (Trubey and Kaye 1973). The National Council on Radiation Protection and Measurements has been asked by $0 O E / E H$ to make a further recommendation concerning the interim dose limit to aquatic biota and to provide additional guidance on monitoring and dose modeling.

\subsection{OUALITY ASSURANCE}

The general quality assurance program provisions of Chapter 10 should* be followed as they apply to performing calculations that assess dose impacts. Specific quality assurance activity requirements for performing dose calculations for a facility/site are to be contained in the Quality Assurance Plan associated with the facility. 


\subsection{RECORDS AND REPORTS}

This chapter identifies and outlines the reporting and record-keeping requirements of major Federal regulations, Office of Management and Budget (OMB) circulars, and DOE Orders applicable to the environmental and effluent radiological surveillance programs at DOE sites. These regulations represent only part of the total environmental requirements that are applicable to DOE sites. Environmental statutes and regulations are constantly changing, and are frequently amended or superceded. The regulations cited in this chapter are those that currently are relevant to DOE sites or facilities and their activities. These listings should not be considered all inclusive, and should be updated as required. Also, not all of the cited regulations are relevant to all sites or their facilities. The applicability is a function of the location, operation, and, in some instances, the age of the facility. All operators must, in conjunction with their operations office, determine the applicability of the many regulations. It is the policy of the DOE to comply with all applicable environmental requirements. Accordingly, DOE officials and DOE Management and Operating Contractors should* identify and comply with the relevant requirements.

Proper record-keeping and reporting is essential to DOE's overall compliance strategy. Timely notification of occurrences and information involving DOE and its contractors should* be made to the appropriate DOE officials and to other responsible authorities. Auditable records relating to environmental surveillance and effluent monitoring should* be maintained. Calculations, computer programs, or other data handling should* be recorded or referenced.

The principal objectives of DOE's reporting system (DOE 5484.1, DOE 5484.2, and DOE 5700.68) and of special reporting requirements in DOE 5400.1, DOE 5400.3, and DOE 5400.5 are to

1) Alert DOE management to occurrences for the purpose of investigation and evaluation of causes, and to identify appropriate measures to prevent recurrences;

2) Obtain early, complete, and factual information on occurrences as a basis for reports to the Secretary of Energy, Congress, other Federal agencies, and the public, as appropriate;

3) Identify trends in areas of concern for DOE and contractor operations;

4) Provide a basis for the improvement of codes, guides, and standards used in the DOE and contractor operations;

5) Monitor, evaluate, and report onsite discharges, liquid and airborne effluents, and environmental conditions in the vicinity of DOE sites to assess the levels of radioactive pollutants and their impact on the public and the environment; and

6) Comply with regulations (e.g., CERCLA reporting requirements). 
General reporting and record-keeping requirements for effluent and environmental surveillance activities are outlined in DOE 5400.1 and DOE 5400.5. These Orders specify the reporting responsibilities, timing, and distribution of routine reports (the requirements for preparation and distribution of accident-related reports are outlined in DOE 5484.1) and contain some details on the required content and format. The following paragraphs provide recommendations for meeting the reporting and record-keeping requirements of DOE 5400.5. Also discussed are other Federal regulations that impact the structure or operation of these programs. State and local regulations, which vary considerably, are not included in this section.

A list of the applicable regulations, OMB circular, and DOE Orders and the relevant reporting requirements is provided in Table 9-1.

\subsection{RECORD-KEEPING}

A number of laws, regulations, and DOE Orders contain record-keeping requirements that may apply to DOE-controlled facility operations. The actual record-keeping requirements are typically broad and general in coverage. A brief discussion of the record-keeping requirements cited in Table 9-1 is provided in the following paragraphs.

\subsubsection{DOE 5400.1 - General Environmental Protection Proqram Requirements}

The purpose of the Order is to establish the environmental protection program requirements for DOE operations that ensure compliance with Federal and State environmental protection laws and regulations, Presidential Executive Orders, and internal DOE policies. The Order requires maintenance and retention of auditable records relating to the environmental surveillance and effl uent monitoring programs, and records of calculations, computer programs, or other information (along with raw data, procedures, etc.). The Order further requires that records be protected against damage or loss; generally this protection entails assurance that a duplicate of records is stored in a separate location.

\subsubsection{DOE 5700.6B - Qualitv Assurance}

The purpose of the Order is to establish the quality assurance requirements for DOE operations. The Order is incorporated by reference from DOE 5484.1, as specified in the Order and as applicable to the environmental surveillance and effl uent monitoring programs.

\subsubsection{CFR Part 61 - National Emission Standards for Hazardous Air Pollutants}

The purpose of $40 \mathrm{CFR}$ Part 61, Subpart $\mathrm{H}$, is to regulate atmospheric radionuclide emissions from DOE facilities. The EPA has not yet finalized the record-keeping requirements applicable to the DOE under 40 CFR Part 61, 
TABLE 9-1. Applicable Environmental and Effluent Regulations and Requirements

Requl ations

1324.2

5400.1

5400.1

5400.1

5400.1

5400.4

5400.5

5484.1

5484.2

$5700.6 \mathrm{~B}$

$5820.2 A$

40 CFR Parts

260-265

40 CFR Part 61 (Subpart H)
Reauirements

Comply with general DOE requirements for records disposition and retention.

Comply with general record-keeping requirements.

Report the radioactive materials in effluents during the previous calendar year by release point using the Effluent Information System and Onsite Discharge Reports.

Describe the status of the environmental monitoring programs at DOE facilities in the Annual Site Environmental Report.

Prepare an Environmental Monitoring Plan for each site, facility, or process; review and update plan at least every 3 years.

Prepare reports describing the extent and/or status of the CERCLA efforts at each facility. Report releases of radionucl ides that exceed "reportable quantities" to the National Response Center.

Comply with general requirements for record-keeping and reporting .

Prepare reports on information having environmental protection, safety, or health protection significance.

Prepare Unusual Occurrence (or other accident) Reports, as required, on the failure of effluent monitoring systems, the inadvertent release of radionuclides, or the discovery of significant radioactive contamination in the onsite or offsite environment attributable to current or past DOE operations.

Comply with general qual ity assurance requirements.

Prepare annual updates of the Waste Management Plan.

Prepare and maintain hazardous- and radioactive-waste operating records.

Submit an Annual Compliance Report to the EPA on or before June 1. 
TABLE 9-1. (contd)

Requl ations

40 CFR Part 191

OMB A-106
Reaui rements

Comply with reporting and record-keeping requirements for the management and disposal of spent nuclear fuel and high-level and transuranic radioactive wastes.

Report pol 1 ution abatement projects as specified under the OMB circular A-106 and in the EPA Procedures for Reporting Pollution Abatement Projects for Federal Facilities.

Subpart H. Such requirements, when effective, will be applicable to DOE facilities. In addition, unless requirements are changed by EPA in future amendments to $40 \mathrm{CFR}$ Part 61, Subpart H, records developed pursuant to these criteria are required to be maintained, as specified in DOE 1324.2, Chapter 5, Attachment 1, Schedule 25 (Medical, Health, and Safety Records).

\subsubsection{CFR Parts 260-265 - Resource Conservation and Recoverv Act $\underline{\text { Requl a tions }}$}

The regulations specified in 40 CFR Parts 260-265 have been issued by the EPA pursuant to the Resource Conservation and Recovery Act (RCRA). Radioactive waste practices at facilities administered under the Atomic Energy Act are not subject to the requirements of Subtitle $C$ of RCRA; however, it is a legal requirement that mixed-waste management practices will be consistent with RCRA requirements. Mixed-waste operating records are to be prepared and maintained in accordance with the requirements of 40 CFR Part 264.73 or 40 CFR Part 265.73. These reporting requirements pertain to the effluent and environmental surveillance program activities only insofar as they require information on activities such as ground-water (40 CFR Part 265.90) or foodchain

(40 CFR Part 265.276) monitoring.

\subsection{REPORTING}

It is the policy of the DOE that timely notification of occurrences involving DOE and contractor operations be made to the responsible authorities. Most of the reporting requirements applicable to DOE-controlled facilities are contained in DOE 5400.1, DOE 5400.5, and DOE 5484.1; however, EPA and $O M B$ requirements must also be met. Most reports require information on the type or quantity of radionuclides released to the environment. For all cases where such information is required, reporting in the same units as the respective standards is most appropriate. DOE 5400.1 established DOE requirements on reporting units. The following sections contain brief descriptions of the reporting requirements described in selected references cited in Table 9-1. 


\subsubsection{DOE 5400.1 - General Environmental Protection Proqram Reauirements}

The Order establ ishes the requirements and procedures for reporting information having environmental protection, safety, or health protection significance for DOE operations. The Order requires the preparation of several reports related to environmental protection, safety, and'health protection. The reports listed below require data from effluent or environmental programs. Reports covering the previous calendar year are required to be submitted to the Information Systems Branch, EG\&G Idaho, Inc., and other identified recipients by April 1. The reports are required to be submitted in accordance with instructions provided in Section II of the Effluent Information System and Onsite Discharge Information System User's Manual (EIS/ODIS) (Batchelder et al. 1977). The EIS/ODIS systems are intended to provide a permanent data base for all offsite and onsite releases of radioactive materials in airborne and liquid effluent streams from DOE-controlled facilities. The reporting procedures are given in DOE 5400.1, with a description of the systems and their capabilities in the EIS/ODIS User's Manual. Both systems include a narrative summary data base describing the discharge points in detail.

Reports covering the previous calendar year are to be prepared annually and distributed by June 1 to $\mathrm{EH}-1$, Headquarters (10 copies), appropriate program offices, the DOE Office of Scientific and Technical Information, and other agencies and organizations, as appropriate. The report must provide a comprehensive review of the environmental surveillance programs, status of environmental compliance, and effluent data for nonradioactive pollutants. The primary purpose of the Annual Site Environmental Report is to provide an update on the environmental status of the facility. This report summarizes the degree of compliance of the facility with applicable environmental regulations and informs the public about the impact of the operations of the facility on the surrounding environment. DOE 5400.1 provides the format and content for preparation of the Annual Site Environmental Report.

DOE 5400.1 requires that a written Environmental Monitoring Plan be prepared for each site, facility, or process that uses, generates, releases, or manages pollutants or hazardous materials. The plan will contain the rationale and design criteria for the monitoring program, the extent and frequency of monitoring and measurements, procedures for laboratory analyses, and the preparation and disposition of reports. The plan will be reviewed annually and updated as needed, at least every 3 years.

DOE 5400.1 requires that before start-up of a new site, facility, or process that has the potential for adverse environmental impact or that will process, release, or dispose of radioactive materials, a preoperational environmental assessment be prepared. The format for the Preoperational Environmental Survey Report is provided in DOE 5400.1. The Order further requires that an Annual Environmental Status Sheet be prepared to provide DOE/EH with an up-to-date summary of information regarding the environmental status of each site. The information will be compiled by DOE/EH. Field office contributions to the report are required to be submitted to DOE/EH by April 1 of each year in the format specified in DOE 5400.1. 


\subsubsection{DOE 1324.2 - Records Disposition}

The objective of the order is "to assign responsibilities and authorities and to prescribe policy, procedures, standards, and guidelines for the orderly disposition of records of DOE and its operating and onsite service contractors." The Order provides the basis for the overall DOE recordkeeping system that is required to be used for all aspects of DOE site operation.

\subsubsection{DOE 5400.4 - Comprehensive Environmental Response, Compensation, and Li abilitv Act Proqram}

DOE 5400.4 provides instructions for 1) implementing a DOE Comprehensive Environmental Response, Compensation, and Liability Act (CERCLA) program, 2) defining actions needed to identify and evaluate inactive hazardous-waste disposal sites on DOE installations, and 3) bringing about remedial actions where necessary to improve control of hazardous substance migration from such sites. Heads of field elements are responsible for preparation of the DOE's CERCLA program reports.

\subsubsection{DOE 5000.3 - Unusual Occurrence Reportina Svstem}

This Order establishes the DOE's policy and provides instructions for a system of reporting, analyzing, and disseminating information on programmat$i$ cally significant events.

\subsubsection{CFR Part 61 - National Emission Standards for Hazardous Air Pollutants}

The EPA regulates airborne radioactive releases from DOE facilities through Subpart H of 40 CFR Part 61, "National Emission Standards for Hazardous Air Pollutants; Standards for Radionuclides." Although the EPA has not yet finalized the reporting requirements applicable to the DOE under 40 CFR Part 61 , Subpart $H$, the DOE has adopted the policy that it will comply with those reporting requirements of 40 CFR Part 61 that have clear intent, such as the annual compliance report that is due June 1 each year. This report is submitted through DOE/HQ to the EPA.

\subsubsection{CFR Part 191 - Environmental Standards for the Management and Disposal of Spent Nuclear Fuel, Hiah-Level and Transuranic Radioactive Wastes}

The EPA has promulgated environmental standards for the management and disposal of spent nuclear fuel and high-level and transuranic radioactive wastes under the authority of the Atomic Energy Act and the Nuclear Waste Pol icy Act. 
9.2.7 Office of Management and Budqet Circular A-106 - Reporting Reauirements in Connection with the Prevention, Control, and Abatement of Environmental Pollution at Existing Federal Facilities

The Office of Management and Budget (OMB) A-106 circular (1975) estab1 ishes a semiannual reporting requirement for implementing Sections 1 through 4 of Presidential Executive Order 12088 and Presidential Executive Order 11752 pertaining to the control of environmental pollution from existing Federal facilities. The reports are to be submitted semiannually on December 31 and June 30. The plans are to identify projects necessary to bring Federal facilities into compliance with applicable environmental standards.

\subsection{QUALITY ASSURANCE}

As they apply to reporting and record-keeping activities, the general quality assurance program provisions of Chapter 10 should* be followed. Specific quality assurance activity requirements for facility reporting and record-keeping activities are to be contained in the Quality Assurance Plan associated with the facility. 


\subsection{QUALITY ASSURANCE}

The primary definition of DOE policy concerning quality assurance (QA) is found in DOE 5700,68. The Order sets forth principles and assigns responsibilities for establishing, implementing, and maintaining programs of plans and actions to provide quality achievement in DOE programs. It is applicable to all DOE programs; however, it does not specifically refer to environmental surveillance and monitoring activities. It specifies that $Q \mathrm{~A}$ activities be identified through the judicious and selective application of appropriate, recognized standards. It identifies American National Standards Institute/ American Society of Mechanical Engineers (ANSI/ASHE) NQA-1 as the preferred standard for nuclear activities. Most DOE effluent and environmental monitoring is performed by contractors. The Order specifies that the DOE field organization and project office managers have overall responsibility and authority for defining and ensuring effective implementation of required $Q \mathrm{~A}$ activities to be established and implemented for DOE programs by contractors under their direction. DOE 5700.68 requires the development of $\mathrm{QA}$ Plans. In addition to these plans, the Environmental Monitoring Plan should* contain a section on $\mathrm{QA}$ and should* cover the monitoring activities at each site, consistent with applicable elements of the 18-element format in ANSI/ASME NQA-1.

The purpose of this section is to define the $Q \mathrm{~A}$ activities that are applicable to DOE monitoring and surveillance programs and to specify the requirements. Discussed are the application of $\mathrm{QA}$ and quality control (QC) practices, which are defined in DOE Orders, environmental legislation, consensus standards, and technical references.

Quality control is a task-specific activity that provides verification of quality of a product or service, as opposed to $Q \mathrm{~A}$, which provides assurance of this quality. The definitions of both QA and QC are provided in DOE 5700.68 under the QA definition.

Quality control is generally performed by the line organization as part of its design or implementation functions. Quality assurance is, in part, an evaluation function that should be performed by an independent organization. Verification of the quality of a product or service is an evaluation function that is performed by persons or organizations not directly responsible for performing the work. Even though these two functions (QA and QC) can be considered separately, they are both necessary parts of a quality program.

Two terms used in the description of $Q A$ activities are "control" and "verification." Control is the act of identifying, reviewing, approving, documenting, and verifying the status of items affecting quality. Verification is the act of reviewing, inspecting, testing, checking, auditing, or otherwise determining and documenting whether items, processes, services, or documents conform to specified requirements. 


\subsection{MANDATORY OA REOUIREMENTS}

DOE 5700.6B states that national consensus QA standards are to be applied where suitable ones are available, and in the nuclear area, ANSI/ASME NQA-1 is the preferred standard. This standard can be applied in a selective manner, depending on the complexity and significance of the particular program or project activity. The QA Plan is the mechanism to be used for selectively applying $Q A$ requirements to the effluent and environmental monitoring programs.

\subsubsection{OA Plan}

A QA Plan for environmental monitoring is required by DOE 5400.5 as a part of the Environmental Monitoring Plan to be prepared for each DOEcontrolled site. Depending on the size of the monitoring program, it might be appropriate to prepare separate sections for each major component of the monitoring program, such as effluent, environmental, ground water, etc. This plan should specify the control elements (for QC) that will be applied to the monitoring activities. The $\mathrm{QA}$ Plan does not have to contain all procedures, guides, quality controls, calibration procedures, etc., but rather it should reference the control elements and assign responsibility for each of the applicable 18 criteria of ANSI/ASME NQA-1. The elements of ANSI/ASME NQA-1 might not all be applicable to the monitoring programs. In that case, a statement qualifying the nonapplicability or a reference to the organization that is responsible for the particular element will be sufficient. The QA Plan should be prepared in conjunction with or approved by the QA organization of the site.

\subsubsection{Audits}

Periodic audits should* be performed to verify compliance with operational and $\mathrm{QC}$ procedures. The frequency of audits should be determined jointly with the site QA organization. The following requirements from ANSI/ ASME NQA-1 should* be followed:

Planned and scheduled audits should* be performed to verify compli ance with all aspects of the quality assurance program and to determine its effectiveness. These audits should* be performed independently in accordance with written procedures or checklists by personnel who do not have direct responsibility for performing the activities being audited (i .e., supervisors cannot audit their own facilities). Audit results shoul.d* be documented and reported to and reviewed by responsible management. Follow-up action should* be taken where indicated.

\subsubsection{Elements of the QA Plan}

The elements of a $Q A$ program .plan should* be derived from the 18 criteria in ANSI/ASME NQA-1 and those stipulated in 10 CFR Part 50. 


\subsection{APPLICABLE EXISTING OA REOUIREMENTS}

There are existing requirements for $\mathrm{QA}$ on all DOE programs,-including monitoring and surveillance activities. In addition to DOE 5700.6B, these requirements come from DOE field organization orders, contractor corporate $\mathrm{QA}$ programs, and environmental legislation $Q A$ requirements.

\subsubsection{DOE Field Orqanization Orders}

The DOE field organizations (Operations Offices) have issued orders that establish $Q A$ policy and responsibility within the field organizations and establish requirements for QA programs for contractors. These requirements specify that $Q \mathrm{~A}$ Implementation Plans (as defined by DOE 5700.6B) be established and implemented for each project and program. These plans are specified as a document identifying the requirements, judiciously selected from the overall $Q \mathrm{~A}$ program, that are applicable to a particular program or project.

\subsubsection{Contractor Coroorate $\mathrm{QA}$ Programs}

The system of DOE Orders (Headquarters and field organizations), as described above, specifies that contractors implement QA programs. DOE $5700.6 \mathrm{~B}$ requires the preparation of $\mathrm{QA}$ implementation plans for assigned projects. Facility managers are to verify implementation of the QA program and plans through audits and appraisals. They are also to provide that $Q \mathrm{~A}$ requirements are incorporated into contracts, work orders, and purchase orders issued under their authority as DOE contractors. All contractors performing environmental and effluent monitoring are required to have $Q \mathrm{~A}$ programs in place that meet the general DOE QA requirements.

\subsubsection{Environmental Leqislation $\mathrm{OA}$ Reauirements}

Environmental legislation, such as the Safe Drinking Water Act and the Clean Air Act, includes requirements for using EPA-approved procedures for monitoring. These monitoring procedures include sample-collection methods, sampling frequency, sample analysis, data reporting, dispersion models, and dose calculations. Monitoring to demonstrate compliance with these environmental laws incorporates the QA/QC requirements that are specified by the EPA. References such as those by the Health Physics Society Committee (1980), Inhorn (1978), NRC Regulatory Guide 11.15, Oakes et al. (1980), and Taylor and Stanley (1985) contain useful guidance on $Q A$ programs that involve monitoring and surveillance.

\subsection{QC GUIDANCE}

Specific operational and $Q C$ program procedures are required to be documented in the site Environmental Monitoring Plan. The paragraphs that follow describe these procedures and programs. 


\subsubsection{Written Monitoring Procedures}

Required written procedures covering monitoring activities include the following topics:

- Environmental and effluent sampling

- Ground-water sampl ing

- Continuous environmental and effluent monitoring systems

- Laboratory analysis

- Data management and calculations

- Transport and pathway model ing

- Dose calculations

- Review and reporting of results.

\subsubsection{Analvtical QC Program}

Each site is required to maintain an analytical $\mathrm{QC}$ program adequate to document and control the accuracy and precision of the analytical results. If analytical work is performed by a subcontractor, the subcontractor is required to meet the same $Q C$ requirements. Guidance on content of analytical $Q C$ programs is provided by Belanger (1984), Goldin (1970), Rosenstein and Goldin (1964), EPA-600/9-76-005, EPA-600/7-77-088, EPA-600/8-78-008, and EPA-600/ 4-79-019.

DOE 5400.5 requires that all organizations performing effluent or environmental monitoring participate in the DOE quality assessment program for those nuclides and media that they regularly measure. Samples are distributed by the Environmental Measurements Laboratory (EML) twice a year, and participants analyze both sets of samples. DOE monitoring organizations should participate in other interlaboratory QC programs such as the EPA Environmental Radioactivity Laboratory Intercomparison Studies Program (EPA-600/ 4-78-032) .

Radiation measuring equipment, including portable instruments, environmental dosimeters, in situ monitoring equipment, and laboratory instruments, should" be calibrated with standards traceable to NIST calibration standards (NCRP 1978; National Bureau of Standards Special Publication 609). 


\subsection{REFERENCES}

American Conference of Governmental Industrial Hygienists. 1974. Air Sampling Instruments for Evaluation of AtmosDheric Contaminants. 4 th ed. Ameri can Conference of Governmental Industrial Hygienists, Washington, D.C.

American National Standards Institute/American Society of Mechanical Engineers (ANSI/ASME) NQA-1, Qual ity Assurance Program Requirements for Nuclear Facilities.

American Public Health Association Intersociety Committee (APHA). 1977. Methods of Air Sampling and Analvsis - Second Edition. American Public Health Association, New York, New York.

American Public Health Association (APHA). 1985. Standard Methods for the Examination of Water and Wastewater. 16th Ed. American Public Health Association, New York, New York.

American Society for Testing and Materials (ASTM). 1985. Annual Book of ASTM Standards, Section 11, Vol 11.03, AtmosDheric Analvsis; 0ccupational Health and Safetv. American Society for Testing and Materials, Philadelphia, Pennsylvania.

American Society for Testing and Materials (ASTM). 1986a. 1986 Annual Book of ASTM Standards, Section 12, Volume 12.02, Nuclear, Solar, and Geothermal Eneray. American Society for Testing and Materials, Philadelphia, Pennsylvania.

American Society for Testing and Materials (ASTM). 1986b. 1986 Annual Book of ASTM Standards. Section 11, Volume 11.02, Water and Environmental Technoloqy. American Society for Testing and Materials, Philddelphia, Pennsylvania.

ANSI/ANS-2.5-1984, American National Standard for Determining Meteorological Information at Nuclear Power Sites.

ANSI N13.1-1969, Guide to Sampling Airborne Radioactive Materials in Nuclear Facilities.

ANSI N42.18-1974 (R 1980), Specification and Performance of On-Site Instrumentation for Continuously Monitoring Radioactivity in Effluents.

ANSI N317-1980, Performance Criteria for Instrumentation Used for Inplant Plutonium Monitoring.

ANSI N413, Guidelines for the Documentation of Digital Computer Programs.

ANSI N545-1975, American National Standard - Performance, Testing, and Procedural Specifications for Thermoluminescent Dosimetry: Environmental Applications. 
Anspaugh, I. R., J. J. Koranda, W. I. Robison, and J. R. Martin. 1973. "The Dose to Man Via Food-Chain Transfer Resulting from Exposure to Tritiated Water Vapor." In Tritium. Messenger Graphics, Las Vegas, Nevada.

Anspaugh, L. R., P. I. Phelps, P. H. Gudiksen, C. L. Lindeken, and G. W. Huckabay. 1974. "The In-Situ Measurement of Radionuclides in the Environment with a Ge(Li) Spectrometer." In Proceedings of the Second International Svmposium on the Natural Radiation Environment, eds. J. A. S. Adams, W. M. Lowder, and T. Gesell. Atomic Energy Commission, Washington, D.C.

Barr, S., and W. E. Clements. 1984. "Diffusion Modeling: Principles of Application." In Atmospheric Science and Power Production. D0E/TIC-27601, U.S. Department of Energy, Washington, D.C.

Batchelder, H. M., K. N. Passmore, and EG\&G Idaho, Inc. 1977. Effluent Information Svstem and Onsite Discharqe Information Svstem User's Manual. U.S. Department of Energy, Washington, D.C.

Belanger, B. 1984. Measurement Assurance Proarams, Part I: General Introduction. National Bureau of Standards Special Publication 676-1, U.S. Department of Commerce, Washington, D.C.

Bellamy, R. R. 1974. "Elemental Iodine and Methyl Iodide Adsorption on Activated Charcoal at Low Concentrations." Nuclear Safetv, Vol . 1516, pp. 711-723, U.S. Atomic Energy Commission Technical Information Center, Oak Ridge, Tennessee.

Briggs, G. A. 1984. "Plume Rise and Buoyancy Effects." In AtmosDheric Science and Power Production. DOE/TIC-27601, U.S. Department of Energy, Washington, D.C.

Committee on Biological Effects of Ionizing Radiation. 1980. The Effects on Populations of Exposure to Low Levels of Ionizing Radiation (BEIR III Report). National Academy of Sciences, Washington, D.C.

Crutcher, H. I. 1984. "Monitoring, Sampling, and Managing Meteorological Data." In Atmospheric Science and Power Production. DOE/TIC-27601, U.S. Department of Energy, Washington, D.C.

Denham, D. H. 1979. "Environmental Radiological Surveillance in Perspective: The Relative Importance of Environmental Media as a Function of Effluent Pathway and Radionuclides." Health Phvsics 36:273-281.

Denham, D. H., D. A. Waite, and J. P. Corley. 1974. Summarv of Selected AEC Contractor Environmental Surveillance Techniques and Capabilities. BNWLB-384, Pacific Northwest Laboratory, Richland, Washington.

dePlanque, G., and T. F. Gesell. 1982. "Thermoluminescence DosimetryEnvironmental Applications." International Journal of Applied Radiation and Isotopes 33:1015-1034. 
dePlanque, G., T. F. Gesell, and K. Becker. 1976. "Second International Intercomparison of Environmental Dosimeters Under Field and Laboratory Conditions." In Proceedings of the Tenth Midyear Topical Symposium of the Health Physics Society, pp. 555-574. Rensselaer Polytechnic Institute, Troy, New York.

DOE 1324.2, Records Disposition, 5-28-80.

DOE 5000.3, Unusual Occurrence Reporting System, 11-7-84.

DOE 5400.1, General Environmental Protection Program Requirements, 11-9-88.

DOE 5400.4, Comprehensive Environmental Response, Compensation, and Liability Act Program, of 10-6-89.

DOE 5400.5, Radiation Protection of the Public and the Environment, 2-8-90.

DOE 5440.1C, Implementation of the National Environmental Pol icy Act, 4-9-85.

DOE 5480.1B, Environment, Safety, and Health Program for Departmental Operations, 9-23-86.

DOE 5480.4, Environmental Protection, Safety, and Health Protection Standards, 5-15-84.

DOE 5480.5, Safety of Nuclear Facilities, 9-23-86.

DOE 5480.6, Safety of Department of Energy-Owned Nuclear Reactors, 9-23-86.

DOE 5480.11, Radiation Protection for Occupational Work, 12-21-88.

DOE 5480.14, Comprehensive Environmental Response, Compensation, and Liability Act Program, 4-26-85.

DOE 5481.1B, Safety Analyses and Review System, 9-23-86.

DOE 5482.1B, Environment, Safety, and Health Appraisal Program, 9-23-86.

DOE 5483.1A, Occupational Safety and Health Program for DOE Contractor Employees at Government-Owned, Contractor-Operated Facilities, 6-22-83.

DOE 5484.1, Environmental Protection, Safety, and Health Protection Information Reporting Requirements, 2-24-81.

DOE 5700.6B, Quality Assurance, 9-23-86.

DOE 5820.2, Radioactive Waste Management, 2-6-84.

D0E/EH-0070, External Dose-Rate Conversion Factors for Calculation of Dose to the Public, 719-88. 
DOE/EH-0071, Internal Dose Conversion Factors for Calculation of Dose to the Public, 719-88.

DOE/EP-0023, A Guide for: Environmental Radiological Surveillance at U.S. Department of Energy Instal 1 ations, 1981.

DOE/EP-0096, A Guide for Effluent Radiological Measurements at DOE Installations.

DOE/EV-1830-T5, A Guide to Reducing Radiation Exposure to as Low as Reasonably Ach i evable, 1980.

DOE/GJ/TMC-13, Procedures for Sampling Radium-Contaminated Soils, 1984.

DOE/ID0-12096, Radiological and Environmental Sciences Laboratory, Analytical Chemistry Branch Procedures Manual, 1982.

DOE/MLM-2015, A Ruggedized Ultrasensitive Field Air Sampler for HTO and HT, Mound Laboratory.

DOE/NV0-213, Radiological Support Project Final Report.

Droppo, J. G., Jr., G. Whelan, J. W. Buck, D. L. Strenge, B. L. Hoopes, M. B. Walter, R. I. Knight, and S. M. Brown. 1979. Supplemental Mathematical Formulations: The Multimedia Environmental Pollutant Assessment Svstem (MEPAS). PNL-7201, Pacific Northwest Laboratory, Richland, Washington.

Dunning, D. E., Jr., R. W. Leggett, and M. G. Yalcintas. 1980. A Combined Methodologv for Estimating Dose Rates and Health Effects from Exposure to Radioactive Pollutants. ORNL/TM-7105, Oak Ridge National Laboratory, Oak Ridge, Tennessee.

EPA-450/2-78-027R, Guidel ine on Air Qual ity Models (Revised), 1986.

EPA-450/4-86-005a, Industrial Source Complex (ISC) Dispersion Model User's Guide, Vol. 1, 2nd ed, 1986.

EPA-450/4-87-103, Onsite Meteorological Program Guidance for Regulatory Modeling Applications, 1987.

EPA 520/1-79-009 (ORNL-5532), AIRDOS-EPA: A Computerized Methodology for Estimating Environmental Concentrations and Dose to Man from Airborne Releases of Radionuclides, 1979.

EPA-520/1-88-020, Federal Guidance Report No. 11, Limiting Values of Radionuclide Intake and Air Concentration and Dose Convers on Factors for Inhalation, Submersion, and Ingestion, 1988.

EPA-520/5-84-006, Eastern Environmental Radiation Facil ity Radiochemistry Procedures Manual, 1984. 
EPA-520/6-89-035, User's Guide for AIRDOS-PC Version 3.0, December 1990.

EPA-600/4-78-032, Environmental Radioactivity Laboratory Intercomparison Studies Program, 1978-1979, 1978.

EPA-600/4-79-019, Handbook for Analytical Qual ity Control in Water and WasteWater Laboratories, 1979.

EPA-600/4-80-032, Prescribed Procedures for Measurement of Radioactivity in Drinking Water, 1980.

EPA-600/7-77-088, Handbook for Analytical Qual ity Control in Radioanalytical Laboratories, 1977.

EPA-600/8-78-008, Manual for the Interim Certification of Laboratories Involved in Analyzing Public Drinking Water Supplies, 1978.

EPA-600/8-84-207, INPUFF - A Single Source Gaussian Puff Dispersion Model User's Guide, 1984.

EPA-600/8-86-024, INPUFF 2.0 - A Multiple Source Gaussian Puff Dispersion Algorithm User's Guide, 1986.

EPA-600/9-76-005, Quality Assurance Handbook for Air Pollution Measurement Systems, Volumes I, II, III, 1976.

EPA-625/6-74-003, Methods for Chemical Analysis of Water and Wastes (with latest revisions).

EPA-5201/1-80-01, Upgrading Environmental Radiation Data, Health Physics Society Committee Report HPSR-1, 1980.

EPA EMSL-LV-0539-17, Radiochemical Analytical Procedures for Analysis of Environmental Samples, 1979.

EPA ORP/SID 72-2, Environmental Radioactivity Surveillance Guide, 1972.

EPA-R4-73-014, Procedures for Radiochemical Analysis of Nuclear Reactor Aqueous Solutions, 1973.

EPA. 1990. The Clean Air Act Assessment Package-1988 (CAP-88): A Dose and Risk Assessment Methodolosv for Radionuclide Emissions to Air, Volume 1: User's Manual; Volume 2: Appendices A-H; Volume 3: Appendices I-M. SC\&A, Inc., McLean, Virginia.

Federal Information Processing Standard, FIPS Pub. 38, Guidelines for Documentation of Computer Programs and Automated Data Systems. 
Finkelstein, P. L., D. A. Mazzarella, T. J. Lockhart, W. 3. King, and J. H. White. 1983. Qualitv Assurance Handbook for Air Pollution Measurement Svstems, Volume IV: Meteorological Measurements. U.S. Environmental Protection Agency, Research Triangle Park, North Carolina.

Fix, J. J., and M. L. Miller. 1978. The Hanford Environmental $\mathrm{CaF}_{2}: \mathrm{Mn}$ Thermoluminescent Dosimeter. PNL-2489, Pacific Northwest Laboratory, Richland, Washington.

Fowler, E. B., W. Henderson, and F. Milligan, compilers. 1971. Proceedings of Environmental Plutonium Symposium--Auqust 4-5, 1971. LA-4756, Los Alamos Scientific Laboratory, Los Alamos, New Mexico.

Fuchs, N. A. 1975. "Review Paper - Sampling of Aerosols." Atmospheric Environment 9:697-707.

Gabay, J. J., C. J. Paperiello, S. Goodyear, J. C. Daly, and J. M. Matuszek. 1974. "A Method for Determining Iodine-129 in Milk and Water." Health Phvsics $26: 89-96$.

Gesell , T. F. 1982. Environmental Monitoring with Thermoluminescence Dosimetry. IEEE Transactions on Nuclear Science, Vol. NS-29, No. 3, Institute of Electrical and Electronics Engineers, Inc., New York, New York.

Gesell, T. F., F. I. Kalbeitzer, and G. dePlanque. 1982. "Highlights of the Sixth International Intercompari son of Environmental Dosimeters." Radiation Protection Dosimetrv 6(1-4):265-268.

Gifford, F. A. 1961. "Use of Routine Meteorological Observations for Estimating Atmospheric Dispersion." Nuclear Safetv 3(4):76-80.

Gifford, F. A. 1968. "An Outline of Theories of Diffusion in the Lower Layers of the Atmosphere." In Meteorologv and Atomic Enerqv - 1968, pp. 65-116. TID-24190, U.S. Atomic Energy Commission, Washington, D.C.

Gifford, F. A. 1976. "Turbulent Diffusion-Typing Schemes: A Review." Nuclear Safetv $17(1): 68-86$.

Gilbert, R. 0. 1987. Statistical Methods for Environmental Pollution Monitoring. Van Nostrand Reinhold Co., New York, New York.

Gilbert, R. O., and R. R. Kinnison. 1981. "Statistical Methods for Estimating the Mean and Variance from Radionuclide Data Sets Containing Negative, Unreported or Less-Than Values." Health Phvsics 40:377-390.

Gilbert, T. L., C. Yu, Y. C. Yuan, A. J. Zielen, M. J. Jusko, and A. Wallo 111. 1989. A Manual for Implementing Residual Radioactive Material Guidel ines. ANL/ES-160, D0E/CH/8901, Argonne National Laboratory, Argonne, III inois. 
Goldin, A. S. 1970. "Evaluation of Internal Control Measurements in Radioassay." Health Physics 47:361.

Griffin, W. R., J. A. Cochran, and A. A. Bertuccio. 1972. A Sampler for Nonaaueous Tritium Gases. U.S. Environmental Protection Agency, Office of Radiation Programs, Winchester, Massachusetts.

Grossman, R. F., and R. W. Holloway. 1985. "Concentrations of Krypton-85 near the Nevada Test Site." Environmental Science and Technoloqy 19:1128-1131.

Hall, R. M., and J. P. LaRocca. 1966. "Thermoluminescent Dosimeters for Environmental Monitors." Health Phvsics 12:851-852.

Hanna, S. R., G. A. Briggs, J. Deardorff, B. A. Egan, F. A. Gifford, and F. Pasquill. 1977. "AMS Workshop on Stability Classification Schemes and Sigma Curves--Summary of Classification Recommendations." Bulletin of the American Meteoroloqical Society 58:1305-1309.

HASL-195, The Radiation Field in Air Due to Distributed Gamma-Ray Sources in the Ground, 1966.

HASL-252, Investigation of a $\mathrm{CaF}_{2}: \mathrm{Mn}$ Thermoluminescent Dosimetry System for Environmental Monitoring, 1972.

HASL-256, In Situ Ge(Li) and NaI(TT) Gamma-Ray Spectrometry, 1972.

HASL-300, EML Procedures Manual (revised annually).

Hawley, K. A., and D. K. Washburn. 1985. Summary of Annual Site Environmental Monitoring Reports, January-December 1983. Prepared by Pacific Northwest Laboratory for the U.S. Department of Energy, Washington, D.C.

Health Physics Society Committee. 1980. "Quality Assurance for Environmental Monitoring Programs." In Uparadina Environmental Radiation Data, Chapter 5. Report HPSR-1, EPA-520/1-80-012, U.S. Environmental Protection Agency, Washington, D. C.

Healy, J. W. 1984. A Proposed Interim Standard for Plutonium in Soils. LA-5483-MS, University of California, Los Alamos Scientific Laboratory, Los Alamos, New Mexico.

Hendee, W. R. 1967. "Radiation Response of LiF at Low Doses." Health Physics 13:1235-1236.

Hesketh, H. E., and F. I. Cross, Jr. 1983. Fuqitive Emissions and Control. Ann Arbor Science Publishers, Inc., Ann Arbor, Michigan.

Hidy, G. M. 1984. Aerosols, An Industrial and Environmental Science. Academic Press, Inc., New York, New York. 
Hinds, W. C. 1982. Aerosol Technology. John Wiley and Sons, New York, New York.

Hoffman, F. O., and C. F. Baes 111. 1979. A Statistical Analvsis of Selected Parameters for Predictins Food Chain Transport and Internal Dose of Radionuclides. NUREG/CR-1004, Oak Ridge National Laboratory, Oak Ridge, Tennessee.

Hoffman, F. O., C. W. Miller, D. L. Shaeffer, and C. T. Garten, Jr. 1977. "Computer Codes for the Assessment of Radionuclides Released to the Environment." Nuclear Safety 18:343.

Hollander, M., and D. A. Wolfe. 1973. Non-Parametric Statistical Methods. John Wiley and Sons, New York, New York.

Hosker, R. P., Jr. 1984. "Flow and Diffusion near Obstacles." In Atmospheric Science and Power Production, pp. 241-326. DOE/TIC-27601, U.S.

Department of Energy, Washington, D.C.

Hoy, J. E. 1971. "Environmental Radiation Monitoring with Thermoluminescent Dosimeters." Health Phvsics 21:860-862.

ICRP Publication 23, Reference Man: Anatomical, Physiological and Metabolic Characteristics.

ICRP Publication 26, Recommendations of the International Commission on Radio logical Protection.

ICRP Publication 30, Limits for Intakes of Radionuclides by Workers.

ICRP Publication 43, Principles of Monitoring for the Radiation Protection of the Population.

ICRP Publication 45, Quantitative Bases for Developing a Unified Index of Harm.

ICRP Publication 48, The Metabolism of Plutonium and Related Elements.

IEC N. 761-1, Equipment for Continuously Monitoring Radioactivity in Gaseous Effluents, Part 1: General Requirements.

IEC N. 761-2, Equipment for Continuously Monitoring Radioactivity in Gaseous Effluents, Part 2: Specific Requirements for Aerosol Effluent Monitors.

IEC N. 761-3, Equipment for Continuously Monitoring Radioactivity in Gaseous Effluents, Part 3: Specific Requirements for Noble Gas Effluent Monitors.

IEC N. 761-4, Equipment for Continuously Monitoring Radioactivity in Gaseous Effluents, Part 4: Specific Requirements for Iodine Monitors.

IEC N. 761-5, Equipment for Continuously Monitoring Radioactivity in Gaseous Effluents, Part 5: Specific Requiremznts for Tritium Effluent Monitors. 
Inhorn, S. L., ed. 1978. Qualitv Assurance Practices for Health Laboratories. American Publ ic Health Association, Washington, D.C.

International Atomic Energy Agency (IAEA) . 1982. Generic Models and Parameters for Assessing the Environmental Transfer of Radionuclides from Routine Releases - Exposures of Critical Groups. Safety Series No. 57, International Atomic Energy Agency, Vienna, Austria.

International Commission on Radiological Protection Task Group on Lung Dynamics (ICRP Task Group). 1966. "Deposition and Retention Models for Internal Dosimetry of the Human Respiratory Tract." Health Phvsics 12:173-297.

International Organization for Standardization (ISO). 1975. General Principles for Sampling Airborne Radioactive Materials. ISO 2889-1975, International Organization for Standardization, Geneva, Switzerland.

Intersociety Committee for a Manual of Methods for Ambient Air Sampl ing and Analysis (Intersociety Committee). 1972. Methods of Air Sampling and Anal- American Public Health Association, Washington, D.C.

Irwin, J. S. 1980. Dispersion Estimate Suqqestion \#8: Estimation of Pasquill Stabilitv Categories. Docket Reference No. II-8-10, U.S. Environmental Protection Agency, Research Triangle Park, North Carolina.

Irwin, J. S. 1983. "Estimating Plume Dispersion--A Comparison of Several Sigma Schemes." Journal of Cl imate and Aool ied Meteorology 22:92-114.

Jackson, W. M., J. D. Spaulding, J. E. Noakes, and G. L. Murphy. 1985. "Comparison of Environmental Radiation Dosimetry and y-ray Spectroscopy." Health Phvsics 48:747-756.

Kahn, B. 1972. "Determination of Radioactive Nuclides in Water." In Water and Waste Pollution Handbook, ed. L. L. Ciacco. M. Decker, Publisher, New York, New York.

Keller, J. H., F. A. Duce, D. T. Pence, and W. J. Maeck. 1970. "Iodine Chemistry in Steam Air Atmospheres." In Proceedings of the Fifth Annual Health Phvsics Societv Mid-Year Symoosium: Health Phvsics Aspects of Nuclear Facilitv Siting, pp. 764-783. Health Physics Society, Idaho Falls, Idaho.

Kennedy, W. E., Jr., and M. A. Mueller. 1982. Summarv of the Environmental Dose Models Used at DOE-Nuclear Sites. PNL-3916, Pacific Northwest Laboratory, Richland, Washington.

Lague, J. S., E. M. Irvine, and T. F. Lavery. 1980. "Validation of Alternate Turbulence Typing Models for Estimating Air Quality Effects of Coastal Sources near Rough Terrain." Presented at the Second Joint Conference on Applications of Air Pollution Meteorology, and the Second Conference on Industrial Meteorology, March 24-27, 1980, New Orleans, Louisiana. 
Lalas, D. P., V. Catsoulis, and M. Petrakis. 1979. "On the Consistency of Stability Classification Schemes when Applied to Non-Homogeneous Terrain." Atmospheric Environment 13:687-691.

Lee, R. E., Jr. 1974. "Measuring Particulate Matter in Air." In Instrumentation for Monitoring Air Ouality. ASTM Publication STP-555, American Society for Testing and Materials, Philadelphia, Pennsylvania.

Ludwig, F. I. 1976. "Siting Air Monitoring Stations." Environmental Science and Technology 12(7):774-778.

Luna, R. E., and H. W. Church. 1972. "A Comparison of Turbulence Intensity and Stability Ratio Measurements to Pasquill Stability Classes. " Journal of Applied Meteorologv 11:663-669.

Mark, D., J. H. Vincent, and W. A. Witherspoon. 1982. "Particle Blow-off: A Source of Error in Blunt Dust Samplers." Aerosol Science and Technology $1: 463-469$.

Mason, C. J., and H. Moses. 1984. "Meteorological Instrumentation." In Atmospheric Science and Power Production, pp. 81-135. DOE/TIC-27601, U.S. Department of Energy, Washington, D.C.

Mejdah1, V. 1970. "Measurement of Environmental Radiation Intensity with Thermoluminescent $\mathrm{CaSO}_{4}$ :Dy." Health Physics 18:164-167.

Meyer, H. R., and J. Purvis. 1985. "Development of an Interference-Corrected Soil Radium Measurement System." Transactions of the American Nuclear Society 50:184-187.

Mitchell, A. E., Jr. 1982. "A Comparison of Short-Term Dispersion Estimates Resulting from Various Atmospheric Stability Classification Schemes." Atmospheric Environment 16:765-773.

Mohrand, R. A., and I. A. Franks. 1982. Compilation of ${ }^{137}$ Cs Concentrations at Selected Sites in the Continental United States. EGG-1183-2437-Rev, EG\&G, Inc., Goleta, California.

Moore, R. E., C. F. Baes 111, L. M. McDowe11-Boyer, A. P. Watson, F. 0. Hoffman, J. C. Pleasant, and C. W. Miller. 1979. AIRDOS-EPA: A Computerized Methodologv for Estimating Environmental Concentrations and Dose to Man from Airborne Releases of Radionuclides. EPA 520/1-79-009 (ORNL-5532), Oak Ridge National Laboratory, Oak Ridge, Tennessee.

Myrick, T. E., B. A. Berven, and F. F. Haywood. 1983. "Determination of Selected Radionuclides in Surface Soil in the United States." Health Physics 45:631-642.

Napier, B. A., et al. 1988. GENII - The Hanford Environmental Radiation Dosimetry Software Svstem. PNL-6584, Pacific Northwest Laboratory, Richland, Washington. 
National Bureau of Standards Special Publication 609, "Proceedings of a Meeting on Traceability for Ionizing Radiation Measurements," 1982.

National Council on Radiation Protection and Measurements (NCRP). 1978. "The Assurance of Accuracy and Precision in National and International Measurements of Radioactivity." In A Handbook of Radioactivitv Measurements Procedures, pp. 299-305. NCRP Report No. 58, National Council on Radiation Protection and Measurements, Bethesda, Maryland.

NCRP Commentary 3, Screening Techniques for Determining Compliance with Environmental Standards, 1986.

NCRP Report No. 76, Radiological Assessment: Predicting the Transport, Bioaccumulation, and Uptake by Man of Radionuclides Released to the Fnvironment.

NRC Regulatory Guide 1.23, Onsite Meteorological Programs, 1972.

NRC Regulatory Guide 1.52, Design, Testing, and Maintenance Criteria for PostAccident Engineered-Safety-Feature Atmosphere Cleanup System Air Filtration and Adsorption Units of Light-Water-cooled Nuclear Power Plants, 1976.

NRC Regulatory Guide 1.109, Appendix I, Calculation of Annual Doses to Man from Routine Releases of Reactor Effluents for the Purposes of Evaluating Compliance with 10 CFR Part 50, 1977.

NRC Regulatory Guide 4.5, Measurement of Radionuclides in the Environment-Sampling and Analysis of Plutonium in Soil.

NRC Regulatory Guide 4.13, Revision 1, Performance, Testing, and Procedural Specifications for Thermoluminescent Dosimetry: Environmental Applications, 1977.

NRC Regulatory Guide 4.15, Quality Assurance for Radiological Monitoring Pro. grams (Normal Operations)--Effluent Streams and the Environment, 1980.

NRC Regulatory Guide 6.25, Calibration and Error Limits of Air Sampling for Total Volume of Air Sampled, 1980.

NUREG/CR-0523, MESODIF-II: A Variable Trajectory Plume Segment Model to Assess Ground-Level Air Concentrations and Deposition from Nuclear Power Facilities, 1979.

NUREG/CR-0798, Evaluation of Empirical Atmospheric Diffusion Data, 1979.

NUREG/CR-3332, Radiological Assessment - A Textbook on Environmental Dose Analysis, 1983.

NUREG/CR-3344, MESOI Version 2.0: An Interactive Mesoscale Lagrangian Puff Dispersion Model with Deposition and Decay, 1983.

NUREG/CR-4000, The MESORAD Dose Assessment Model, 1986. 
Oakes, T. W., K. E. Shank, and J. S. Eldridge. 1980. "Quality Assurance Applied to Environmental Radiological Surveillance." Nuclear Safety $21(2): 217-226$.

Okazaki, K., R. Wiener, and K. Willeke. 1985. "Sampling Efficiencies of Aerosol Sampl ing Inlets." Paper presented at the Seventeenth Aerosol Technology Meeting, August 26-28, 1985, Columbus, Ohio.

OMB Circular A-106, Reporting Requirements in Connection with the Prevention, Control, and Abatement of Environmental Pollution at Existing Federal Facilities, 1975.

Osborne, R. V. 1974. "Sampling for Tritiated Water Vapour." In Proceedings of the Third International congress of the International Radiation Protection Association, Seotember 9-14, 1973, Washinaton, D.C., Paper No. 222. U.S. Atomic Energy Commission Technical Information Center, Oak Ridge, Tennessee.

Ostlund, H. G. 1970. A Rapid Field Sampling for Tritium in AtmosDheric Hydrogen. Report ML 70075, Rosenstiel School of Marine and Atmospheric Sciences, University of Miami, Miami, Florida.

Pasquill, F, 1961. "The Estimation of the Dispersion of Windborne Material." Meteorological Maqazine 90(1063):33-49.

Pasquill, F. 1979. "Atmospheric Dispersion Modeling.' Journal of the Air Pollution Control Association 29: 117-119.

PHS Publication No. 999-AP-26, Workbook of Atmospheric Dispersion Estimates, 1969.

Presidential Executive Order 11752, "Prevention, Control, and Abatement of Environmental Pollution at Federal Facilities," 38 Federal Reqister 34793 (December 19, 1973).

Presidential Executive Order 12088, "Federal Compliance with Pollution Control Standards," 43 Federal Reqister 47707-09 (October 13, 1978).

Ramsdell, J. V., S. R. Hanna, and H. E. Cramer. 1982. Turbulent Diffusion Coefficients Within and Above the Urban Domain. Prepared for the U.S: Army Atmospheric Sciences Laboratory by Battelle, Pacific Northwest Laboratories, Richland, Washington.

Randerson, D. 1984a. "Atmospheric Boundary Layer." In Atmosoheric Science and Power Production, pp. 147-188, DOE/TIC-27801, U.S. Department of Energy, Washington, D.C.

Randerson, D. 19840, "Power Production and the Atmosphere." In AtmosDheric Science and Power Production, pp. 1-31. DOE/TIC-27601, U.S. Department of Energy, Washington, D.C. 
Randerson, D., ed. 1984c. Atmosoheric Science and Power Production. DOE/ TIC-27601, U.S. Department of Energy, Washington, D.C.

Rosenstein, M., and A. S. Goldin. 1964. Statistical Techniaues for Quality Control of Environmental Radioassav. Air Quality Control Service Report Stat-1, U.S. Public Health Service, Winchester, Massachusetts.

Sedefian, I., and E. Bennett. 1980. "A Comparison of Turbulence Classificati on Schemes." Atmospheric Environment 14:741-750.

Shaw, R. W., R. K. Stevens, C. W. Lewis, and J. H. Chance. 1983. ''Comparison of Aerosol Sampler Inlets." Aerosol Science and Technologv 2 :53-67.

Sill, C. W., and R. L. Williams. 1971. "Rapid Identification and Determination of Alpha Emitters in Environmental Samples." In Rapid Methods for Measuring Radioactivitv in the Environment, p. 201. International Atomic Energy Agency, Vienna, Austria.

Skaggs, D. I., and E. Robinson. 1976. "A Comparison of Methods for Estimating Atmospheric Stability and Diffusion Coefficients." Journal of the Air Pollution Control Association 26:888-891.

Slade, D. H., ed. 1968. Meteorologv and Atomic Enerqv - 1968. TID-24190, U.S. Atomic Energy Commission, Washington, D.C.

Smith, W. S., ed. 1984. EPA Stationary Source Samplinq Methods Notebook (NSPS and NESHAP Methods).. McIlvaine Company, Northbrook, Illinois.

Snldat, J. K., and R. D. Harr. 1971. "Radiation Dose Model." In HERMES - A Diqital Computer Code for Estimating Reqional Effects from the Nuclear Power Industry. HEDL-TME-71-68, Hanford Engineering Development Laboratory, Richland, Washington.

Soldat, J. K., N. M. Robinson, and D. A. Baker. 1974. Models and Computer Codes for Evaluating Environmental Radiation Doses. BNWL-1754, Battelle, Pacific Northwest Laboratories, Richland, Washington.

Stanley, R. E., and A. R. Moghissi, eds. 1974. Noble Gases: Proceedings of a Conference Held in Las Veqas, Nevada, Auqust 1972. Messenger Graphics, Phoenix, Arizona.

Taylor, J. K., and T. W. Stanley, eds. 1985. Quality Assurance for Environmental Measurements. ASTM Special Technical Publication 867, American Society for Testing and Materials, Philadelphia, Pennsylvania.

Title 10 CFR Part 50, Domestic Licensing of Production and Utilization Facilities.

Title 10 CFR Part 50, Appendix B, Quality Assurance Criteria for Nuclear Power Plants and Fuel Reprocessing Plants. 
Title 10 CFR Part 60, Disposal of High-Level Wastes in Geologic Repositories. Title 40 CFR Part 61, National Emission Standards for Radionuclide Emissions from Department of Energy (DOE) Facilities.

Title 40 CFR Part 141, Subparts A and H, National Interim Primary Drinking Water Regulations (Safe Drinking Water Act).

Title 40 CFR Part 191, Environmental Standards for the Management and Disposal of Spent Nuclear Fuel, High-Level and Transuranic Radioactive Wastes.

Title 40 CFR Part 192, Health and Environmental Protection Standards for Uranium and Thorium Mill Tailings.

Title 40 CFR Part 260, General Regulations on Hazardous Waste Management.

Title 40 CFR Part 261, Identification and Listing of Hazardous Waste.

Title 40 CFR Part 262, Standards Applicable to Generators of Hazardous Waste.

Title 40 CFR Part 263, Standards for Owners and Operators of Hazardous Waste Treatment, Storage, and Disposal Facilities.

Title 40 CFR Part 264, Regulations for Owners and Operators of Permitted Hazardous Waste Facilities.

Title 40 CFR Part 265, Interim Standards for Owners and Operators of Permitted Hazardous Waste Facilities.

Title 42 U.S.C. 300, et seg., Safe Drinking Water Act, as amended.

Title 33 U.S.C. 466, et seg., Federal Water Pollution Control Act, as amended.

Title 42 U.S.C. 2011, et seq., Atomic Energy Act of 1954, as amended.

Title 42 U.S.C. 4341, et seg., National Environmental Policy Act of 1969, as amended.

Title 42 U.S.C. 6901, et seq., Resource Conservation and Recovery Act of 1976 (RCRA) .

Title 42 U.S.C. 7401, et seg., Clean Air Act, as amended.

Title 42 U.S.C. 9615 (Superfund), Comprehensive Environmental Response, Compensation, and Liability Act of 1980 (CERCLA) .

Title 42 U.S.C. 10101, et seq., Nuclear Waste Policy Act of 1982, as amended. 
Trevathan, M. S., and K. R. Price. 1985. "Ambient Krypton-85 Air Sampling at Hanford." In Proceedinas of the Fifth DOE Environmental Protection Information Meeting, CONF-841187, vol. 2, pp. 655-662. U.S. Department of Energy, Washington, D.C.

Trubey, D. K., and S. V. Kaye. 1973. The EXREM II I Computer Code for Estimating External Radiation Doses to Pooulations from Environmental Releases. ORNL-TM-4322, Oak Ridge National Laboratory, Oak Ridge, Tennessee.

Turner, D. B. 1964. "A Diffusion Model for an Urban Area." Journal of Aoplied Meteorologv 3:83-91,

Urabe, I., and K. Katsurayama. 1984. "Feasibility Study on a Continuous Envi ronmental Gamma-Ray Monitor Using a NaI(Tl) Scintillation Spectrometer." Health Phvsics 47:559-566.

Vincent, J. H., P. C. Emmett, and D. Mark. 1985, "The Effect of Turbulence on the Entry of Airborne Particles into a Blunt Dust Sampler." Aerosol Science and Technology 1(4):17-29.

Waite, D. A. 1973a, Analvsis of an Analvtical Technique for Distributing Air Sampling Locations Around Nuclear Facilities. BNWL-SA-4676, Pacific Northwest Laboratory, Richland, Washington.

Waite, D. A. 1973b. An Analytical Techniaue for Distributing Air Sampling Locations Around Nuclear Facilities. BNWL-SA-4534, Pacific Northwest Laboratory, Richland, Washington.

Watson, J. E. (chairman). 1980. Uparadina Environmental Radiation Data, Health Phvsics Societv Committee Reoort HPSR-1 (1980). EPA 5201/1-80-01, U.S. Environmental Protection Agency, Washington, D.C.

Wedding, J. B., A. R. Andrews, and J. E. Cermak. 1977. "Large Particle Collection Characteristics of Ambient Air Samplers." Environmental Science and Technology 4(11):387-390.

Weil, J. C. 1979. "Applicability of Stability Classification Schemes and Associated Parameters to Dispersion of Tall Stack Plumes in Maryland." Atmosoheric Environment 13:819-831.

Whelan, G., D. L. Strenge, J. G. Droppo, Jr., B. L. Steelman, and J. W. Buck. 1987. The Remedial Action Prioritv Svstem (RAPS): Mathematical Formulations. PNL-6200, 00E/RL/87-09, Pacific Northwest Laboratory, Richland, Washington.

Winer, B. J. 1971. Statistical Princioles in Experimental Design. McGrawHill Book Company, New York, New York. 


\section{APPENDIX A}

\section{DEFINITIONS}

Abnormal Operation ("Upset") is a situation in which emission rates change because of unusual occurrences that affect normal plant operating conditions.

Absorbed Dose (D) is the energy imparted to matter by ionizing radiation per unit mass of irradiated material at the place of interest in that material. The absorbed dose is expressed in units of rad (gray) where $1 \mathrm{rad}=$ 0.01 joule $/ \mathrm{kg}$ material $(1 \mathrm{gray}=100 \mathrm{rad})$.

Acceptance Sampling is the procedure by which decisions to accept or reject a sampled lot or population are made based on the results of a sample inspection.

$\underline{\text { Accuracv }}$ is the degree of agreement of a measurement with an accepted reference or true value. It is expressed as the difference between the two values, as the difference as a percentage of the reference or true value, or as a ratio of the measured value and the reference or true value.

ALARA (As Low As Reasonably Achievable) is a phrase (acronym) used to describe an approach to radiation protection to control or manage exposures (both individual and collective to the workforce and the general public) and releases of radioactive material to the environment as low as social, technical, economic, practical, and public policy considerations will permit. As used in this guide, ALARA is not a dose limit, but rather $i \mathrm{t}$ is a process that has as its objective the attainment of dose levels as far below applicable limits as is practicabie.

Aliauot is the fraction of a field sample taken for complete processing through an analytical procedure (a "laboratory sample" of a field sample).

Analytical Blank - See "Blank."

Analytical Detection Limit - See "Lower Limit of Detection (LLD)."

Analytical Limit of Discrimination is a concentration above which one can, with relative certainty, ascribe the results from an analysis to concentrations that exist in the environment or system being evaluated.

Aquatic Biota is plant or animal life living in, near, or on water, or having water as a habitat. 
Arithmetic Mean is the most commonly used measure of central tendency, commonly called the "average." Mathematically, it is the sum of all the values of a set divided by the number of values in the set:

$$
\bar{x}=\frac{\sum_{i=1}^{n} X_{i}}{n}
$$

Audit/Appraisal is a planned and documented activity performed in accordance with procedures to determine, by examination and evaluation of objective evidence, the adequacy of and extent to which applicable elements of the program have been developed, documented, and effectively implemented in accordance with specified requirements. Audits can be either internal examinations of programs or activities under an organization's control and within its organizational structure or external examinations of programs or activities of another organization.

\section{Average - See "Arithmetic Mean."}

Best Available Technology (BAT) means the preferred technology for treating a particular process liquid waste, selected from among others after taking into account factors related to technology, economics, public policy, and other parameters. BAT is not a specific level of treatment but the conclusion of a selection process that includes several treatment alternatives.

Bias is a consistent under- or over-estimation of the true values representing a population.

Blank is a sample of the carrying agent (gas, liquid, or solid) normally used to selectively measure a material of interest that is subjected to the usual analytical procedures process to establish a baseline or background value. This value is then used to adjust or correct the routine analytical results.

Calibration is the adjustment of the system and the determination of system accuracy using known sources and instrument measurements. Adjustment of flow, temperature, humidity, or pressure gauges and the determination of system accuracy must be conducted using standard operating procedures and "Standard Reference Materials" (SRM) that are traceable to the National Institute of Standards and Technology (NIST) or other "Certified Reference Materials" (CRM) .

Calibration Standard is a standard used to quantify the relationship between the output of a sensor and a property to be measured. Calibration standards must be traceable to "Standard Reference Materials" (SRM) from NIST or Certified Reference Materials (CRM).

Check Source is a source ( $\mathrm{e}, \mathrm{g}$, , a radioactive source) not necessarily calibrated that is used to confirm the continuing satisfactory operation of an instrument (also termed "Reference Source"). 
Coefficient of Variation [CV; or Relative Standard Deviation (RSD)] is a measure of precision calculated as the standard deviation value (s for a sample or $\sigma$ for a population) divided by the average of a set of values ( $X$ for a sample or $\mu$ for a population). It is usually multiplied by 100 to be expressed as a percentage.

$$
\begin{aligned}
& \mathrm{CV}=\mathrm{RSD}=\frac{\mathrm{S}}{\mathrm{X}} \times 100 \text { for a sample, or } \\
& \mathrm{CV}^{\prime}=\mathrm{RSD}^{\prime}=\frac{\sigma}{\mu} \times 100 \text { for a population. }
\end{aligned}
$$

Collective Dose Eauivalent is the sum of the dose equivalents of all individuals in a specified population, frequently considered to be that within $50 \mathrm{mi}$ of the facility or release point. It is expressed in units of person-rem or person-sieverts ( 1 person-Sv $=100$ person-rem).

Collective Effective Dose Eauivalent is the sum of the effective dose equivalents of all individuals in a specified population, frequently considered to be that within $50 \mathrm{mi}$ of the facility or release point. It is expressed in units of person-rem or person-sieverts (1 person-Sv $=100$ person-rem).

Collectors (Control Equipment) are devices designed to remove and collect contaminants from an effluent stream.

Committed Dose Eauivalent $\left(H_{50}\right)$ is the predicted total dose equivalent to a tissue or organ over a 50-year period after a known intake of a radionuclide into the body. It does not include contributions from external dose. Committed dose equivalent is expressed in units of rem (or sievert).

Committed Effective Dose Eauivalent $\left(\mathrm{H}_{\mathrm{F}_{50}}\right)$ is the sum of the committed dose equivalents to various tissues in the body, each multiplied by the appropriate weighting factor. Committed effective dose equivalent is expressed in terms of rem (or sievert).

Confidence Coefficient is the chance or probability, usually expressed as a percentage, that a confidence interval includes some defined parameter of a population. The confidence coefficients usually associated with confidence intervals are $90 \%, 95 \%$, and $99 \%$. For a given sample size, the width of the confidence interval increases as the confidence coefficient increases.

Confidence Interval is a value interval that has a designated probability (the confidence coefficient) of including some.defined parameter of the population.

Confidence Limits are the outer boundaries of a confidence interval.

Continuous Monitoring is the real-time measurement of 1 iquid, gaseous, and/or airborne effluents and contaminants using in situ measurement systems. 
Continuous Sampling includes both noninterrupted sampling and repetitive sequential collection of small samples obtained automatically at intervals short enough to yield a representative sample for the entire sampling period.

Control Chart is a graphic chart with statistical control limits and plotted values (usually in chronological order) of some measured parameter for a series of samples. . Use of the charts provides a visual display of the pattern of the data, enabling early detection of time trends and shifts in level.

Corroborative Tests are the evaluation of an analytical method in which a number of laboratories analyze portions of carefully prepared homogeneous samples.

Critical Organ is the human organ or tissue receiving the largest fraction of a specified dose limit.

Critical Pathway is the specific route of transfer of radionuclides from one environmental component to another (e.g., from one trophic level to another) that results in the greatest fraction of an applicable dose limit to a population group or an individual's whole body, organ, or tissue.

Critical Population Group is the population group showing the greatest fraction of an applicable radiation dose limit as a result of site releases.

Data Validation is a systematic review of a data set to identify outliers or suspect values. The process uses appropriate statistical techniques to screen out impossible or highly unlikely values.

Deep Dose Eauivalent, as used in this guide, means the dose equivalent in tissue at a depth of $1 \mathrm{~cm}$ or greater, selected to maximize the dose equivalent derived from external (penetrating) radiation.

Derived Concentration Guide (DCG) is the concentration of a radionuclide in air or water that, under conditions of continuous exposure by one exposure mode (i e., ingestion of water, or submersion in air, or inhalation), for one year would result in an effective dose equivalent of 100 mrem (1 mSv) to a "reference man."

Detector is a device for converting radiation flux and energy to a signal suitable for measurement purposes.

Diffuse Source is a source or sources of radioactive contaminants (emissions) released into the atmosphere that do not have a defined point (origin) of release (i e., a non-point source). Such sources are also known as area sources.

Discharge Point is any discernible, confined, and discrete conveyance, including but not limited to any stack, duct, vent, pipe, ditch, channel, tunnel, conduit, well, discrete fissure, container, or vessel from which any radioactively contaminated gas or water is discharged to the atmosphere or waters accessible by the general public. 
Dose Eauivalent (D) is the product of the absorbed dose in rads (grays) in tissue, a quality Factor, and other modifying factors. Dose equivalent is expressed in units of rem (or sievert). (1 rem $=0.01$ sievert.) For purposes of this guide, the dose equivalent to an organ, tissue, or whole body in a year will be that received from the direct exposure plus the 50-year committed dose equivalent received from radionuclides taken into the body during the year.

Effective Dose Eauivalent (HE or EDE) is the summation of the products of the dose equivalent received by specified tissues of the body and a tissuespecific weighting factor. This sum is a risk-equivalent value and can be used to estimate the health-effects risk of the exposed individual. The tissue-specific weighting factor represents the fraction of the total health risk resulting from uniform whole-body irradiation that would be contributed by that particular tissue. The effective dose equivalent includes the committed effective dose equivalent from internal deposition of radionuclides and the effective dose equivalent due to penetrating radiation from sources external to the body; it is expressed in units of rem (or sievert).

Effluent is any treated or untreated air emission or liquid discharge, including stormwater runoff, at a DOE site or facility.

Effluent Monitoring is the collection and analysis of samples or measurements of liquid, gaseous, or airborne effluents for the purpose of characterizing and quantifying contaminants and process stream characteristics, assessing radiation exposures to members of the public, and demonstrating compliance with applicable standards.

Emission - See "Effluent."

Environmental Detection Limit is the smallest level at which a radionuclide in an environmental medium can be unambiguously distinguished for a given confidence level using a particular combination of sampling and measurement procedures, sample volume, analytical detection limit, and processing procedure.

Environmental Medium is a discrete portion of the total environment, animate or inanimate, that may be sampled or measured directly.

Environmenial Surveillance is the collection and analysis of samples of air, water, soil, foodstuffs, biota, and other media from DOE sites and their environs and the measurement of external radiation for purposes of demonstrating compliance with applicable standards, assessing radiation exposures to members of the public, and assessing effects, if any, on the local environment.

Environs are the environment surrounding a facility or site.

Error is the difference between an observed or measured value and its true value. 
Facilitv, as used by DOE, refers to a building, structure, or group of buildings and/or structures that releases radionuclides and is subject to the regulations/standards pertinent to this guide. When considering 40 CFR Part

61-related subjects for reporting to EPA, the term "facility" is to be considered the same as the DOE term "site," and the term "source" is to be considered the same as the DOE term "facility."

Geometric Mean is mathematically expressed as the $n^{\text {th }}$ root of the product of all values in a set of $n$ values:

1) $\bar{X}_{g}=\left[\begin{array}{ll}\prod_{j=1}^{n} & X_{i}\end{array}\right] 1 / r$

or as the antilogarithm of the arithmetic mean of the logarithms of all the values of a set of $n$ values:

2) $\bar{x}_{g}=\operatorname{antilog}\left[\frac{\sum_{i=1}^{n} \log x_{i}}{n}\right]$

The geometric mean is generally used when the logarithms of a set of values are normally distributed, as is the case for much of the monitoring and survei 11 ance data.

Geometric Standard Deviation is mathematically expressed as the antilog of the standard deviation of the logarithms of the measurements:

$$
\operatorname{sg}=\operatorname{antilog}\left[\sum_{i=1}^{n}\left\lceil\frac{\log x_{i}-\frac{\sum_{i=1}^{n} \log x_{i}}{n}}{n-1}\right]^{2}\right]^{1 / 2}
$$

Grab Sample is a single sample acquired from an effluent stream over a short interval of time.

Impaction is a process by which a particle or droplet is removed from an airstream by striking a surface in contact with the airstream. When a particle grazes a surface and is thus retained, the term "interception" applies. 
In-line refers to a system in which a detector or other measuring device is placed in the effluent stream for purposes of performing measurements on the effluent stream.

Isokinetic describes a condition that prevails when the velocity of air entering a sampling probe held in the airstream is identical to the velocity and axis of flow of the airstream being sampled at that point.

Less Than Detectable (LTD) refers to a measurement or calculated concentration that is not statistically different from the associated background or control value at a preselected confidence level.

Lower Limit of Detection (LLD) is the smallest amount of a contaminant that can be distinguished in a sample by a given measurement procedure at a given confidence level. [Also called "Minimum Detection Level" (MDL).]

Management and Operating (M\&O) Contract means an agreement under which DOE contracts for the operation, maintenance, or support, on its behalf, of a Federally owned or controlled research, development, special-production, or testing establishment wholly or principally devoted to one or more major programs of DOE (source: $48 \mathrm{CFR}$ 17.601). M\&O contracts are designated as such only by the Secretary or Under Secretary, in accordance with 48 CFR 17.602.

Measurement is the quantification of a parameter, a contaminant, or gross.content of material associated with a liquid or airborne effluent stream.

Measures of Central Tendencv are measures of the tendency of values within a set of data to be centered at some location (e.g., median, mode, arithmetic mean, and geometric mean).

Measures of Dispersion or Variabilitv are measures of the differences, scatter, or variability of values within a set of numbers. Commonly used measures of dispersion or variability are the range, standard deviation, variance, and coefficient of variation.

Median is the middle value of a set of data when the data are ranked in increasing or decreasing order. If there are an even number of values in the set, the median is the arithmetic average of the two middle values; if the number of values is odd, it is the middle value.

Membrane Filter is one of several commercially available filter media consisting generally of very thin organic-based films having a range of selectable porosities and controlled composition. Very thin, porous metallic filters are also known as membrane filters.

Minimum Detection Level (MDL) - See "Lower Limit of Detection (DID)."

Mode refers to the value occurring most frequently in a data set. 
Monitor has two definitions: 1) To measure certain constituents or parameters in an effluent stream continuously or at a frequency that permits a representative estimate of the amount over a specified interval of time; and 2) the instrumentation or device used in monitoring.

Monitoring is the use of instruments, systems, or special techniques to measure 1iquid, gaseous, and/or airborne effluents and contaminants.

Off-Line Monitoring Systems are systems in which an aliquot is withdrawn from the effluent stream for collection or conveyance to a detector or assembly.

Onsite refers to the area within the boundaries of a facility or site that is or can be controlled with respect to access by the general public.

Outlier is an extreme value in a data set so far removed from the other values with which it is associated that the chance probability of its being a valid member of the group is very small. Such a questionable value may be el iminated from the group on the basis of further statistical investigations of the data set.

Particle is an aggregate of molecules forming a solid or liquid that ranges in size from a few molecular diameters to a few millimeters.

Penetration is the passage of some material through a filter or other collector.

Performance Audit is a quantitative check of an analytical procedure with a material or device with known properties or characteristics to verify the accuracy of a project measurement system. The audit is usually performed by a person different from the routine operator/analyst, using standards and equipment different from the calibration equipment.

Plate Out is a thermal, electrical, chemical, or mechanical action that results in a loss of material by deposition on surfaces.

Point Source is the single defined point (origin) of an airborne release such as a stack or vent.

Precision is the dispersion around a central value, usually represented as a variance, standard deviation, standard error, or confidence interval.

Proficjency Testing is a special series of planned tests to determine the ability of field technicians or laboratory analysts who normally perform routine analyses. The results may be used for comparison against established criteria, or for relative comparison with the results from another group of technicians or analysts.

Proportional Sample is a sample consisting of a known fraction of the original stream, 
Ouality refers to the total ity of features and characteristics of a material, process, product, service, or activity that bears on its ability to satisfy a given purpose.

Qualitv Assurance (OA) refers to those planned and systematic actions necessary to provide adequate confidence that a facility, structure, system, or component will perform satisfactorily and safely in service. Quality assurance includes quality control (QC), which comprises all those actions necessary to control and verify the features and characteristics of a material, process, product, or service to specified requirements.

Quality Control (OC) refers to those actions necessary to control and verify the features and characteristics of a material, process, product, service, or activity to specified requirements. The aim of quality control is to provide qual ity that is satisfactory, adequate, dependable, and economic.

Quality Factor $(0)$ is the principal modifying factor used to calculate the dose equivalent from the absorbed dose. For purposes of DOE 5400.5, the following quality factors are to be used:

\begin{tabular}{|c|c|}
\hline Radiation Type & Qual ity Factor \\
\hline $\begin{array}{l}\text { X-rays, gamma rays, positrons, } \\
\text { beta partjcles, el ectrons } \\
\text { (including tritium) }\end{array}$ & 1 \\
\hline Neutrons, $<10 \mathrm{keV}$ & 3 \\
\hline $\begin{array}{l}\text { Neutrons, >10 keV } \\
\text { Protons and single-charged } \\
\text { particles of unknown energy } \\
\text { with rest mass greater than } \\
\text { one atomic mass unit }\end{array}$ & 10 \\
\hline $\begin{array}{l}\text { Alpha particles and other } \\
\text { mult iple-charged particles } \\
\text { (other heavy jons and particies } \\
\text { of unknown charge) of unknown } \\
\text { energy }\end{array}$ & 20 \\
\hline
\end{tabular}

Radioactive Material refers to any material or combination of materials that spontaneously emits ionizing radiation.

Radionucl ide refers to a radioactive nuclide. There are several hundred known radionuclides, both produced and naturally occurring; radionuclides are characterized by the number of neutrons and protons in an atom's nucleus. 
Radionuclide Emissions are releases of radioactive materials to the environment.

Random Error refers to variations of repeated measurements made within a sample set that are random in nature and individually not predictable. The causes of random error are assumed to be indeterminate or nonassignable. Random errors are generally assumed to be normally distributed.

Random Samples are samples obtained in such a manner that all items or members of the lot, or population, have an equal chance of being selected in the sample.

Range is the difference between the maximum and minimum values of a set of val ues.

Readout is the device that conveys information regarding the measurement being made to the user.

Reference Source - See "Check Source."

Reference Man refers to a hypothetical aggregation of human (male and female) physical and physiological characteristics arrived at by international consensus (ICRP Publication 23). These characteristics may be used by researchers and public health workers to standardize results of experiments and to relate biological insult from iopizing radiation to a common base. "Reference man" is assumed to inhale $8400 \mathrm{~m}^{3}$ of air in a year and to ingest $730 \mathrm{~L}$ of water in a year.

Relative Error is an error expressed as a percentage of the true value or accepted reference value.

Reliability is the capability of a system to perform a required function under stated conditions for a stated period of time.

Repeatabilitv is the precision, usually expressed as a standard deviation, measuring the variability among replicates. It refers to the closeness with which the measurements agree with each other.

Replicability is the precision, usually expressed as a standard deviation, measuring the variability among replicates.

Replicates are repeated but independent determinations of the same sample.

Representative Sample is a sample taken to depict the characteristics of a lot or population as accurately and precisely as possible. A representative sample may be a "random sample" or a "stratified sample" depending upon the objective of the sampling and the characteristics of the conceptual

population. 
Reproducibility is the degree of precision of a laboratory (repeatedly) and/or of different laboratories obtaining the same measurement values of the same sample.

Response lime is the time interval between when the detector senses a charged particle (e.g., $\beta, \alpha$ ) or photon (e.g., $\gamma, x$-ray) and when the signal is registered by the measurement sys em's data storage device.

Rusqedness lesting is a spec al series of tests performed to determine the sensitivity of a measurement system to variations of certain factors suspected of affecting the measurement system.

Sample has two definitions: 1) A subset or group of objects selected from a larger set, called the "lot" or "population"; and 2) an extracted portion or subset of an effluent stream or environmental media.

Sample Blank - See "Blank."

Sampling is the extraction of a prescribed portion of an effluent stream or of an environmental medium for purposes of inspection and/or analysis.

Sensitivity is the minimum amount of a radionuclide or other material of interest, expressed as a ratio (e.g., \% or ppm), that can repeatedly be detected by an instrument, system, or procedure.

Sequential Sampling refers to timed samples collected from an effluent stream.

"Should*" Statements indicate performance criteria and procedures required to operate and maintain an acceptable radiation protection program for the public and the environment.

"Should" Statements indicate flexible guidance for an acceptable radiation protection program.

Site refers to the overall DOE complex consisting of one or more facilities located in a defined geographic area.

Source (Radioactive) is either 1) a known amount of radioactive material emanating a characteristic amount of energy in the form of alpha, beta, gamma, neutron, or x-ray emissions (or a combination of such emissions), or 2) a single process or release point that contributes to or causes a release to the environment and that can be separated from other processes by a break in the flow of material.

Spiked SamDle is a normal sample of material (gas, liquid, or solid) to which a known amount of some substance of interest is added. Spiked samples are used to check on the accuracy of a routine analysis or the recovery efficiency of an analytical method.

Standard is a material having a known property that can be accurately estab1 ished based on its physical or chemical characteristics. 
Standard Deviation is an indication of the dispersion of a set of results around the average of samples collected or the mean of a population; it is the positive square root of the sample variance. For samples taken from a population, the standard deviation, $s$, is calculated as:

$$
s=\left[\frac{\sum_{i=1}^{n}\left(X_{i}-\bar{X}\right)^{2}}{n-1}\right]^{1 / 2}
$$

where $X=$ average value of the samples measured

$\mathrm{n}=$ number of samples measured

$X_{i}=$ individual measurement value Tor sample $i$.

For a finite population, the standard deviation $(\sigma)$ is

$$
\sigma=\left[\frac{\sum_{i=1}^{N}\left(X_{i}-\mu\right)^{2}}{N}\right]^{1 / 2}
$$

where $\mu$ is the mean value of the population and $N$ is the number of values within the popul ation.

Standard Operating Procedures (SOP) refers to a written document that details an operation, analysis, or action whose mechanisms are thoroughly .prescribed and are commonly accepted as the method for performing certain routine or repetitive tasks.

Standard Reference Material (SRM) is a material produced in quantity, of which certain properties have been certified by the National Institute of Standards and Technology (NIST) to the extent possible to satisfy its intended use. The material should be in a matrix similar to actual samples to be measured by a measurement system or to be used directly in preparing such a matrix.

Intended uses include standardization of solutions, calibration of equipment, and auditing the accuracy and precision of measurement systems.

Standard Reference SamDle (SRS) is a carefully prepared material produced from or compared against a Standard Reference Material (SRM) such that accuracy is maintained. These samples are intended for use primarily as reference standards to determine the precision and accuracy of measurement systems, to evaluate calibration standards, and to evaluate qual ity control reference samples.

Standardization is a physical or mathematical adjustment or correction of a measurement system to make the measurements conform to predetermined values. 
Standards in Naturallv Occurring Matrix are standards that relate to the composition of the sample being measured. Standards in a naturally occurring matrix include standard reference materials and standard reference samples.

Stratified SamDle (Stratified Random Samole) refers to a sample consisting of various portions that have been obtained from identified subparts or subcategories (strata) of the total lot or population. Within each category or stratum, the samples are taken randomly. The objective of taking stratified samples is to obtain a more representative sample than might be obtained by a completely random sampling.

Svstematic Error is the condition in which there is a consistent deviation of the results from the actual or true values by a measurement process. The cause for the deviation, or bias, may be known or unknown; however, it is considered "assignable" (i.e., the cause can be reasonably determined).

Testing is short-term evaluation of radioactive material releases that is representative of typical operations using prescribed techniques.

Tolerance Limits refers to a particular type of confidence limit used frequently in quality control work, where the limits apply to a percentage of the individual values of the population.

Traceabilitv refers to a documented chain of comparisons connecting a working standard (in as few steps as is practical) to a national (or international) standard, such as a standard maintained by the NIST.

Unusual Occurrence is any sudden release or sustained deviation from a regulated or planned performance at a DOE operation that has environmental protection and compliance significance.

Upset - See "Abnormal Operation."

Variabilitv is a general term for the dispersion of values in a data set.

Variance is a measure of the variability of samples within a subset or the entire population. Mathematically, the sample variance ' $\left(s^{2}\right)$ is the sm of squares of the differences between the individual values of a set and the arithmetic average of the set, divided by one less than the number of values:

$$
s^{2}-\frac{\sum_{i=1}^{n}\left(x_{i}-\bar{X}\right)^{2}}{n-1}
$$

where $X_{\dot{1}}=$ value of sample $\mathrm{i}$

$\mathbf{X}=$ average of samples measured

$\mathrm{n}=$ number of samples measured. 
For a finite population, the variance $\left(\sigma^{2}\right)$ is the sum of squares of deviations from the arithmetic mean, divided by the number of values in the popul ation:

$$
\sigma^{2}=\frac{\sum_{i=1}^{N}\left(X_{i}-\mu\right)^{2}}{N}
$$

where $\mu$ is the mean value of the population and $N$ is the number of values within the population.

Weishtins Factors (W $/$ are tissue-specific and represent the fraction of the total health risk resulting from uniform, whole-body irradiation that could be contributed to that particular tissue. They are used in the calculation of annual and committed effective dose equivalent to equate the risk arising from the irradiation of tissue $T$ to the total risk when the whole body is uniformly irradiated. The weighting factors recommended by the ICRP (Publication 26) and used here are

\begin{tabular}{lc} 
Organ or Tissue & Weightina Factor \\
\hline Gonads & 0.25 \\
Breasts & 0.15 \\
Red Bone Marrow & 0.12 \\
Lungs & 0.12 \\
Thyroid & 0.03 \\
Bone Surfaces & 0.03 \\
Remainder(a) & 0.30 \\
& \\
\hline & \\
(a) Remainder means the five other organs with \\
the next highest risk, including liver, \\
kidney, spleen, thymus, adrenals, pan- \\
creas, stomach, small intestine or upper \\
and lower large intestine, but excluding \\
skin, lens of the eye, and extremities. \\
The weighting factor for each such organ \\
is 0.06.
\end{tabular}

Whole-Bodv refers, for radiation dose purposes, to the uniform exposure of all organs and tissues in a human body.

Workina Standard (Quality Control Reference Sample) is a material used to assess the performance of a measurement system. It is intended primarily for routine intralaboratory use in maintaining control of accuracy and should be prepared from or traceable to a calibration standard. 